\title{
A CHARTBOOK OF
}

\section{INTERNATIONAL LABOR}

\section{COMPARISONS}

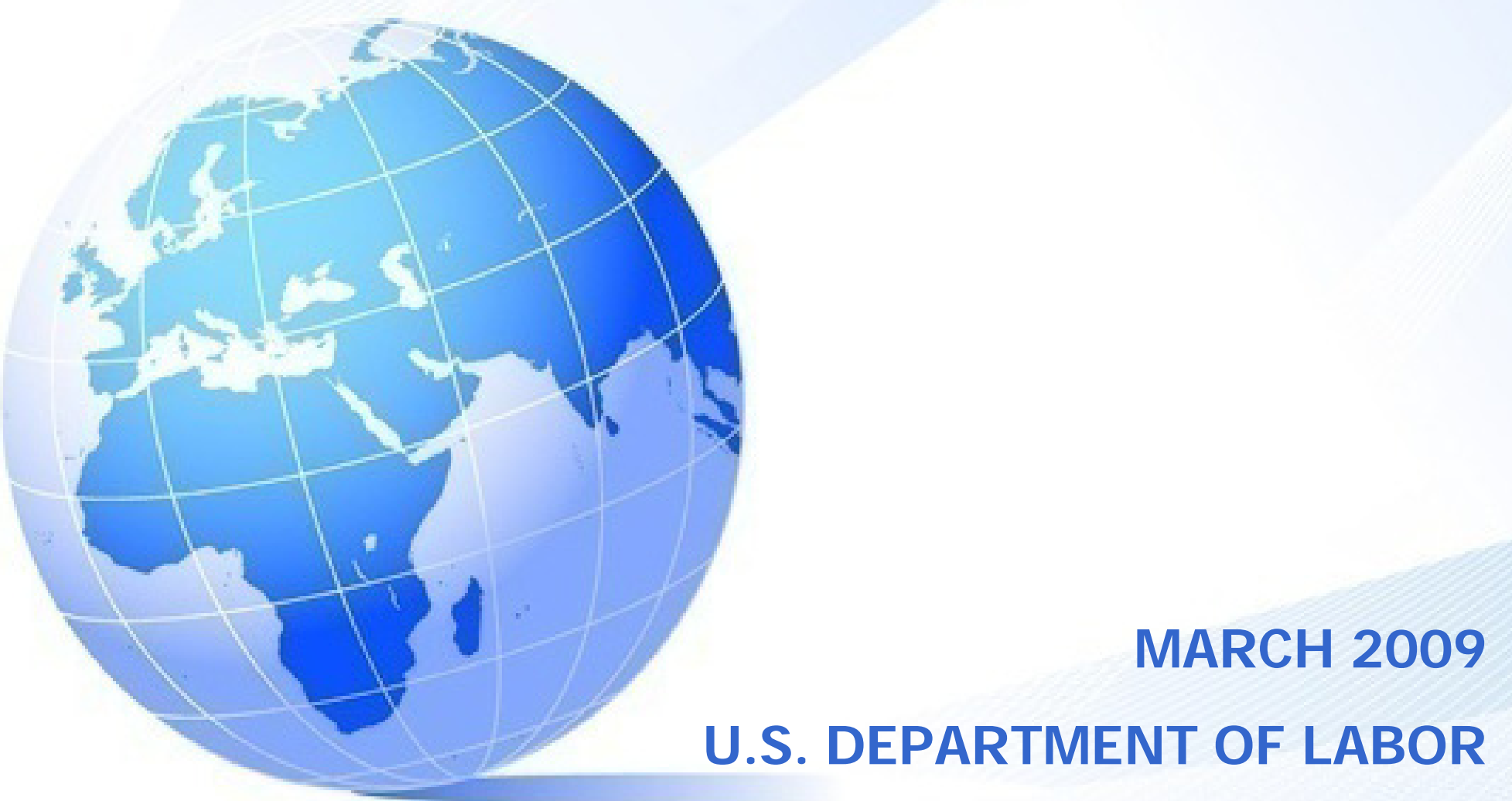


Material contained in this document is in the public domain and may be reproduced, fully or partially, without permission of the Federal Government. Source credit is requested.

This document is available on the Internet at: http://www.bls.gov/ilc/chartbook2009/home.htm.

To receive notice of future editions of this chartbook and international data comparisons produced by the Bureau of Labor Statistics (BLS), send an email with "subscribe" in the subject line to ILCPR@bls.gov. 


\section{A CHARTBOOK OF}

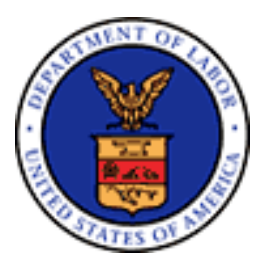

INTERNATIONAL LABOR

COMPARISONS

MARCH 2009

U.S. DEPARTMENT OF LABOR 

The U.S. Department of Labor fosters and promotes the welfare of America's job seekers, wage earners, and retirees by improving their working conditions, advancing their opportunities for profitable employment, and protecting their retirement and health-care benefits. We also help employers find workers, strengthen free collective bargaining, and track changes in employment, prices, and other national economic measurements.

The aspirations guiding our mission - to enhance the well-being and productivity of working people-are shared worldwide.

Governments across the globe are grappling with a worldwide recession and its impact on their workers, their families, and their communities. As we confront these challenges, it is useful to track how key labor market and other national economic measurements compare, so as to gauge trends and to provide government officials and citizens worldwide the opportunity to learn from each other.

This Chartbook is a gateway to explore the wealth of data produced by the Bureau of Labor Statistics' (BLS) Division of International Labor Comparisons and the international labor policy and research programs maintained by the Bureau of International Labor Affairs (ILAB). For more information, please visit http://www.bls.gov/ilc/ and http://www.dol.gov/ilab/.
I hope you find this Chartbook useful in your own work, and that you share it with your colleagues.

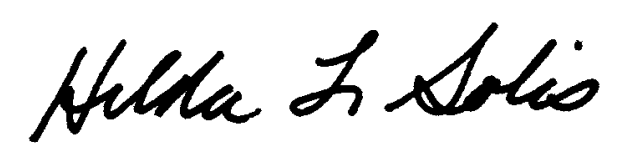

Hilda L. Solis

Secretary of Labor 

This chartbook focuses on the labor market situation in selected countries for the most recent year available; some charts also show trends. Charts in sections 1-4 and section 6 include countries in North America (the United States, Canada, and Mexico) and selected AsianPacific and European economies. Some countries do not appear on all charts due to the lack of suitable data. It should also be noted that the selected economies are not representative of all of Europe and the AsianPacific region; rather, they tend to be the more industrialized economies in these regions. Weighted aggregates for 15 European Union countries (EU-15) also are shown on many of the charts in these sections. These represent European Union member countries prior to the expansion of the European Union to 25 countries on May 1, 2004, and to 27 countries on January 1, 2007. The EU-15 countries are Austria, Belgium, Denmark, Finland, France, Germany, Greece, Ireland, Italy, Luxembourg, the Netherlands, Portugal, Spain, Sweden, and the United Kingdom. In section 5, several indicators are presented for six large emerging economies: Brazil, China, India, Indonesia, the Russian Federation, and South Africa.

The appendix describes the definitions, sources, and methods used to compile the data in the chartbook. For some series, the appendix provides cautions about the exact comparability of the measures.

Section 1, on Gross Domestic Product (GDP) per capita, portrays overall measures of comparative living standards. Section 2 highlights the state of the labor market by comparing major labor force, employment, and unemployment indicators. Section 3 examines the competitive position of the United States in the global marketplace by comparing hourly compensation costs in manufacturing, trends in manufacturing labor productivity and unit labor costs, and manufacturing output as a percent of world manufacturing output. Section 4 includes charts that compare public expenditures on labor market programs, regulation measures on labor and product markets, taxes on labor, and trade in goods. Section 5 presents charts on various topics for large emerging economies. Section 6 presents a visual abstract of the 2008 Employment Outlook published by the Organization for Economic Cooperation and Development (OECD). The Employment Outlook is an annual publication that explores recent labor market developments of interest to the 30 OECD member countries. This final section is the second of a series of one-time supplemental sections that highlight topics of particular interest, but with occasional data availability.

The chartbook was a cooperative effort of three agencies in the Department of Labor: the Bureau of International Labor Affairs (ILAB), http://www.dol.gov/ilab/; the Office of the Assistant Secretary for Policy (OASP), http://www.dol.gov/asp/; and the Bureau of Labor Statistics (BLS), http://www.bls.gov/. Since 1960, BLS has adjusted selected labor market data of foreign countries to improve their comparability with U.S. data. The chartbook is representative of the main output of the BLS program of international labor comparisons. In order to increase country and indicator coverage, BLS data are supplemented by data from OECD and other international organizations.

A team led by Jennifer Raynor of the BLS Division of International Labor Comparisons (ILC), http://www.bls.gov/ilc/, in cooperation with Kenneth Swinnerton and Sarah Donovan of the ILAB Division of Economic and Labor Research prepared the chartbook. The following persons comprised the BLS team: Rich Esposito, Mubarka Haq, Wolodar Lysko, Andrew Petajan, Jessica Sincavage, Marie-Claire Sodergren, and Chris Sparks. Constance Sorrentino, Division Chief of ILC, and Ronald Bird, David Langdon, and Stephanie Swirsky of OASP provided overall guidance. 


\section{CONTENTS}

SECTION 1 GROSS DOMESTIC PRODUCT PER CAPITA

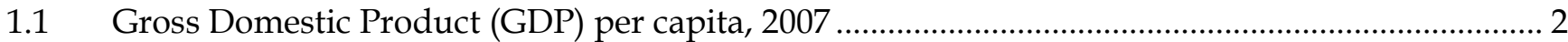

1.2 Average annual growth rates for real GDP per capita, 1997-2007 ................................................... 3

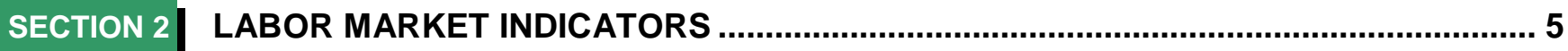

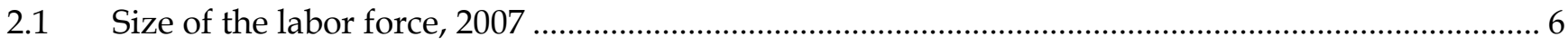

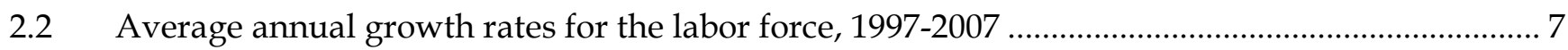

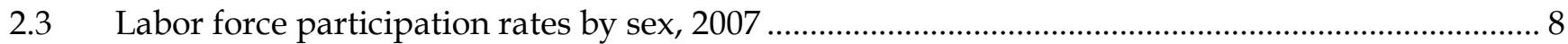

2.4 Labor force participation rates for youths, 2007 ...................................................................... 9

$2.5 \quad$ Labor force participation rates for older workers, 2007 ................................................................ 10

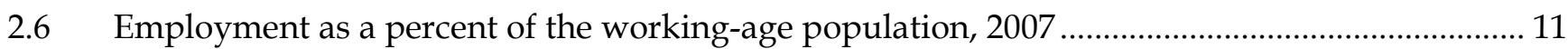

2.7 Average annual growth rates for employment, 1997-2007 .......................................................... 12

2.8 Average annual growth rates for full-time and part-time employment, 1996-2006 …….............. 13

2.9 Annual hours worked per employed person, 1997 and 2007 ..................................................... 14

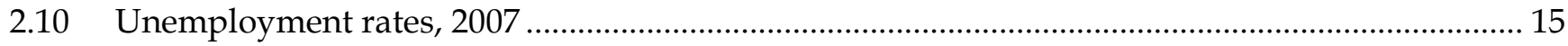

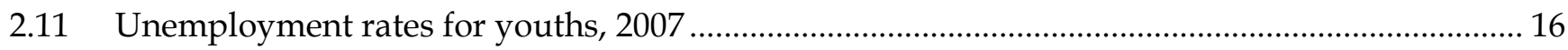

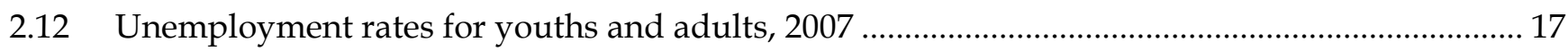

2.13 Persons unemployed one year or longer as a percent of total unemployment, 2007 ……............ 18

2.14 Ratios of unemployment rates of persons without high school degrees to those of persons with college or university degrees, 2006 .................................................................................... 19

2.15 Educational attainment of the adult population, 2006 .................................................................... 20

SECTION 3 COMPETITIVENESS INDICATORS FOR MANUFACTURING ..................................... 21

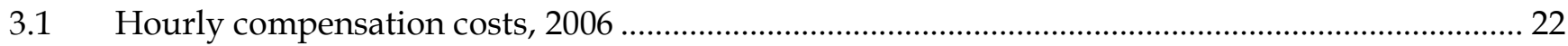

3.2 Average annual growth rates for hourly compensation costs, 1996-2006 .................................... 23

3.3 Employer social insurance expenditures and other labor taxes as a percent of hourly

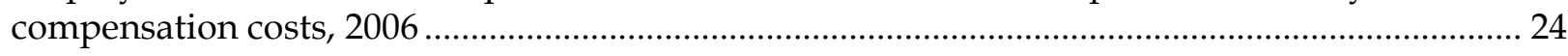

3.4 Average annual growth rates for manufacturing productivity, 1997-2007................................... 25

3.5 Average annual growth rates for manufacturing output and hours worked, 1997-2007 …........ 26

3.6 Average annual growth rates for manufacturing unit labor costs in U.S. dollars, 1997-2007 ..... 27

3.7 Manufacturing output as a percent of world manufacturing output, 2007 .................................... 28

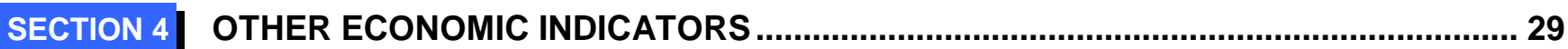

4.1 Public expenditures on labor market programs as a percent of GDP, 2006 .................................... 30

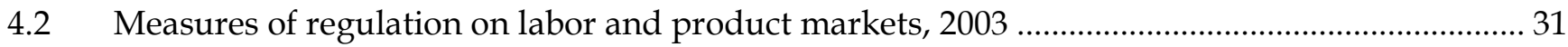

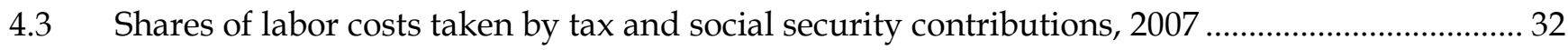

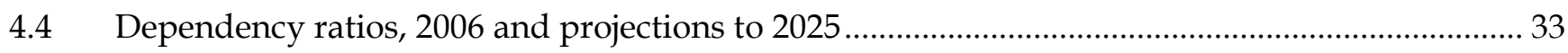

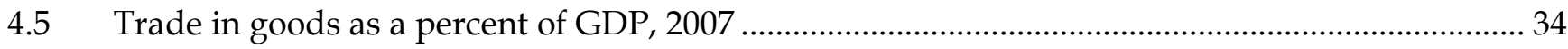




\section{CONTENTS (cont.)}

SECTION 5 INDICATORS FOR LARGE EMERGING ECONOMIES 35

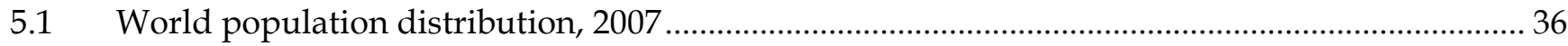

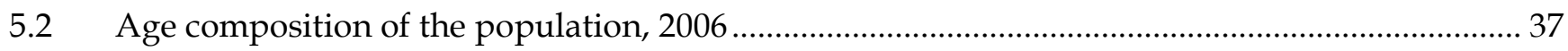

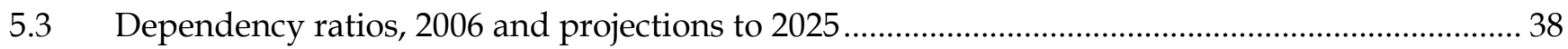

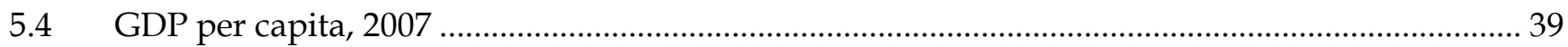

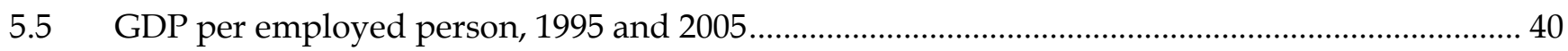

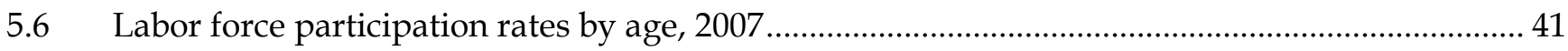

$5.7 \quad$ Employment as a percent of the working-age population by sex, 2006 ….................................. 42

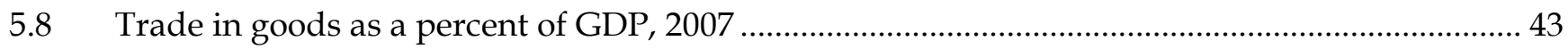

5.9 Manufacturing output as a percent of world manufacturing output, 2007 ............................... 44

SECTION 6 EMPLOYMENT OUTLOOK INDICATORS ............................................................... 45

6.1 Part-time employment for youths as a percent of total employment for youths,

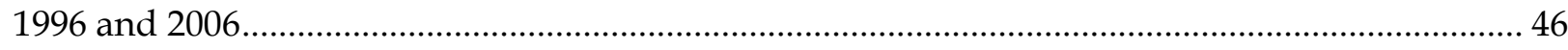

6.2 Employment as a percent of the prime-age population by sex, 2007 ....................................... 47

6.3 Ratios of psychological distress rates of workers in low-skilled occupations to those of all

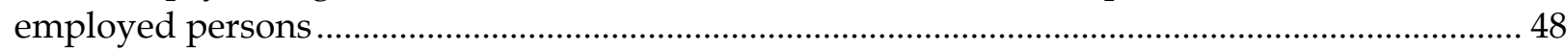

6.4 Shares of global foreign direct investment expenditures and receipts, 1995, 2000, and 2005 ...... 49 



\section{SECTI ON 1}

Gross Domestic Product (GDP) per capita, when converted to U.S. dollars using Purchasing Power Parities (PPPs), is the most widely used income measure for international comparisons of living standards. It should be recognized that income measures do not capture a number of variables affecting economic well-being, such as leisure time, health, safety, and cultural resources.

\section{Domestic} Product

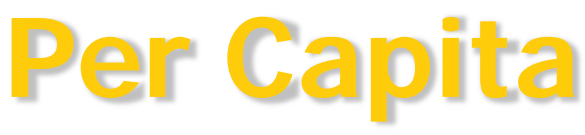

PPPs are the number of foreign currency units required to buy goods and services in a foreign country equivalent to what can be bought with one dollar in the United States. These are used to equalize the purchasing power of different currencies. PPPs are used instead of exchange rates because market exchange rates do not necessarily reflect the relative purchasing power of different currencies.

Charts 1.1 and 1.2 compare the level of GDP per capita in the most recent year and the trend over the past 10 years for 20 of the 22 economies shown on various charts in this chartbook. A weighted aggregate for 15 European Union countries (EU-15) also is included on both charts. 


\section{Gross Domestic Product (GDP) per capita, 2007 converted at PPP rates}

- Norway had the highest GDP per capita, followed by the United States, Ireland, and Hong Kong SAR.

- The other economies showed levels of GDP per capita between 84 percent (Netherlands) and 28 percent (Mexico) of the U.S. level.

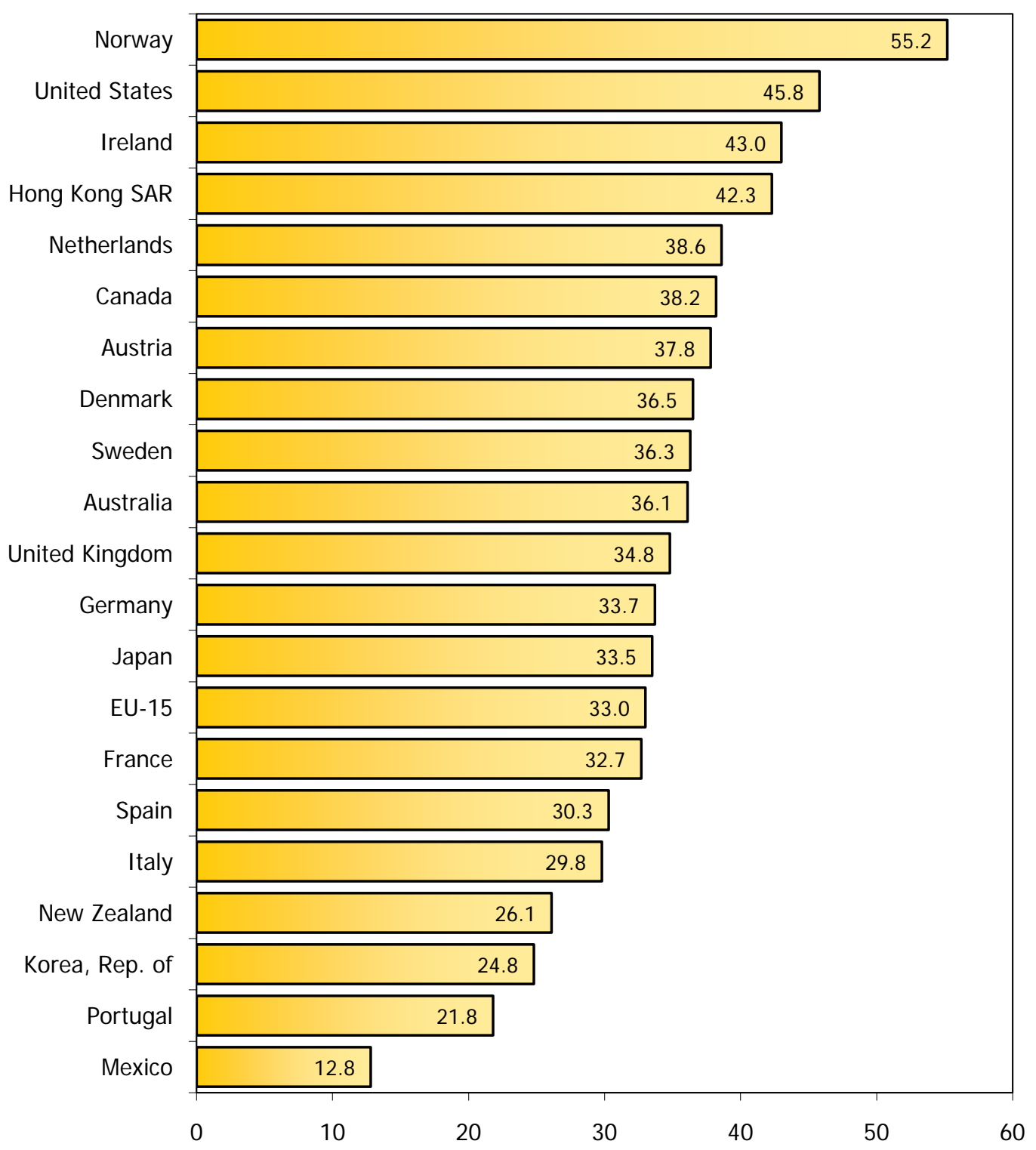

Thousands of U.S. dollars

NOTE: Hong Kong SAR stands for Hong Kong Special Administrative Region of China. Purchasing Power Parity (PPP) is the number of foreign currency units required to buy goods and services in a foreign country equivalent to what can be bought with one dollar in the United States.

SOURCES: Bureau of Labor Statistics and World Bank. 


\section{Average annual growth rates for real GDP per capita, 1997-2007}

- In most of the economies, real GDP per capita grew during the decade at an average rate of 1.3 to 2.5 percent per year; the U.S. growth rate was in the middle of the range, at 1.8 percent per year.

- Ireland registered the greatest increase in real GDP per capita, followed by the Republic of Korea; I taly and J apan had the smallest increases.

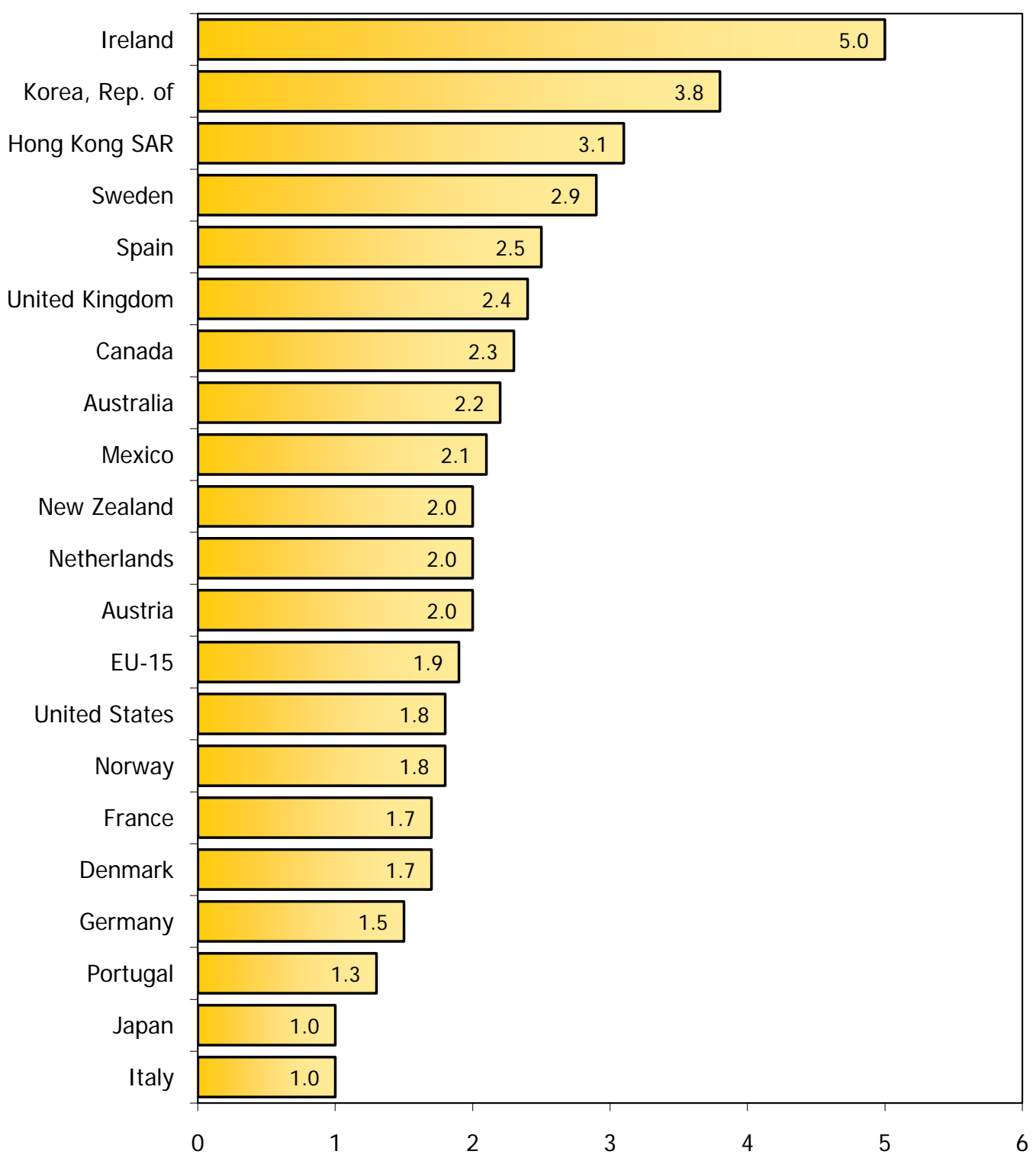

Percent

NOTE: 1997-2006 for Mexico and New Zealand. Hong Kong SAR stands for Hong Kong Special Administrative Region of China. SOURCES: Bureau of Labor Statistics, including special tabulations using data from the Organization for Economic Cooperation and Development and national sources. 



\section{Labor Market Indicators}

Charts 2.1-2.15 show comparisons of the labor force, employment, unemployment, and related indicators. The size of the labor force is shown in chart 2.1. Labor force growth (chart 2.2) sums up changes in both employment and unemployment over the period. Labor force participation rates (charts 2.3-2.5) measure the share of the population that is working or unemployed. Here, comparisons are shown by sex and for four selected age groups relating to youths and older workers.

Employment and unemployment are key indicators of the functioning of labor markets both within and among countries. Charts 2.6-2.9 compare the proportion of the working-age population employed, employment growth rates, trends in full-time and part-time employment, and trends in annual hours worked per employed person. Charts 2.10-2.15 explore unemployment rates, long-duration unemployment, and the connection between unemployment rates and levels of education.

Nineteen countries are covered in this section. In addition, a weighted aggregate for 15 European Union countries (EU-15) is shown on the majority of charts. 


\subsection{Size of the labor force, 2007}

- The U.S. labor force was the largest.

- The EU-15 countries combined had a larger labor force than the United States.

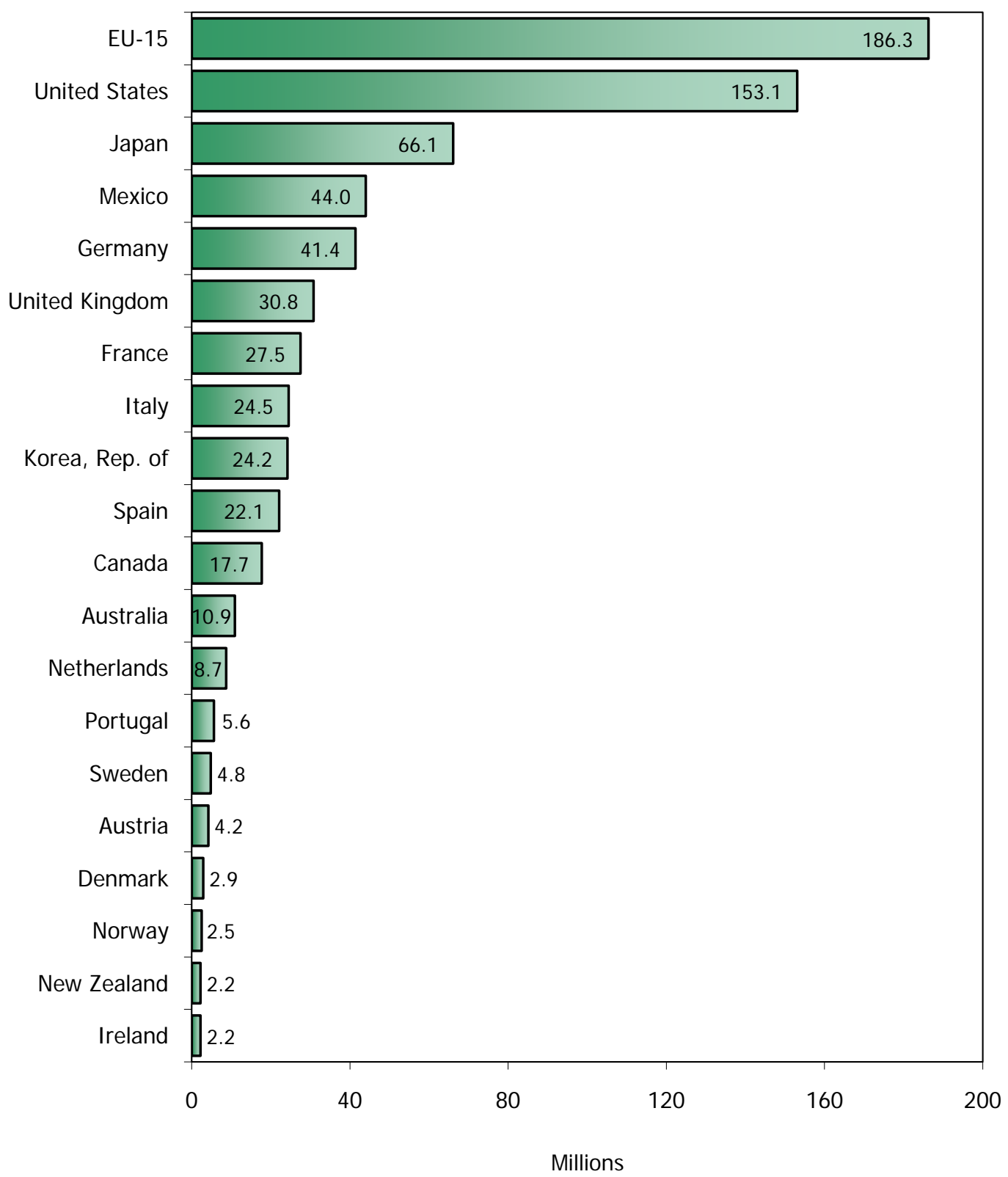

SOURCES: Bureau of Labor Statistics and Organization for Economic Cooperation and Development. 


\subsection{Average annual growth rates for the labor force, 1997-2007}

- U.S. labor force growth outpaced that of the EU-15 average. In Europe, labor force growth was stronger in Ireland, Spain, Portugal, and the Netherlands than in the United States.

- The labor force declined only in J apan.

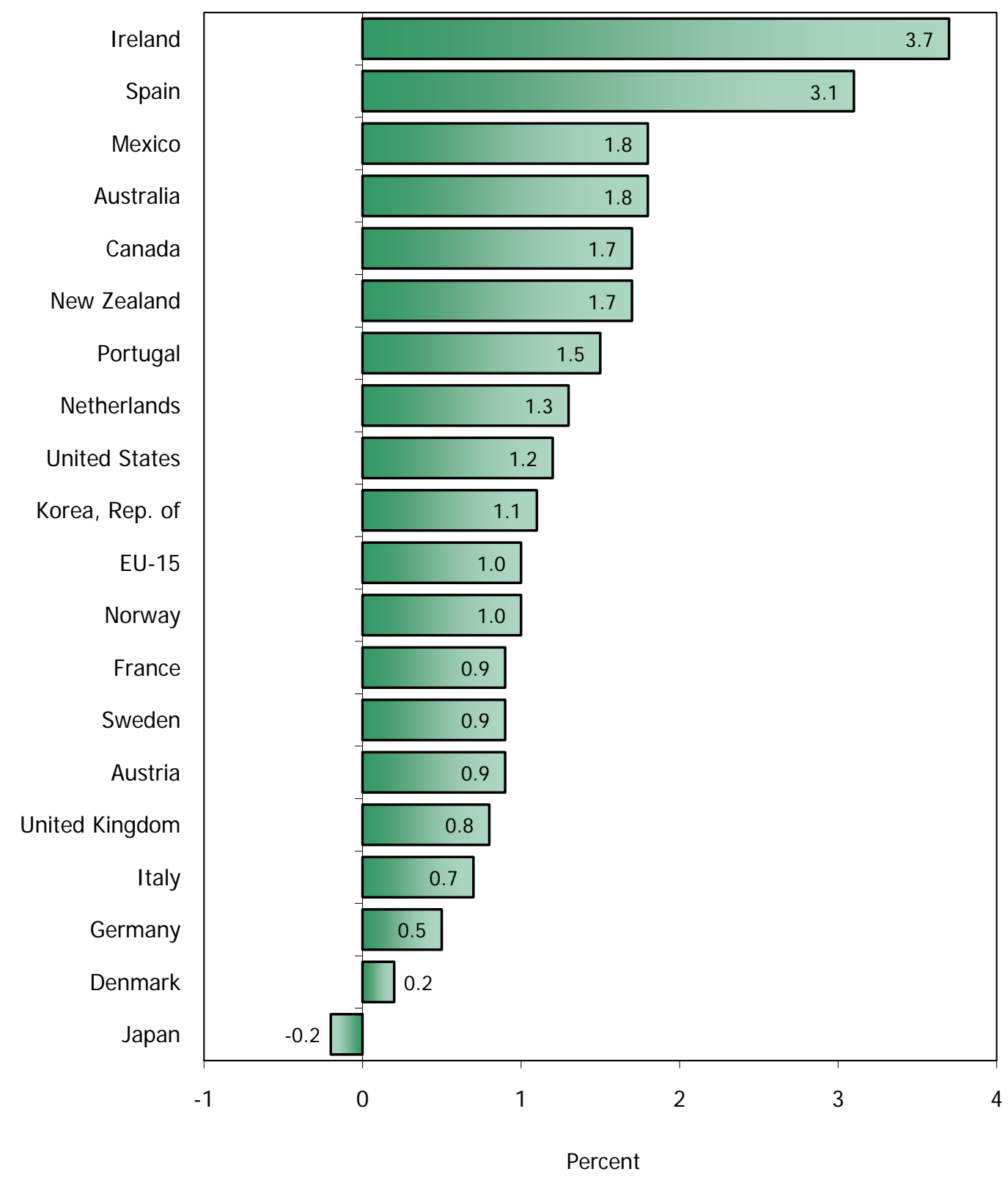

SOURCES: Bureau of Labor Statistics and Organization for Economic Cooperation and Development. 


\subsection{Labor force participation rates by sex, 2007}

- In Denmark, New Zealand, the Netherlands, and Australia, women participated in the labor force at about the same high rate as U.S. women. Canadian women had the highest participation rates, while Italian and Mexican women had the lowest.

- Participation rates for men were at least 70 percent in 11 out of 19 countries; the lowest rates for men were found in I taly and France.

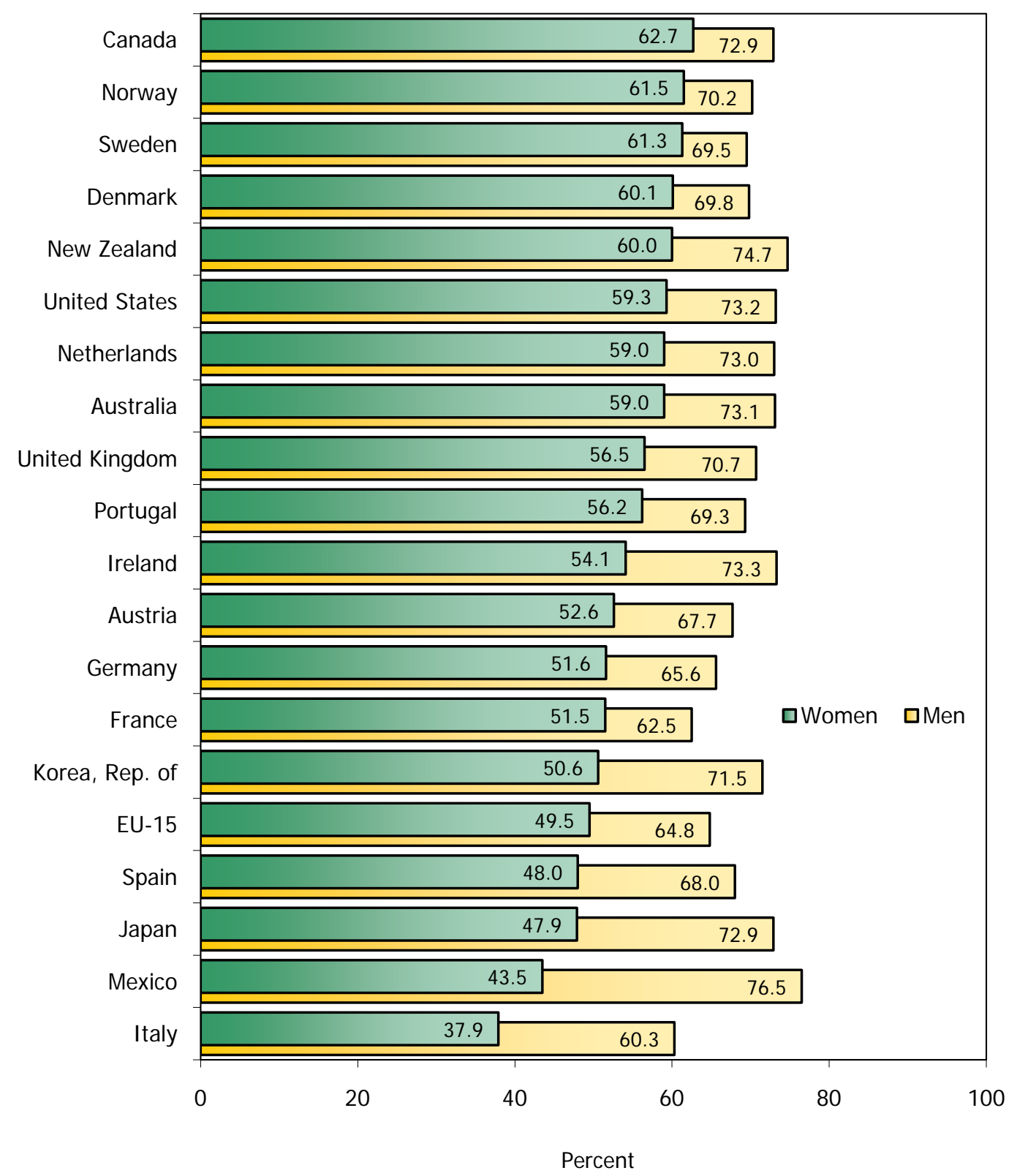

SOURCES: Bureau of Labor Statistics and Organization for Economic Cooperation and Development. 


\subsection{Labor force participation rates for youths, 2007}

- Labor force participation rates varied widely for teenagers, ranging from 7.2 percent (the Republic of Korea) to 63.3 percent (Denmark).

- Persons ages 20 to 24 participated in the labor market to a much greater extent than teenagers, with the highest participation rates in Denmark and Australia.

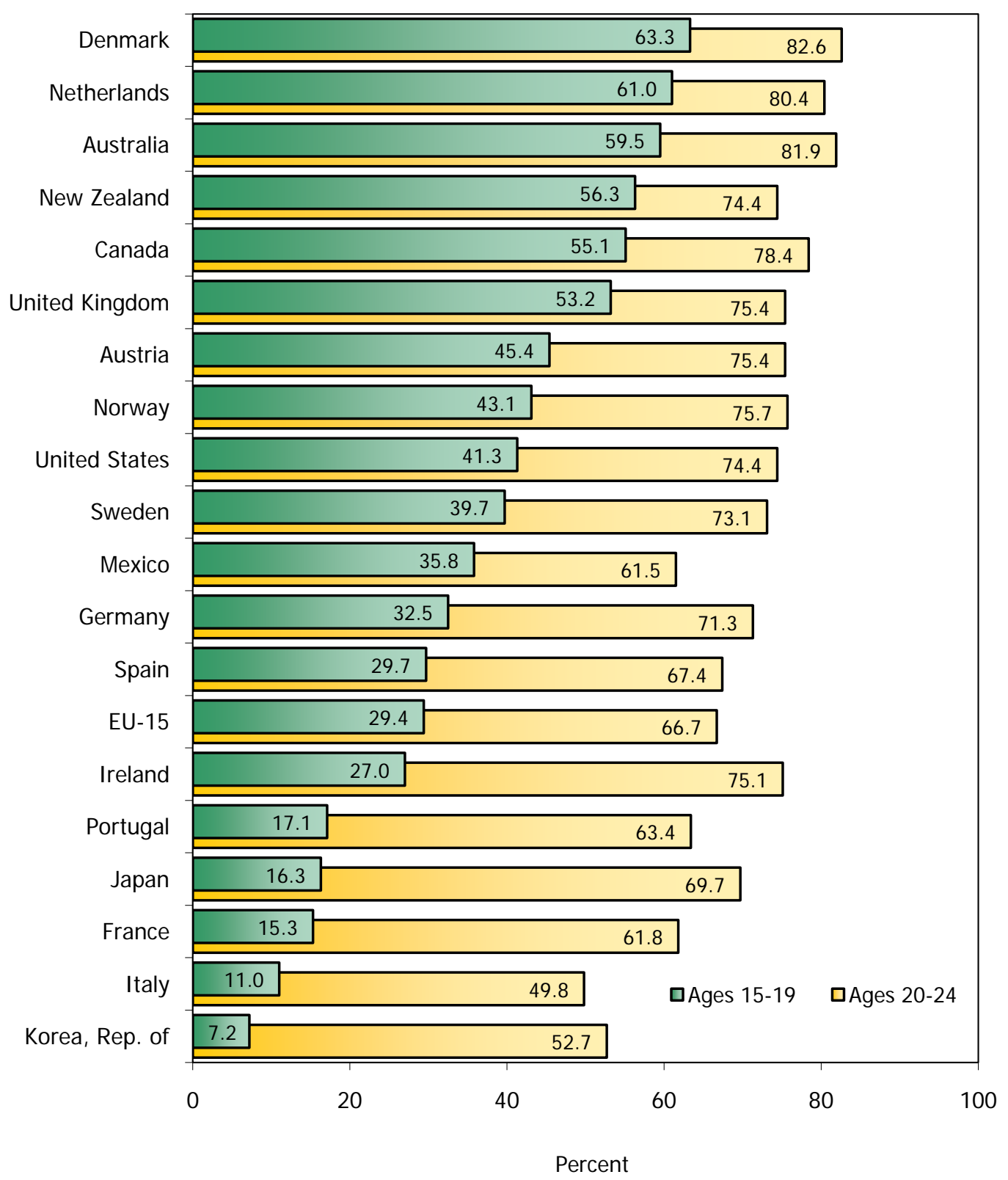

NOTE: Persons ages 16 to 19 instead of ages 15 to 19 for Norway, Spain, the United Kingdom, and the United States.

SOURCE: Organization for Economic Cooperation and Development. 


\subsection{Labor force participation rates for older workers, 2007}

- Persons ages 55 to 64 participated in the labor market far less in Italy, Austria, and France than in the remaining countries.

- Participation rates for persons ages 65 and over varied widely from 1.4 percent (France) to 31.3 percent (the Republic of Korea); the U.S. rate was nearly four times higher than the EU-15 average.

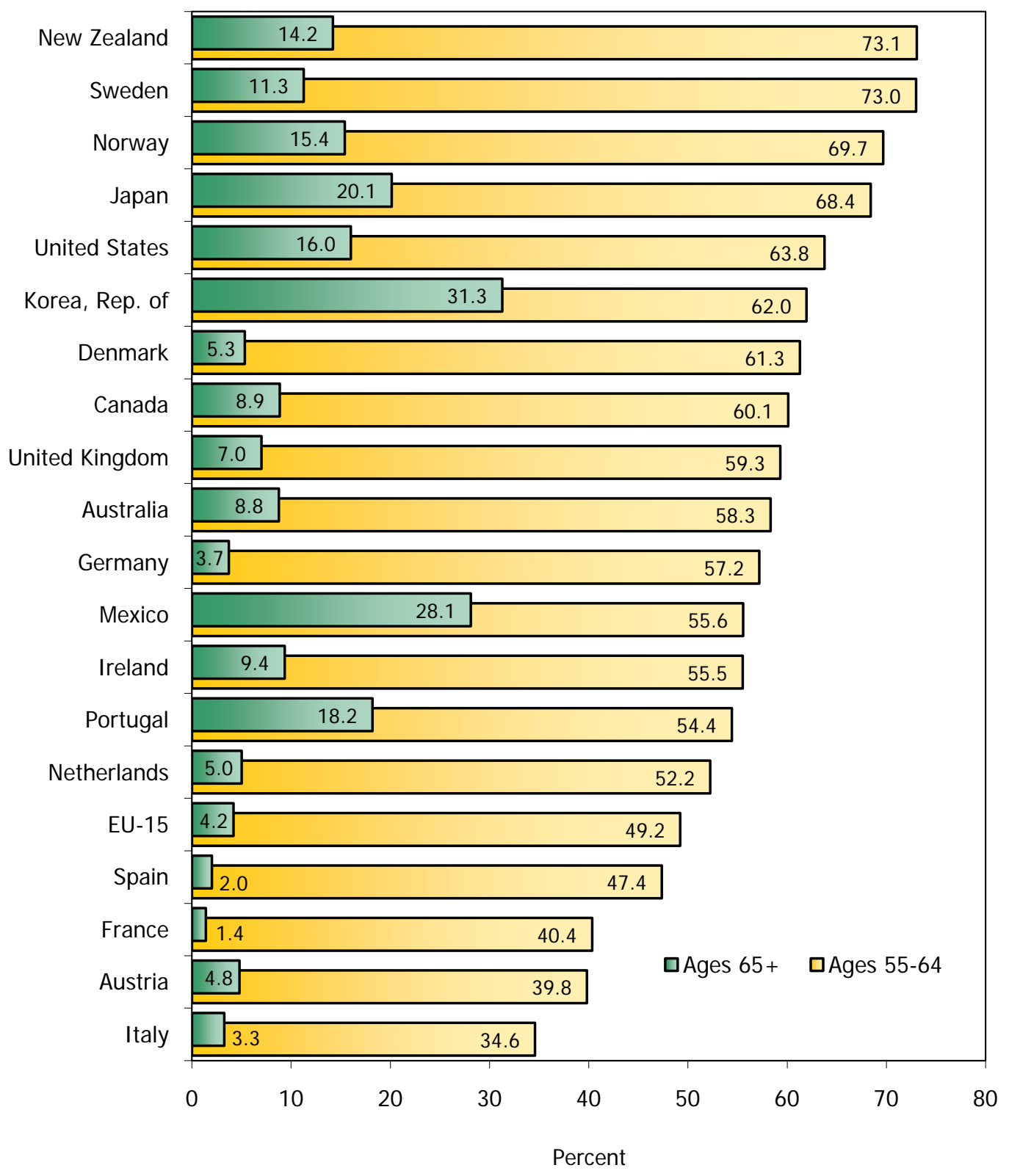

SOURCE: Organization for Economic Cooperation and Development. 


\subsection{Employment as a percent of the working-age population, 2007}

- New Zealand, Canada, and Norway had the highest percentages of the working-age population employed.

- In Italy, less than half of the working-age population was employed.

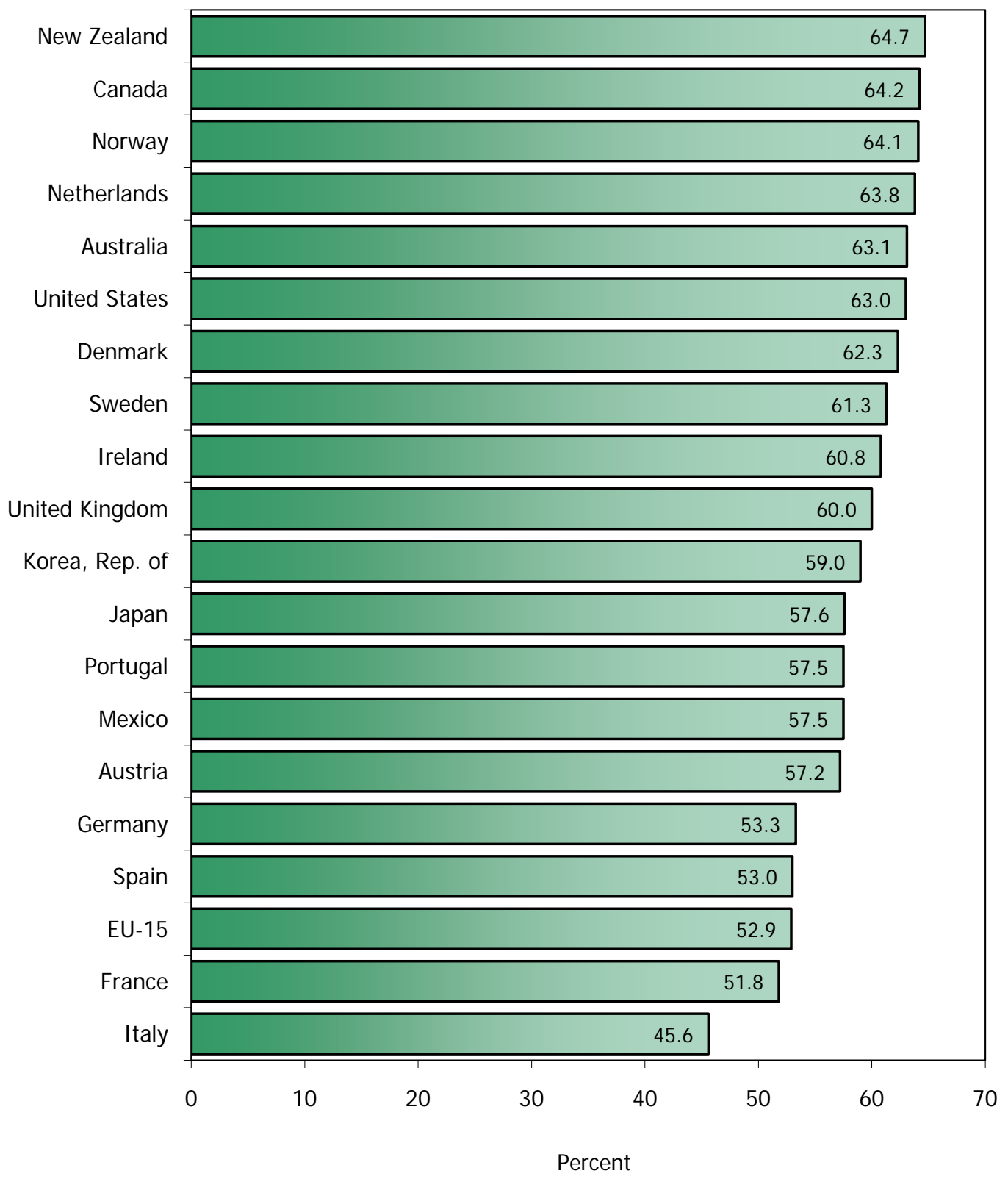

NOTE: The working-age population is defined as persons ages 15 and over for all countries except Canada, France, Sweden, the United Kingdom, and the United States, where it is defined as persons ages 16 and over.

SOURCES: Bureau of Labor Statistics and Organization for Economic Cooperation and Development. 


\subsection{Average annual growth rates for employment, 1997-2007}

- Ireland and Spain had the highest growth rates for employment. Employment declined only in Japan.

- U.S. employment growth outpaced that of 5 of the 12 European countries, Japan, and the Republic of Korea.

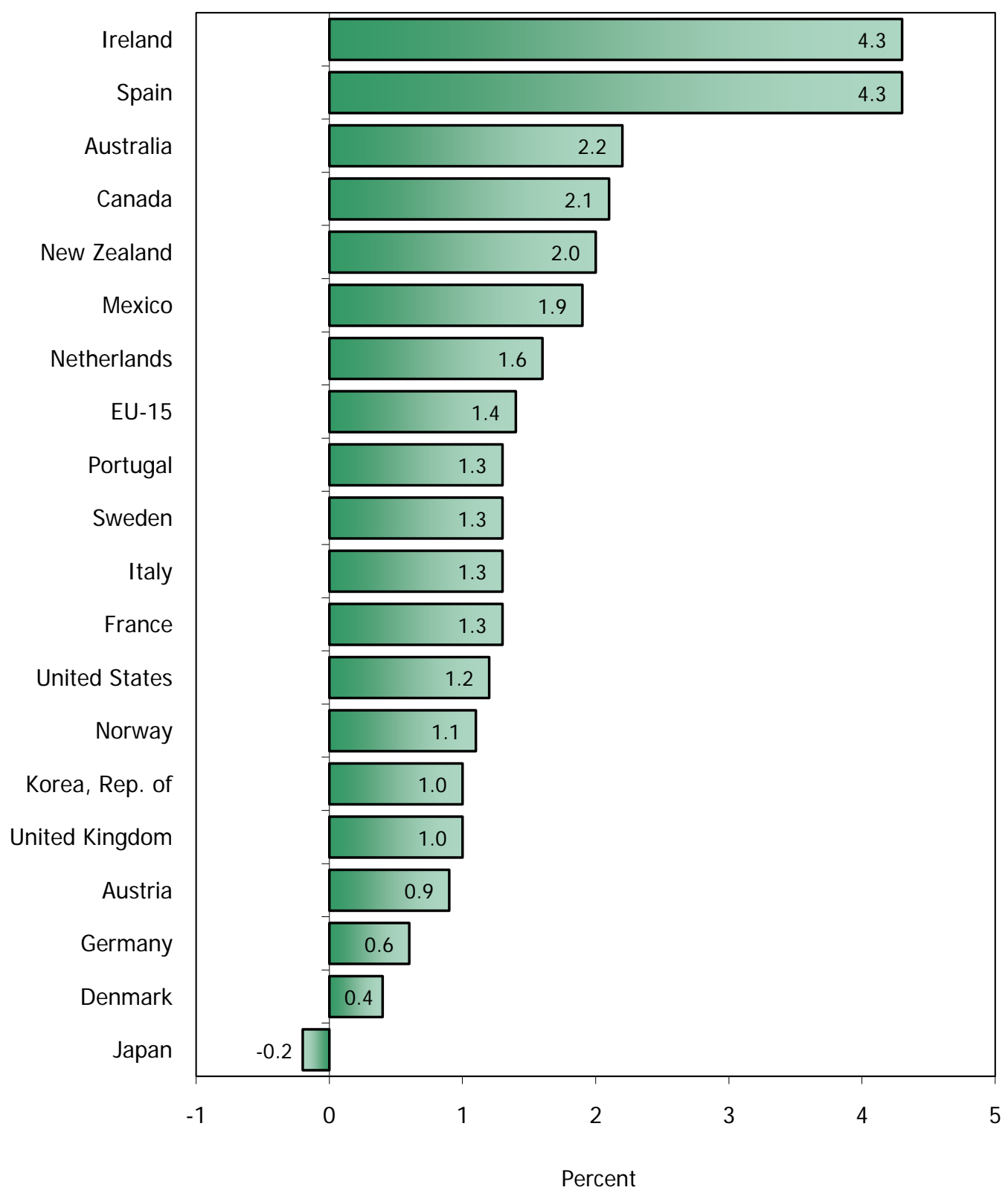

SOURCES: Bureau of Labor Statistics and Organization for Economic Cooperation and Development. 


\subsection{Average annual growth rates for full-time and part- time employment, 1996-2006}

- Full-time employment grew faster than part-time employment in six countries, including the United States.

- Average annual growth rates for full-time employment were highest in Spain, followed by Ireland, Mexico, and Canada.

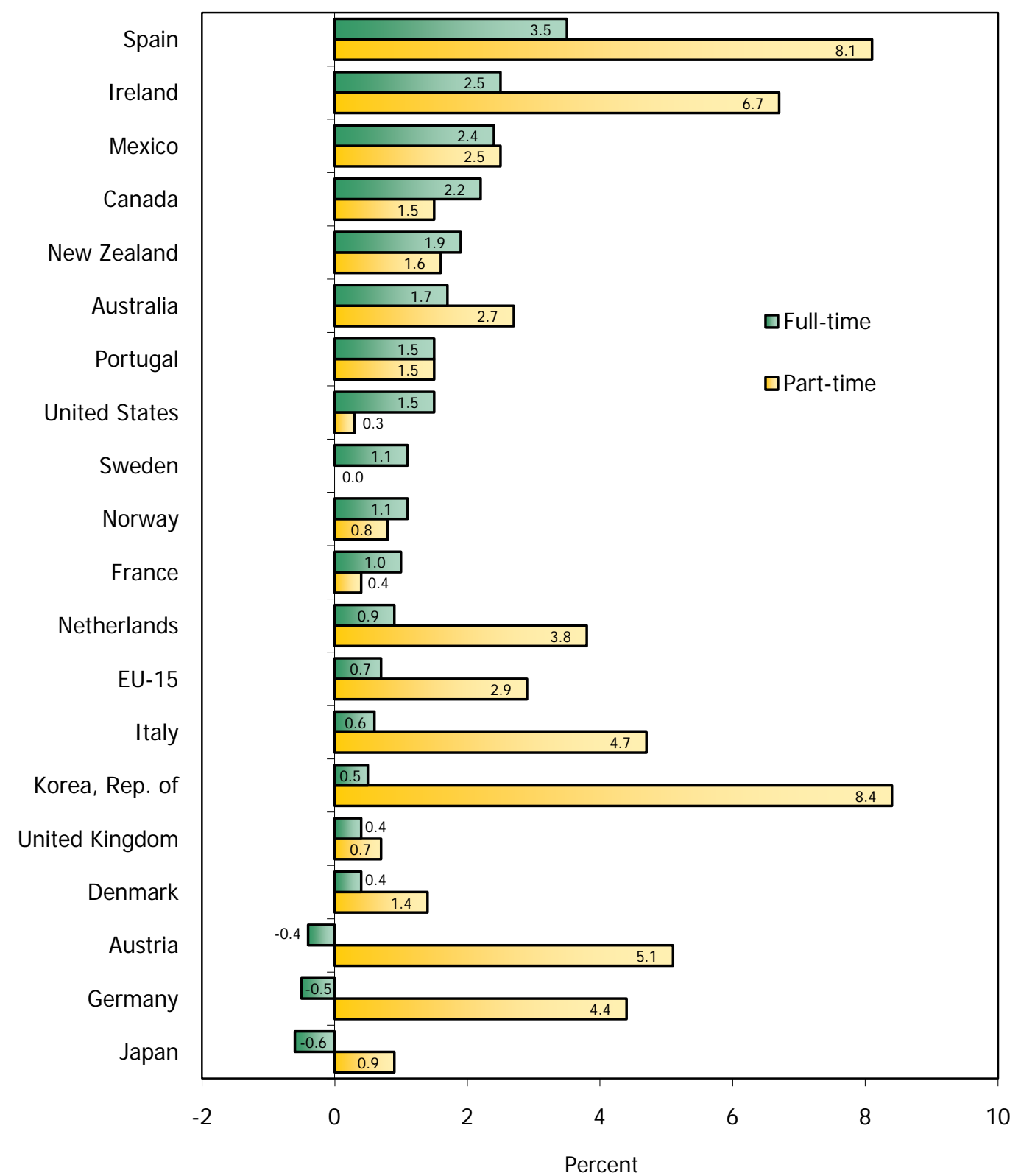

NOTE: 1996-2004 for Mexico. Full-time employment is defined as persons usually working over 30 hours per week in their main job. U.S. data refer to wage and salary workers only. Data for other countries refer to total employment, which includes wage and salary workers, self-employed persons, and unpaid family workers.

SOURCE: Organization for Economic Cooperation and Development. 


\subsection{Annual hours worked per employed person, 1997 and 2007}

- In both years, Koreans worked the most hours annually.

- The Republic of Korea and I reland experienced the largest reductions in annual hours worked per employed person. Hours worked increased only in Denmark.

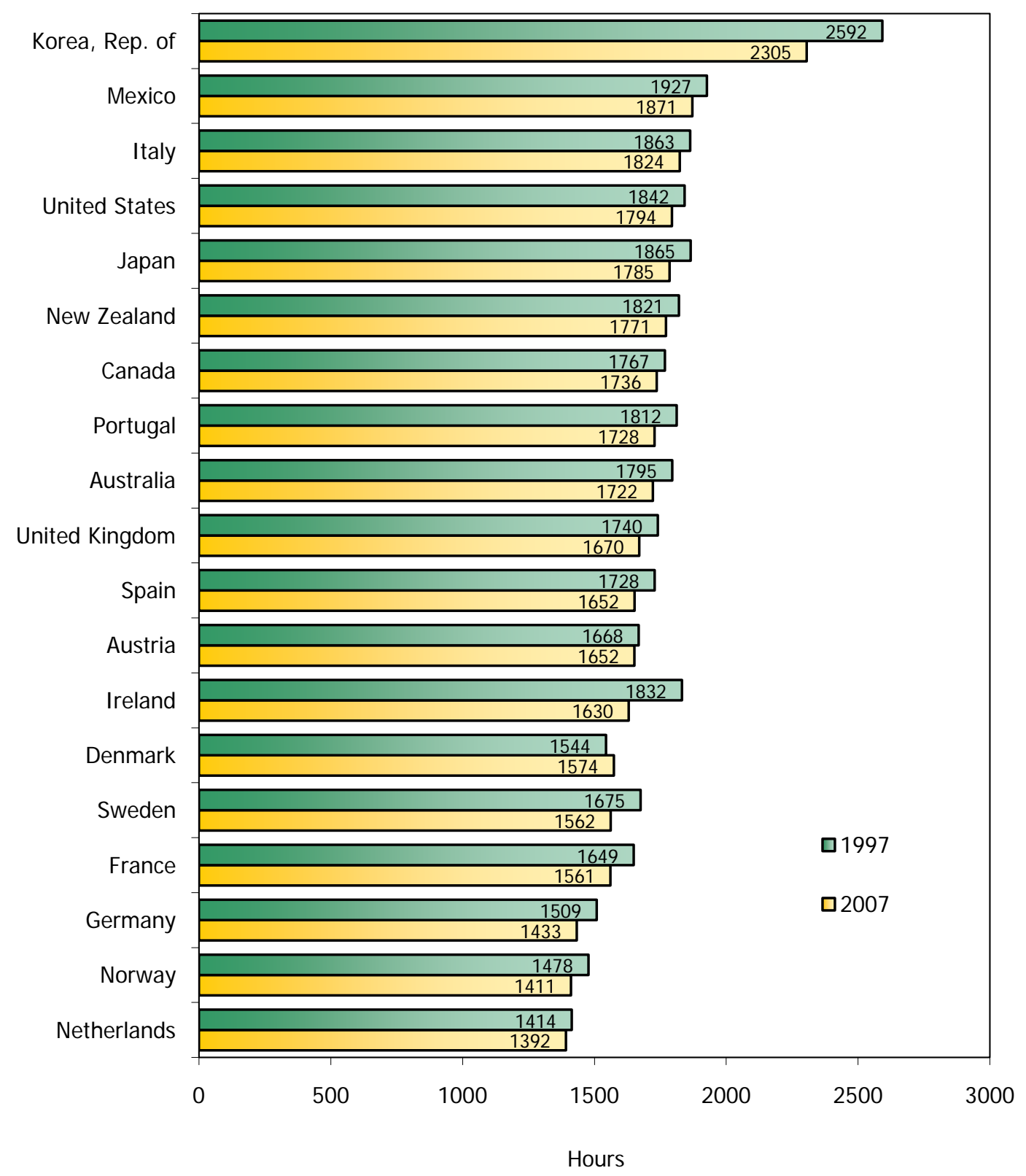

NOTE: 2006 for Denmark and the Republic of Korea.

SOURCE: Organization for Economic Cooperation and Development. 


\subsection{Unemployment rates, 2007}

- Most of the European countries had higher unemployment rates than the United States.

- Norway, the Netherlands, and the Republic of Korea had the lowest unemployment rates.

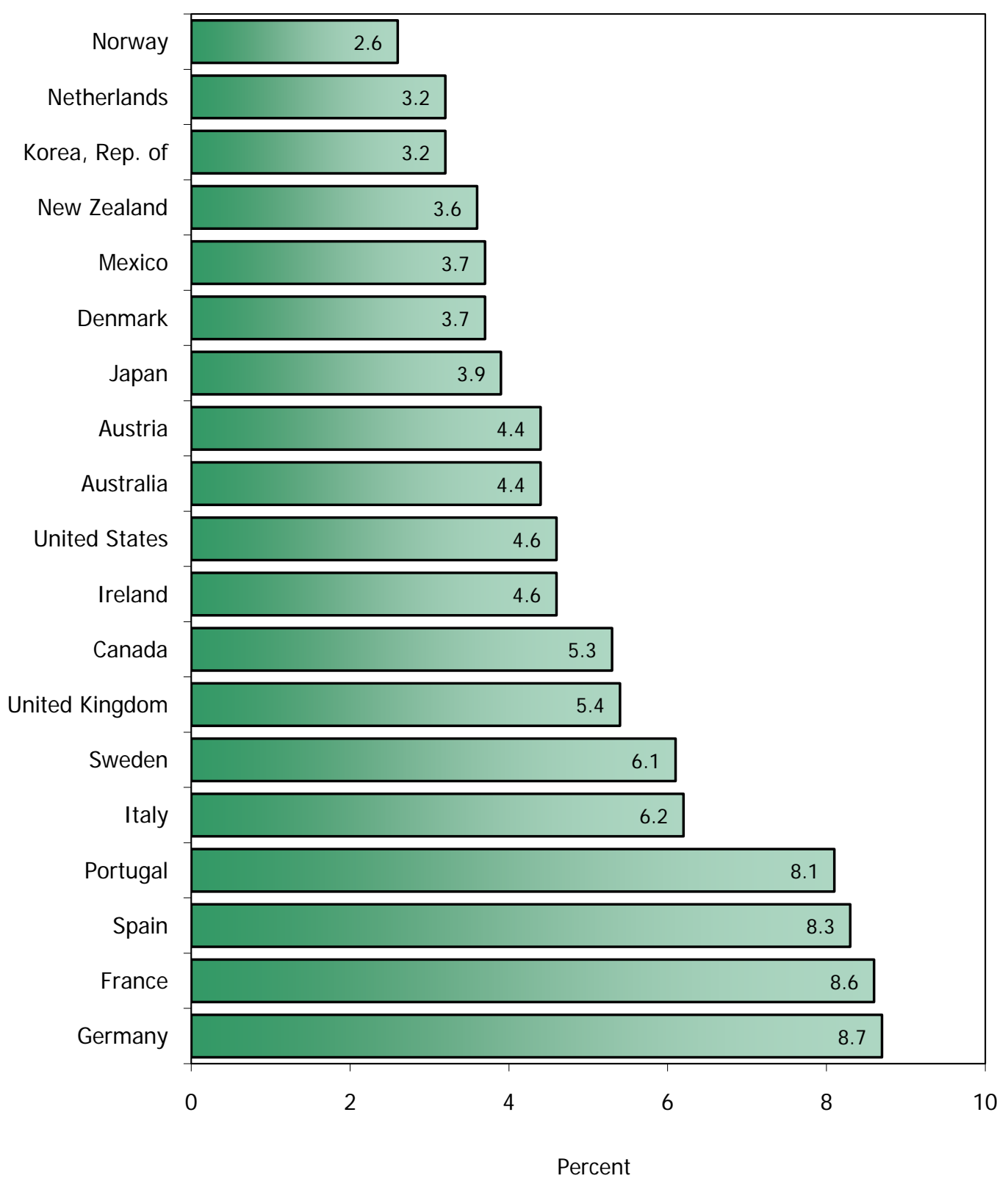

SOURCES: Bureau of Labor Statistics and Organization for Economic Cooperation and Development. 


\subsection{Unemployment rates for youths, 2007}

- Unemployment rates for teenagers were higher than those for persons ages 20 to 24 in all countries.

- Italian teenagers had the highest unemployment rate, followed by their counterparts in Sweden, Spain, and France.

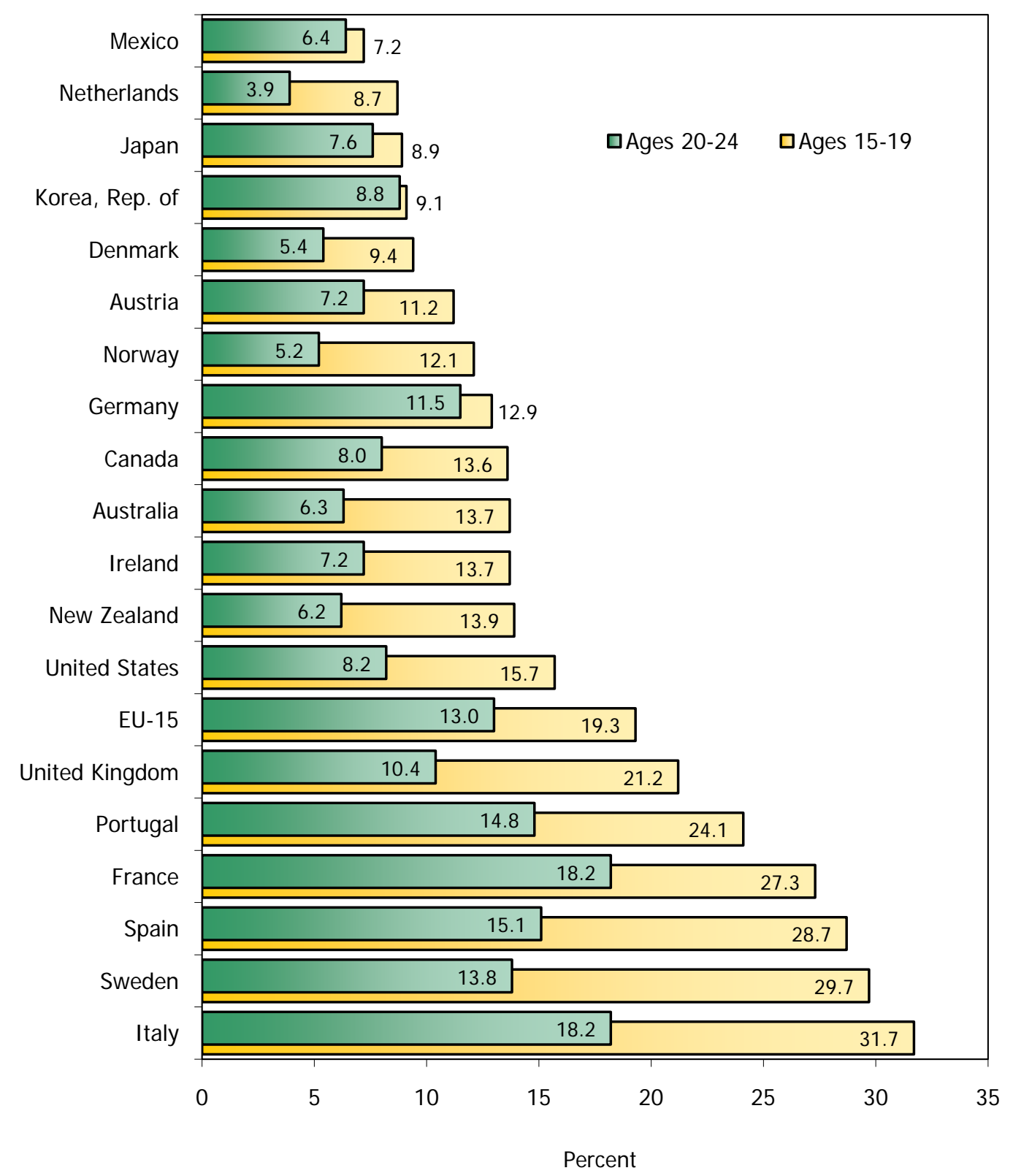

NOTE: Persons ages 16 to 19 instead of ages 15 to 19 for Canada, France, Norway, Spain, Sweden, the United Kingdom, and the United States.

SOURCES: Bureau of Labor Statistics and Organization for Economic Cooperation and Development. 


\subsection{Unemployment rates for youths and adults, 2007}

- In most countries, unemployment rates were two to three times higher for youths than for adults.

- The largest gaps between unemployment rates for youths and adults were in Italy and Sweden; the gap was smallest in the Netherlands.

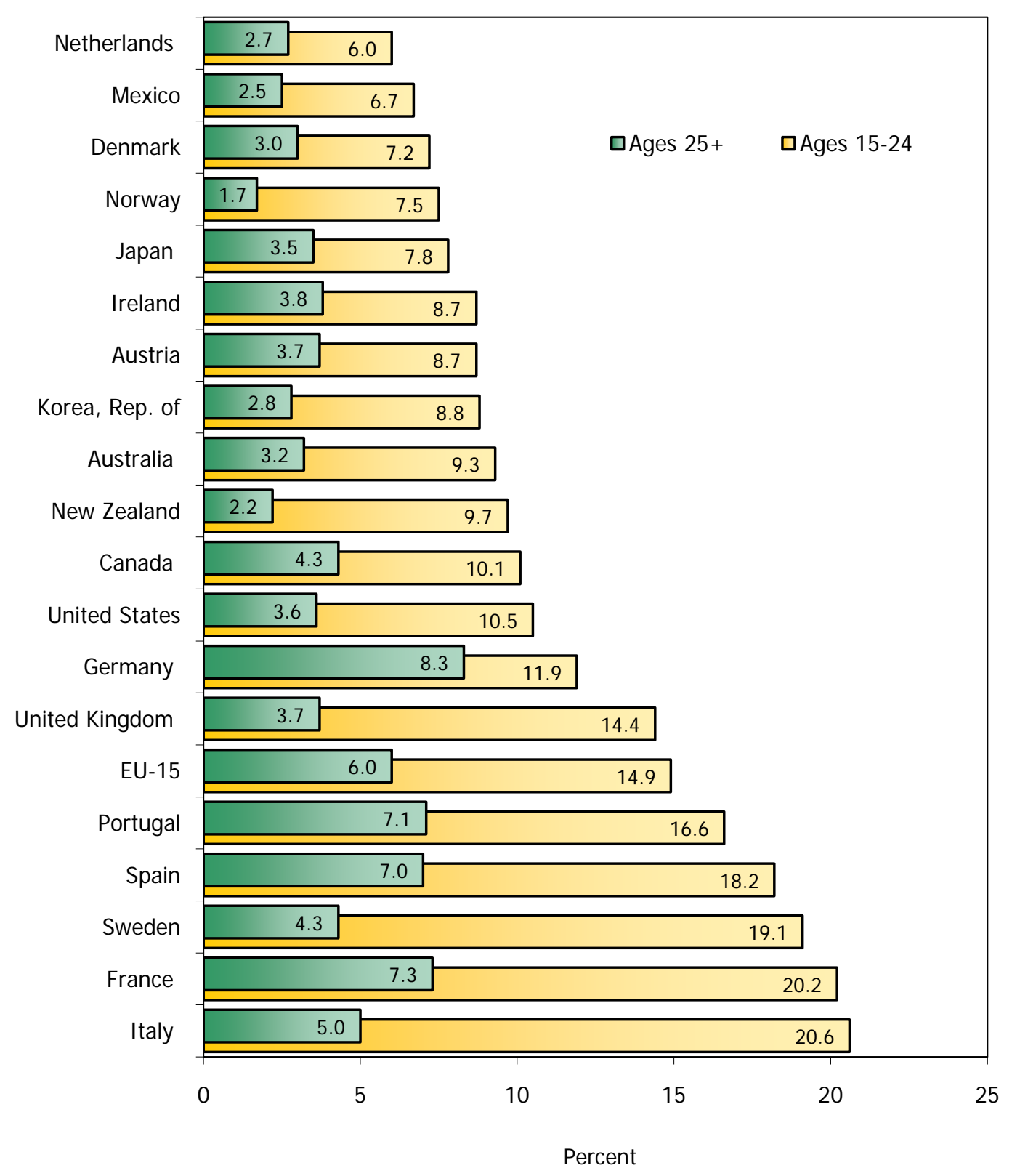

NOTE: Persons ages 16 to 24 instead of ages 15 to 24 for Canada, France, Norway, Spain, Sweden, the United Kingdom, and the United States.

SOURCES: Bureau of Labor Statistics and Organization for Economic Cooperation and Development. 


\subsection{Persons unemployed one year or longer as a percent of total unemployment, 2007}

- Long-duration unemployment was least prevalent in the Republic of Korea and Mexico.

- The EU-15 countries combined had a relatively high percentage of persons unemployed one year or longer. More than half of the unemployed were without work for at least one year in Germany.

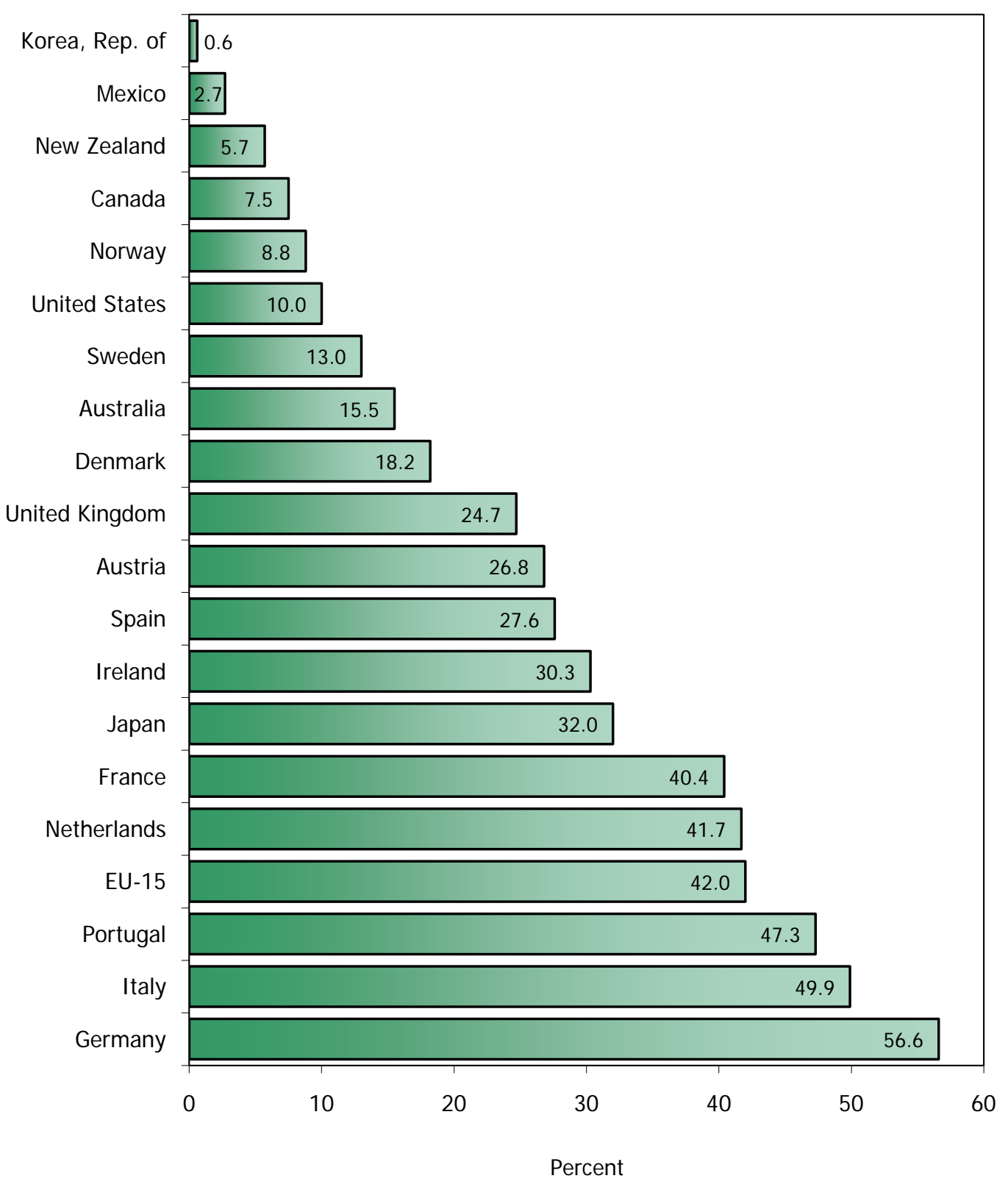

SOURCE: Organization for Economic Cooperation and Development. 


\subsection{Ratios of unemployment rates of persons without high school degrees to those of persons with college or university degrees, 2006}

- Unemployment rates of persons without high school degrees were higher than those of persons with college or university degrees, except for men and women in Mexico and for women in the Republic of Korea.

- The ratios of unemployment rates for the two education levels were highest for men in Germany and Austria and for women in the United States.

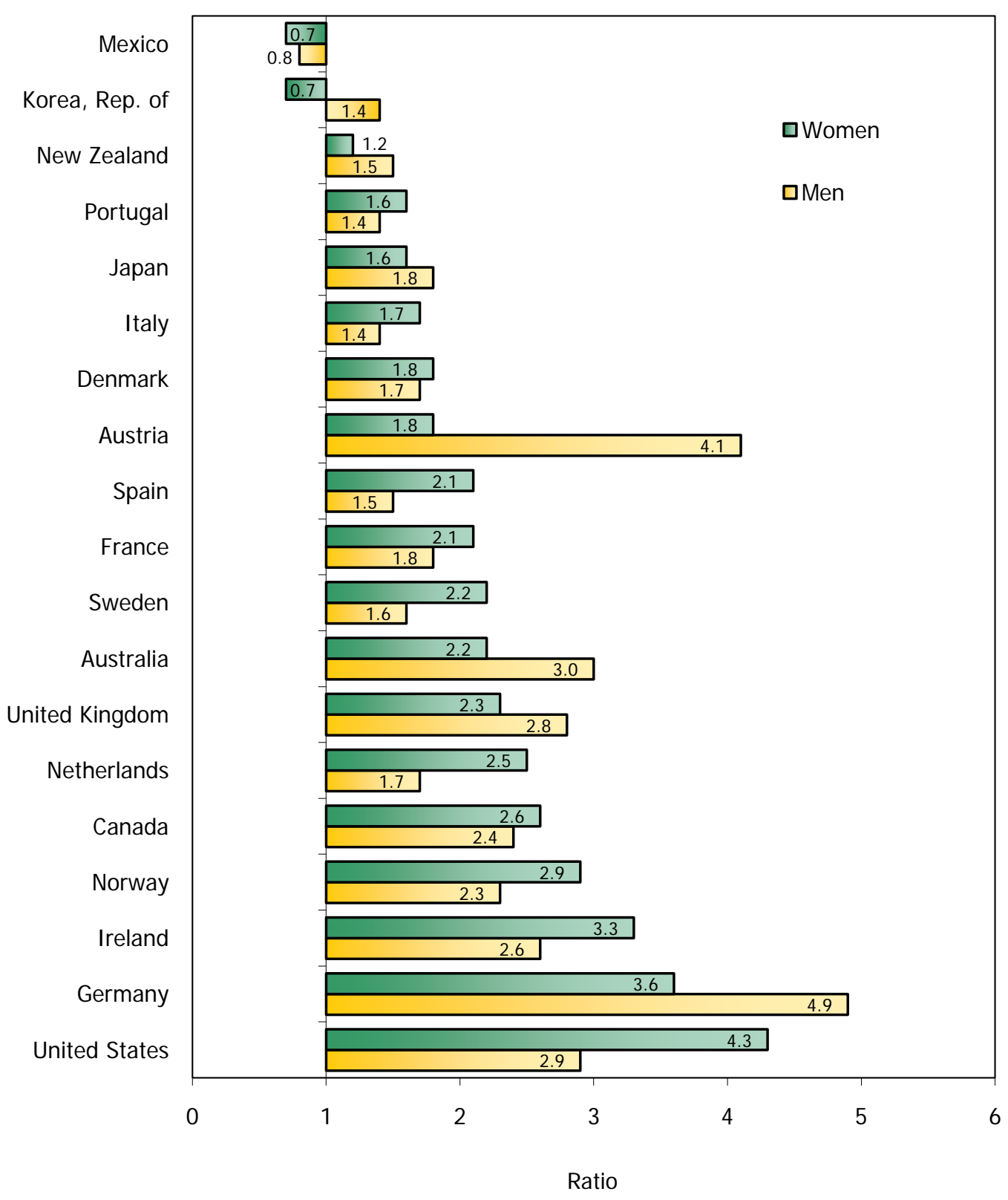

NOTE: The ratio for J apan compares the unemployment rate of persons with high school degrees to that of persons with college or university degrees. The unemployment rates used to calculate these ratios are for men and women ages 25 to 64 .

SOURCE: Organization for Economic Cooperation and Development. 


\subsection{Educational attainment of the adult population, 2006 by highest level completed}

- More than one-third of the adult population has attained a college or university degree in Canada, Japan, the United States, New Zealand, and Denmark.

- In Mexico and Portugal, more than 70 percent of the adult population has completed less than high school education.

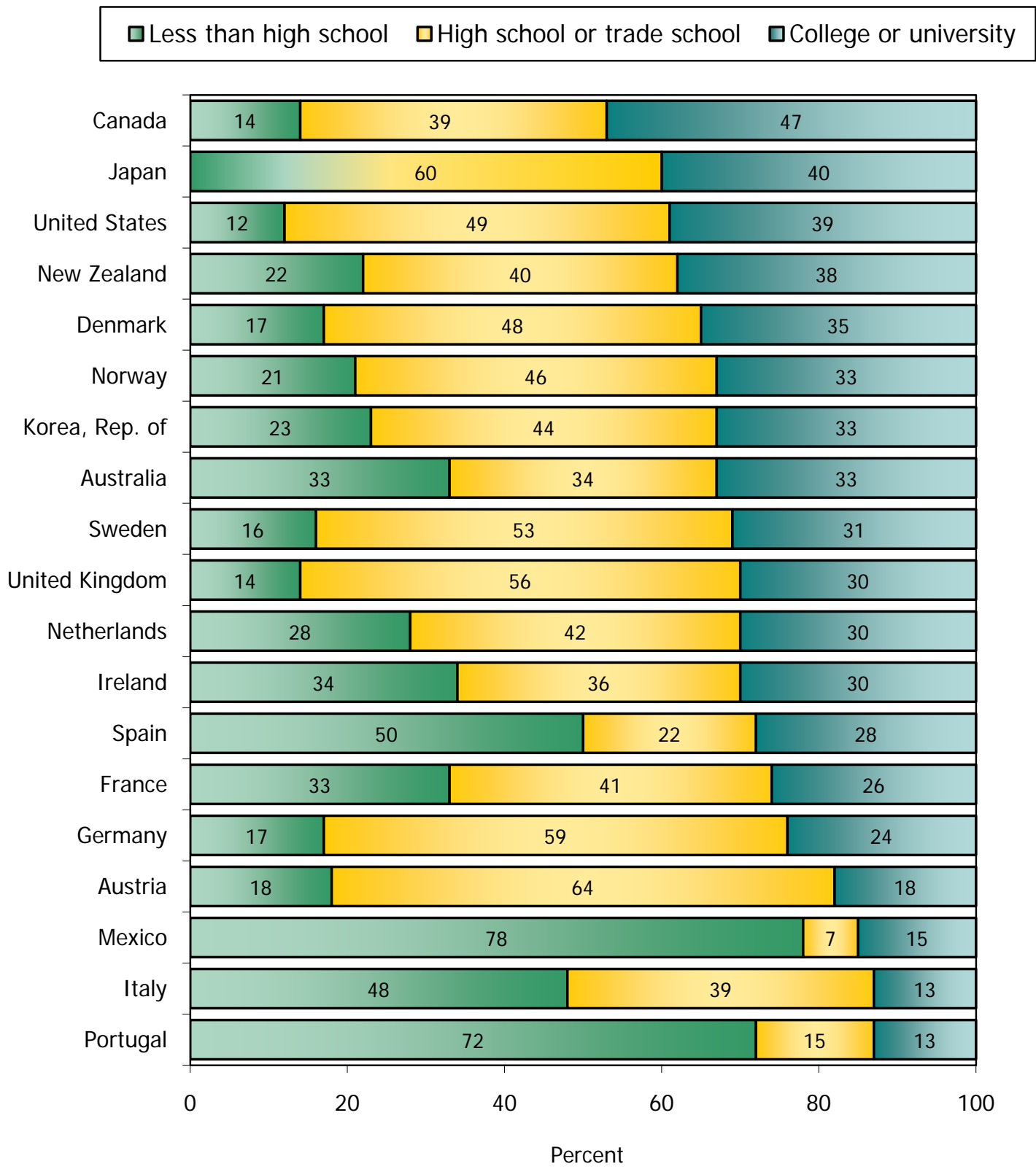

NOTE: For J apan, persons who have completed less than high school are combined with persons who have completed high school or trade school. The adult population is defined as persons ages 25 to 64 .

SOURCE: Organization for Economic Cooperation and Development. 
Competitiveness Indicators for

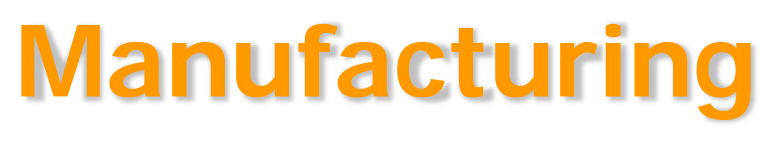

Relative levels and changes in manufacturing hourly compensation costs and relative changes in manufacturing labor productivity (output per hour) and unit labor costs are useful for partially assessing international competitiveness. The data presented in this section are for the manufacturing sector only.

Charts 3.1 and 3.2 compare the level and trends of hourly compensation costs for production workers in manufacturing. Chart 3.3 depicts employer social insurance expenditures and other labor taxes as a percent of hourly compensation costs.

Charts 3.4-3.7 provide comparisons of manufacturing productivity growth rates, the composition of productivity growth in terms of changes in output and hours worked, trends in unit labor costs, and shares of world manufacturing output.

This section covers 16 to 22 economies, the most extensive coverage in this chartbook. In addition, a weighted aggregate for 15 European Union countries (EU-15) is shown on one chart. 

for production workers in manufacturing in U.S. dollars

- Ten of the 12 European countries, as well as Australia and Canada, had higher hourly compensation costs than the United States.

- Hourly compensation costs were under \$10 in Mexico, Hong Kong SAR, Taiwan, Portugal, and Singapore.

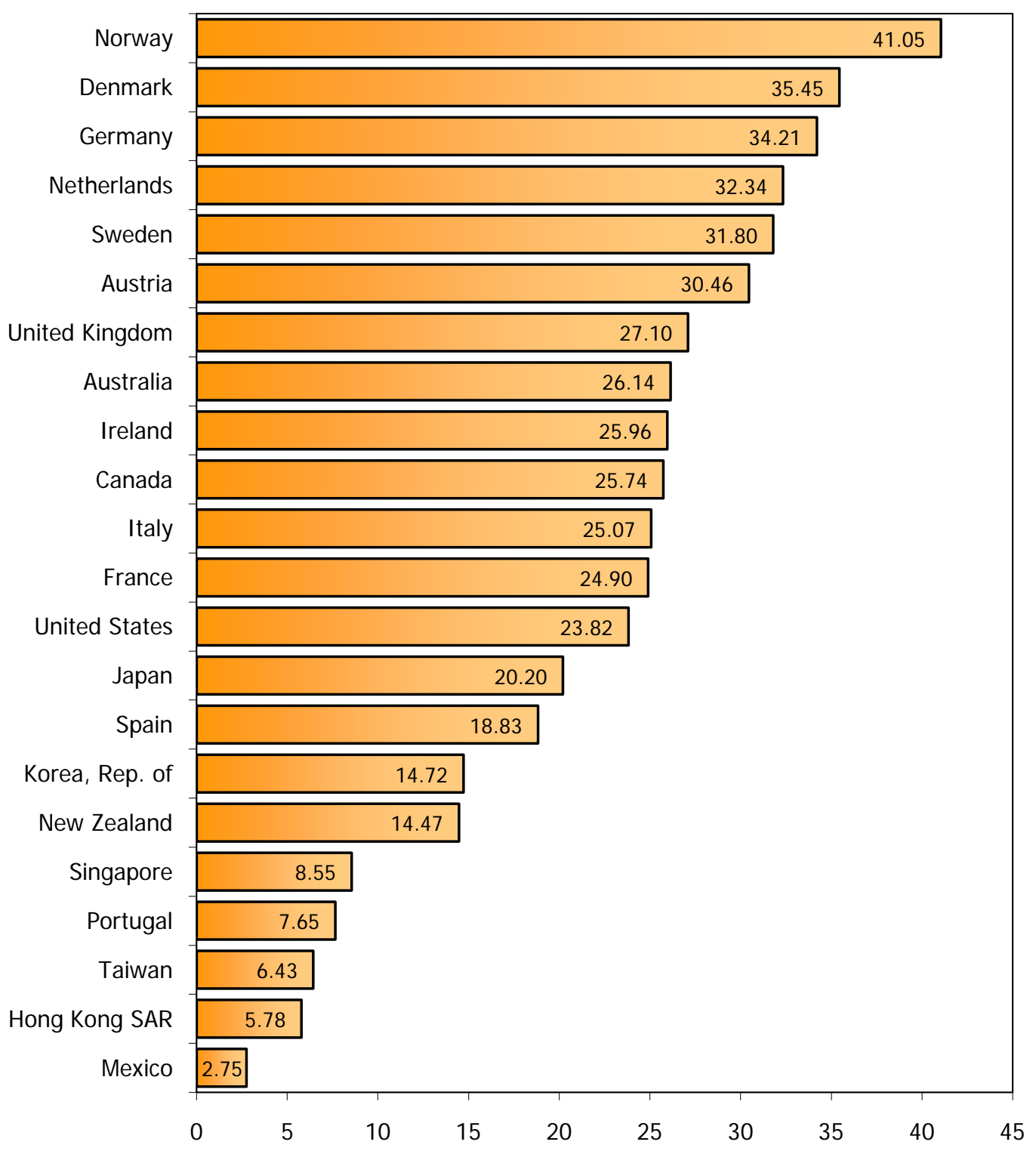

U.S. dollars

NOTE: Hong Kong SAR stands for Hong Kong Special Administrative Region of China.

SOURCE: Bureau of Labor Statistics. 


\section{Average annual growth rates for hourly compensation costs, 1996-2006 for production workers in manufacturing in U.S. dollars}

- Growth in hourly compensation costs in U.S. dollars was greatest for the United Kingdom, Ireland, and the Republic of Korea.

- Only Japan had a decrease in hourly compensation costs over the period.

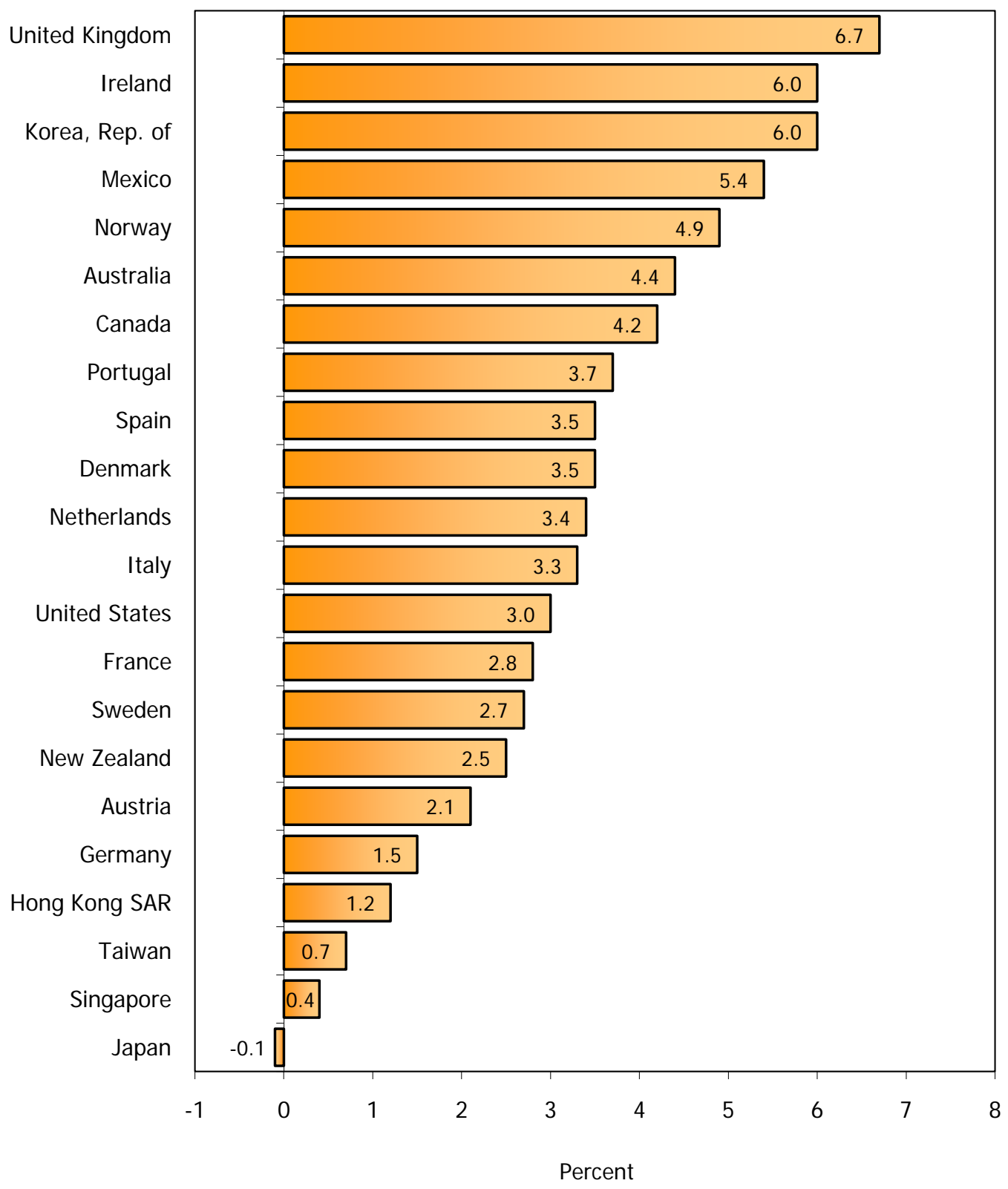

NOTE: Hong Kong SAR stands for Hong Kong Special Administrative Region of China.

SOURCE: Bureau of Labor Statistics. 


\section{Employer social insurance expenditures and other labor taxes as a percent of hourly compensation costs, 2006 for production workers in manufacturing}

- Employer social insurance costs as a percent of hourly compensation costs were higher in the United States than in all of the non-European economies.

- In Europe, social insurance costs as a percent of total hourly compensation costs ranged widely, from 10.4 percent (Denmark) to 33.1 percent (Sweden).

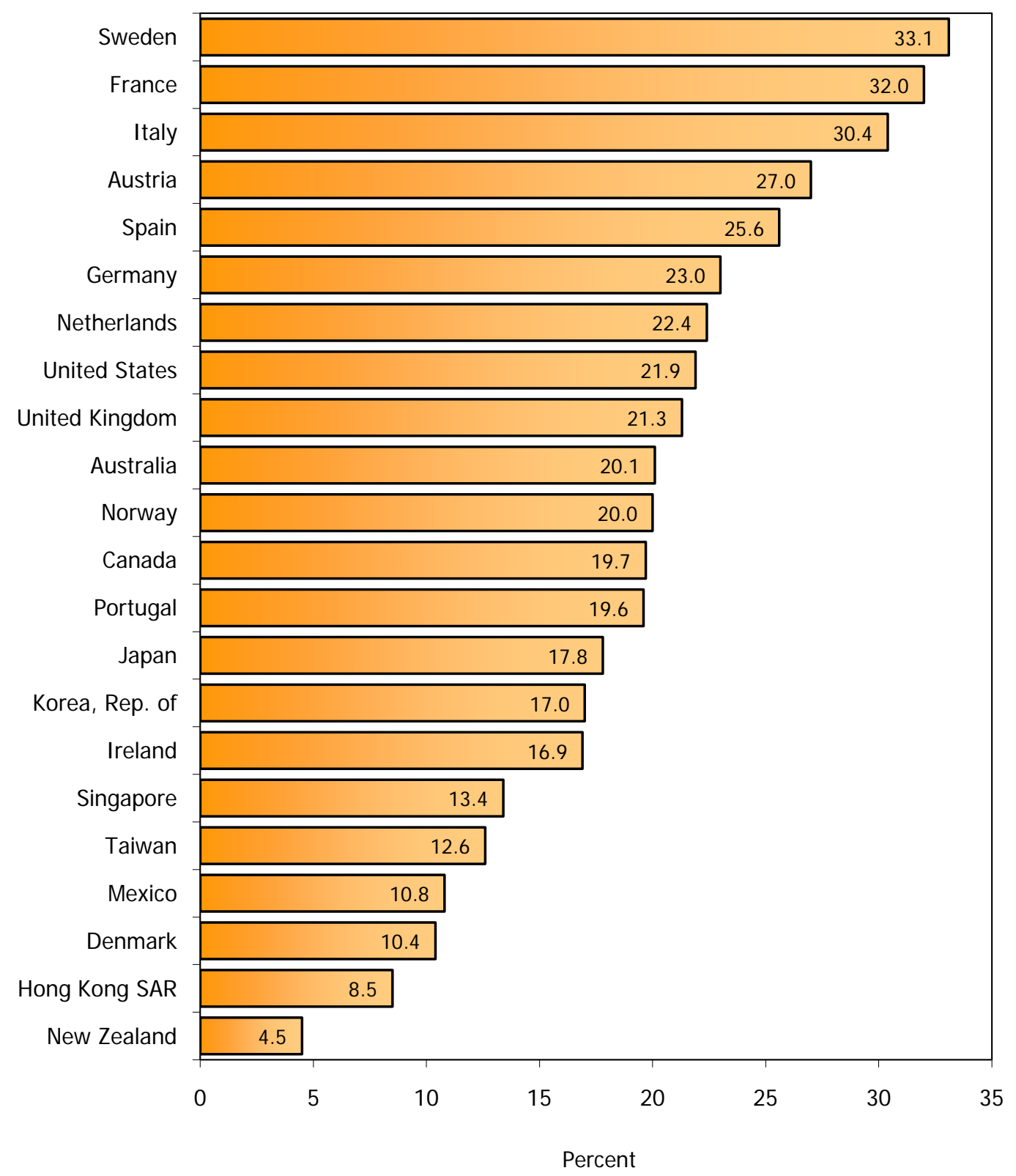

NOTE: Hong Kong SAR stands for Hong Kong Special Administrative Region of China.

SOURCE: Bureau of Labor Statistics. 


\section{Average annual growth rates for manufacturing productivity, 1997-2007}

- The Republic of Korea had the largest increase in manufacturing labor productivity, followed by Sweden, Taiwan, and the United States.

- Growth in manufacturing labor productivity was lowest in Italy.

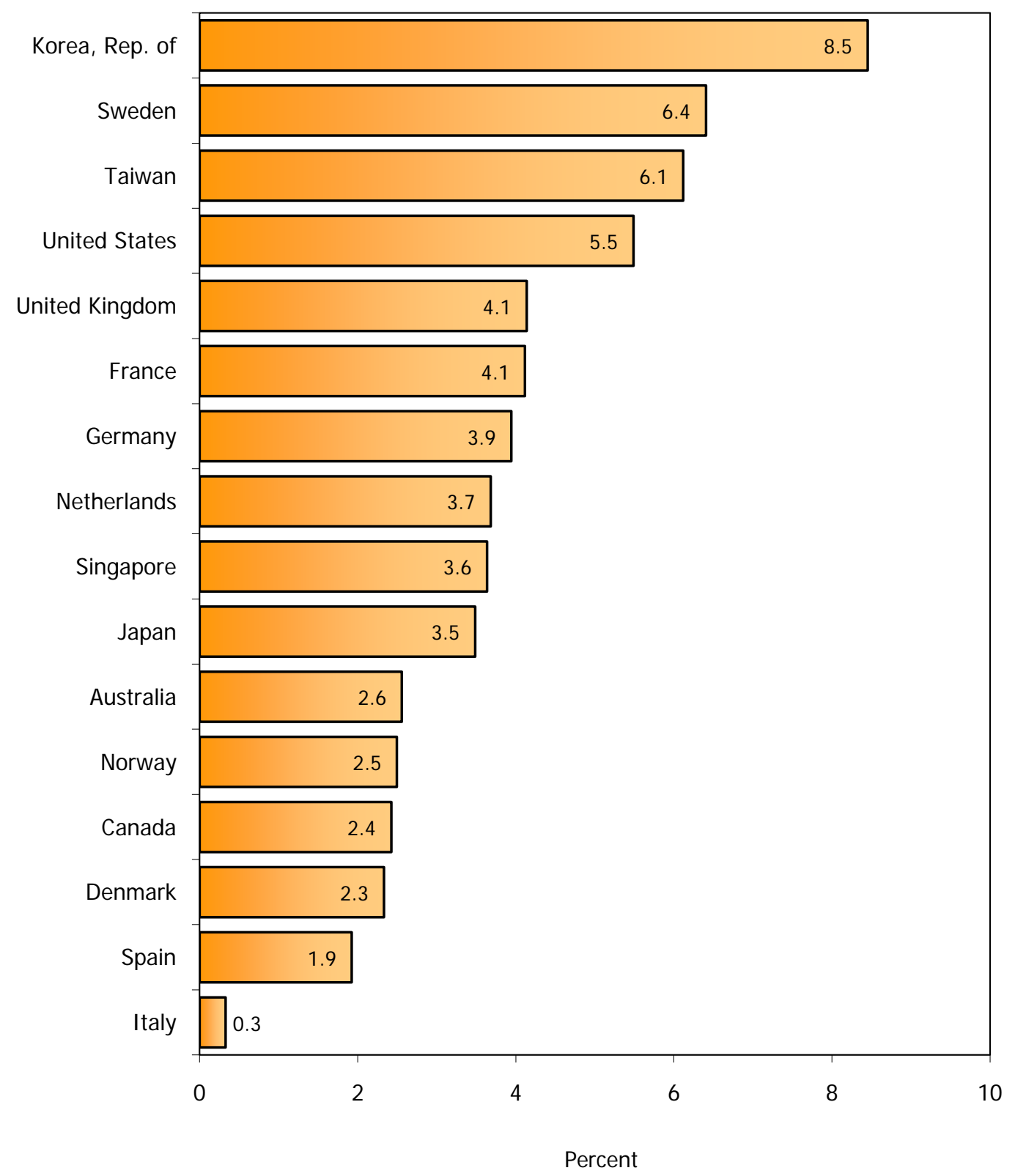

NOTE: Productivity is defined as output per hour worked.

SOURCE: Bureau of Labor Statistics. 


\subsection{Average annual growth rates for manufacturing output and hours worked, 1997-2007}

- Average annual growth rates for manufacturing output were highest in the Republic of Korea, Singapore, Sweden, and Taiwan.

- The United Kingdom, the United States, France, and J apan had the largest percentage declines in hours worked; by contrast, hours worked increased only in Singapore and Spain.

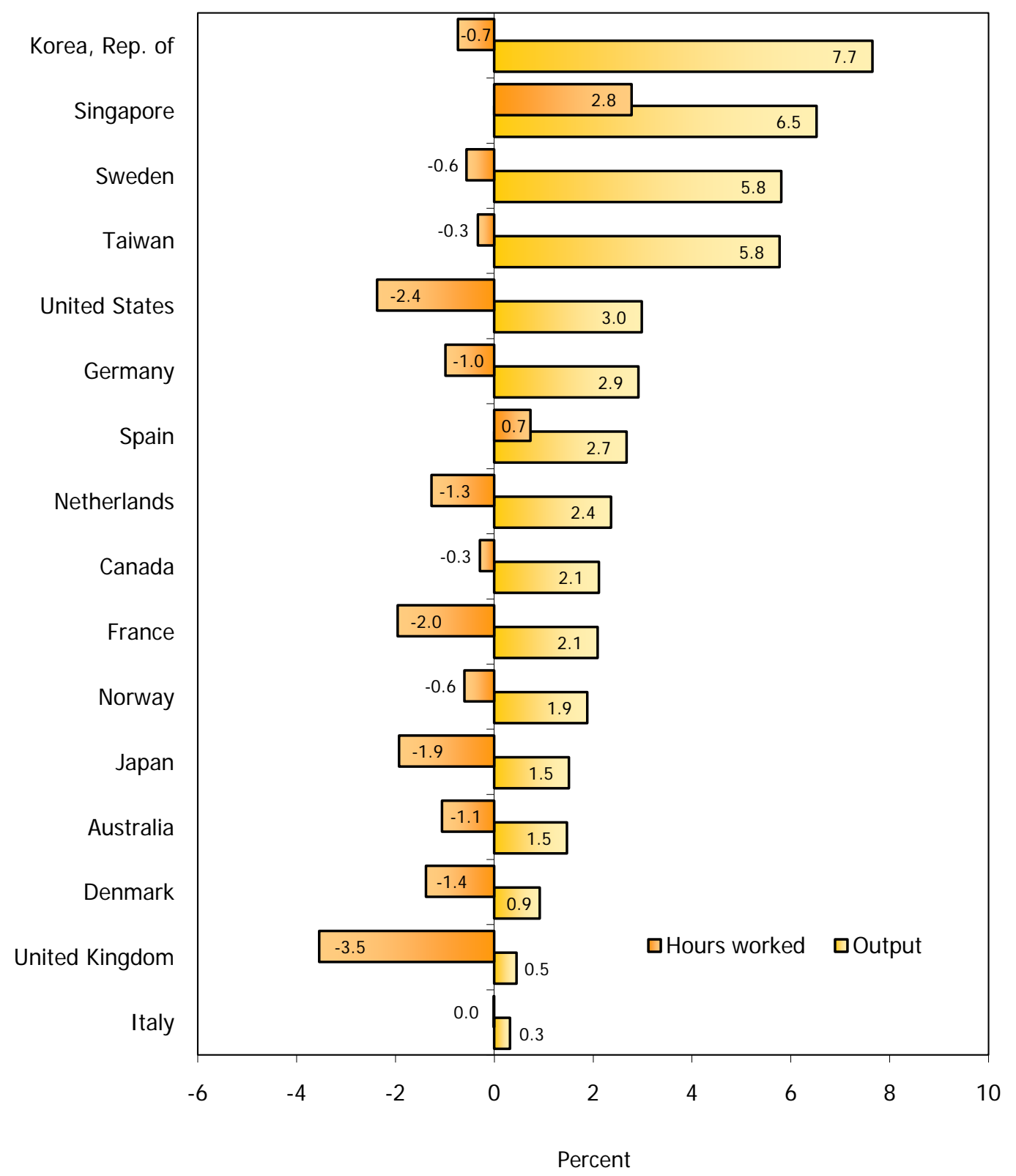

SOURCE: Bureau of Labor Statistics. 


\section{Average annual growth rates for manufacturing unit labor costs in U.S. dollars, 1997-2007}

- Unit labor costs (ULC) are a component of total production costs and product prices. Declines in ULC indicate that an economy is becoming more cost-competitive.

- ULC declined over the period in more than one-third of the economies, including the United States.

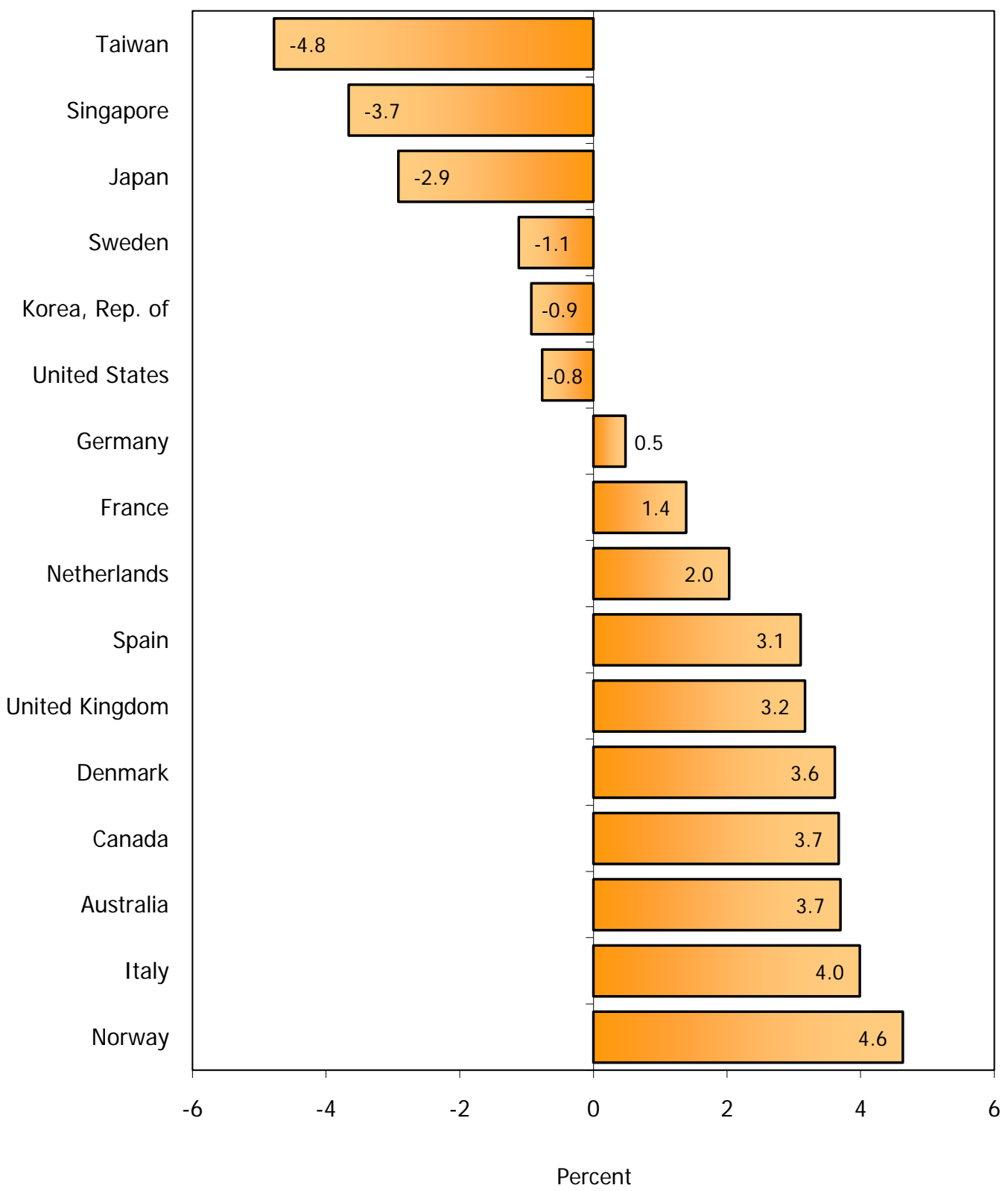

NOTE: Unit labor costs are defined as the cost of labor compensation per unit of output. 


\subsection{Manufacturing output as a percent of world manufacturing output, 2007}

- The United States is the world's leading producer of manufactured goods.

- The EU-15 countries' combined share of world manufacturing output surpassed that of the United States.

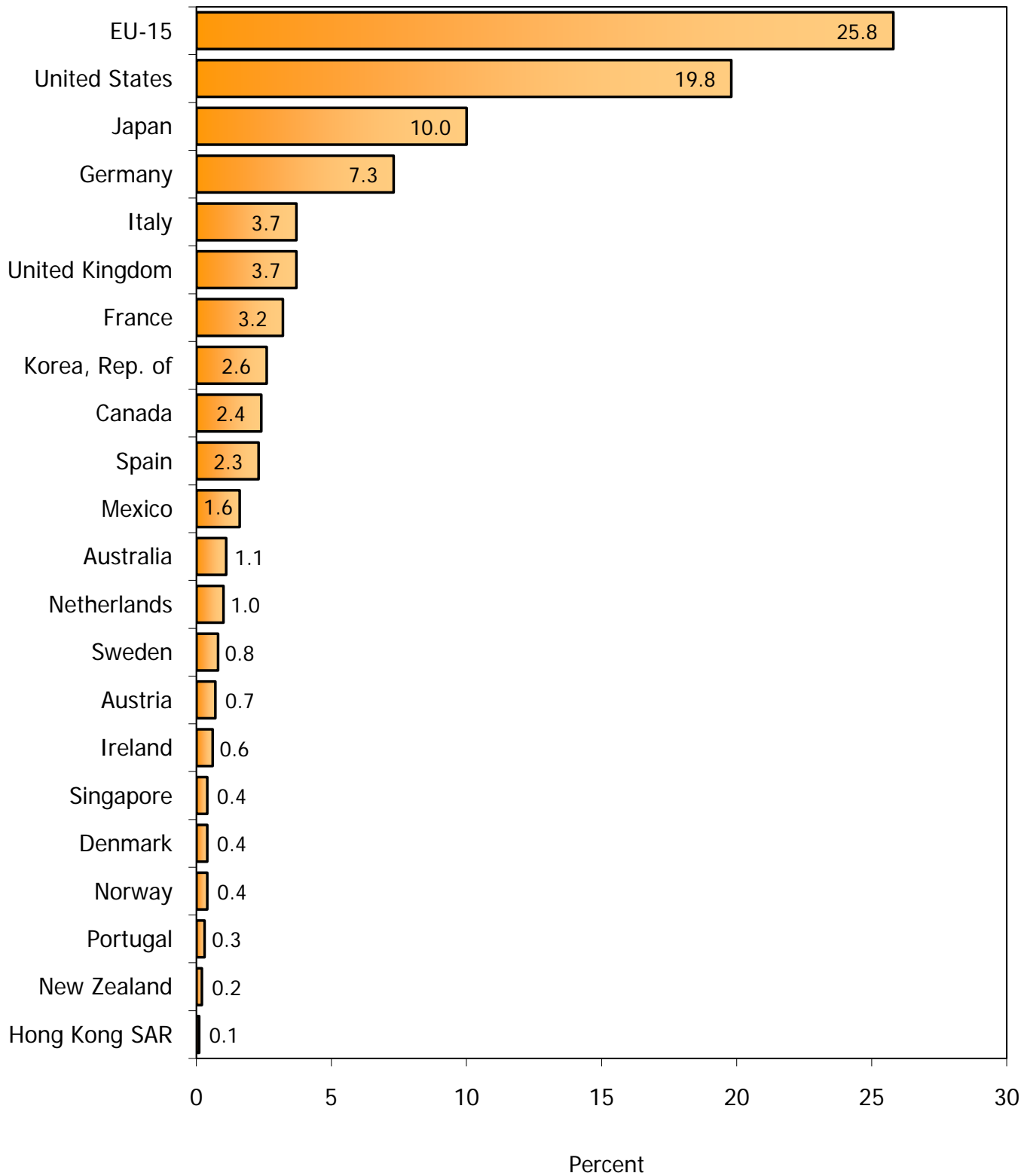

NOTE: Hong Kong SAR stands for Hong Kong Special Administrative Region of China.

SOURCE: United Nations. 
Charts 4.1-4.5 show indicators of broad labor market and population issues, some of these in the policy field. Charts 4.1-4.3 compare the following policy issues: public expenditures on labor market programs, the extent of labor and product market regulations, and the level of taxation on labor.

\section{Other}

\section{Economic} Indicators

Chart 4.4 shows dependency ratios. The dependency ratio is an overall measure of the dependence of children and the elderly on people of working age. However, dependency ratios show the age composition of a population, not necessarily economic dependency. Some children and elderly people are part of the labor force and some working-age people are not.

Chart 4.5 compares data on trade in goods as a percent of GDP. This indicator shows an economy's degree of openness.

The number of countries covered in this section varies from 18 to 21 . In addition, a weighted aggregate for 15 European Union countries (EU-15) is shown on one chart. 


\subsection{Public expenditures on labor market programs as a percent of GDP, 2006}

- Expenditures on labor market programs were less than one percent of GDP in seven countries, including the United States.

- The highest relative expenditures were in Denmark, followed by Germany and the Netherlands.

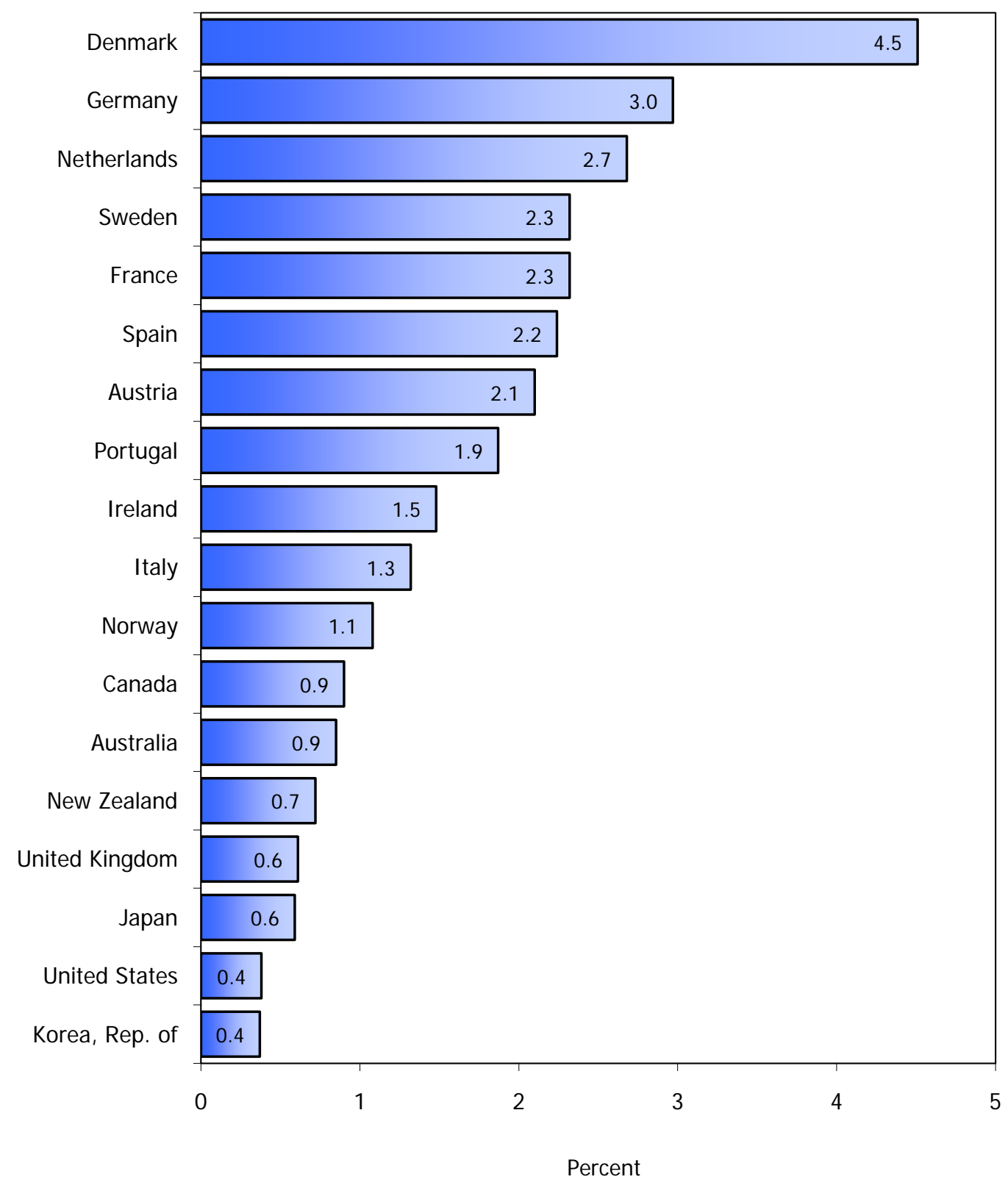

NOTE: 2004 for Denmark. Fiscal year 2006-2007 for Australia, Canada, Japan, New Zealand, United Kingdom, and the United States.

SOURCE: Organization for Economic Cooperation and Development. 


\subsection{Measures of regulation on labor and product markets, 2003}

- Regulations on labor market activity were least restrictive in the United States, the United Kingdom, and Canada. The United Kingdom, Australia, and the United States had the least restrictive product markets.

- $\quad$ Portugal, Mexico, Spain, and France had the most restrictive labor markets; restrictive product markets were most pronounced in Mexico and I taly.

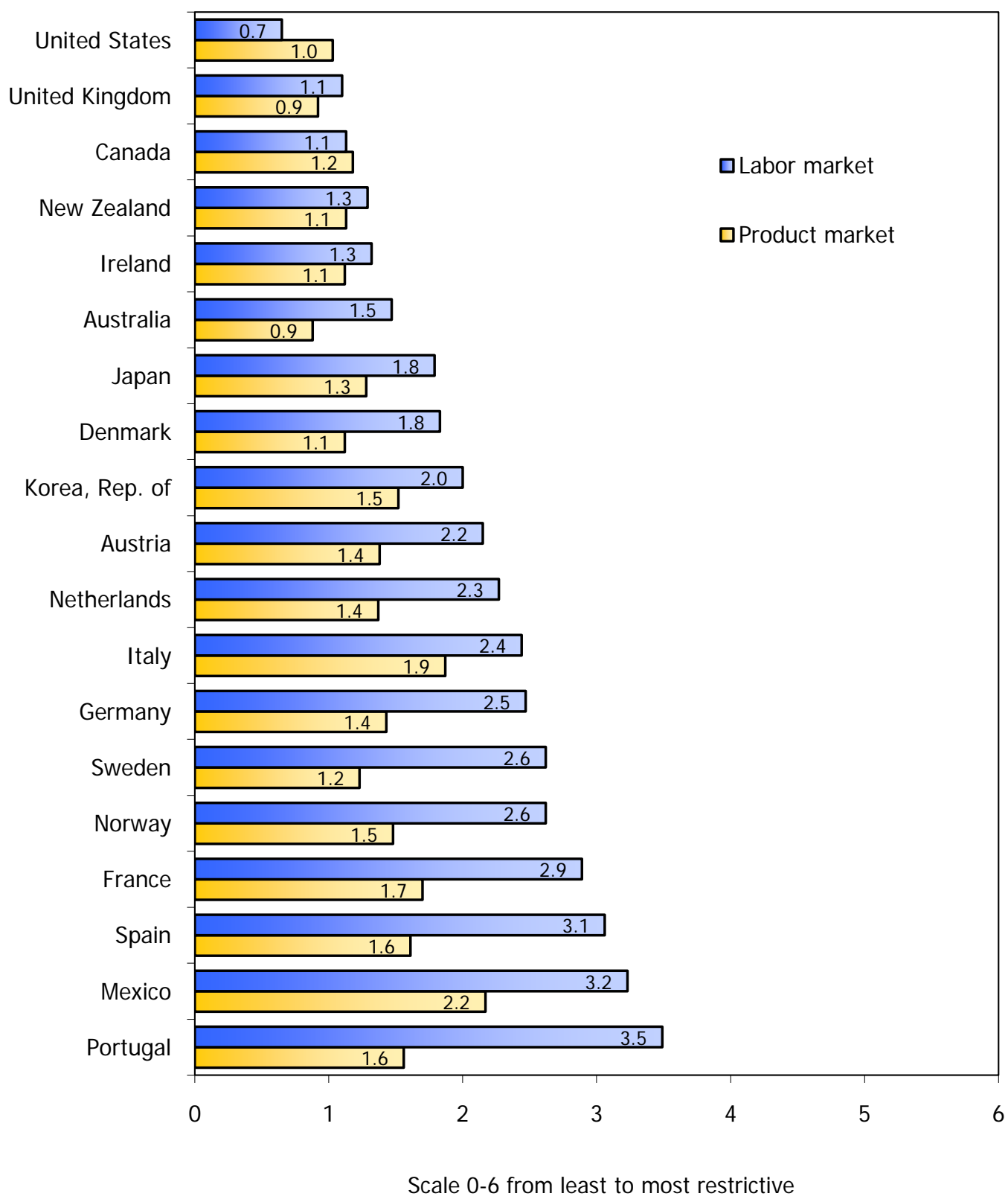

SOURCE: Organization for Economic Cooperation and Development. 


\subsection{Shares of labor costs taken by tax and social security contributions, 2007}

- $\quad$ For the average single worker without children, the combined employer-employee tax burden varied widely, from 15.3 percent (Mexico) to 52.2 percent (Germany).

- The combined employer-employee tax burden was lower in the United States than in all European countries except I reland.

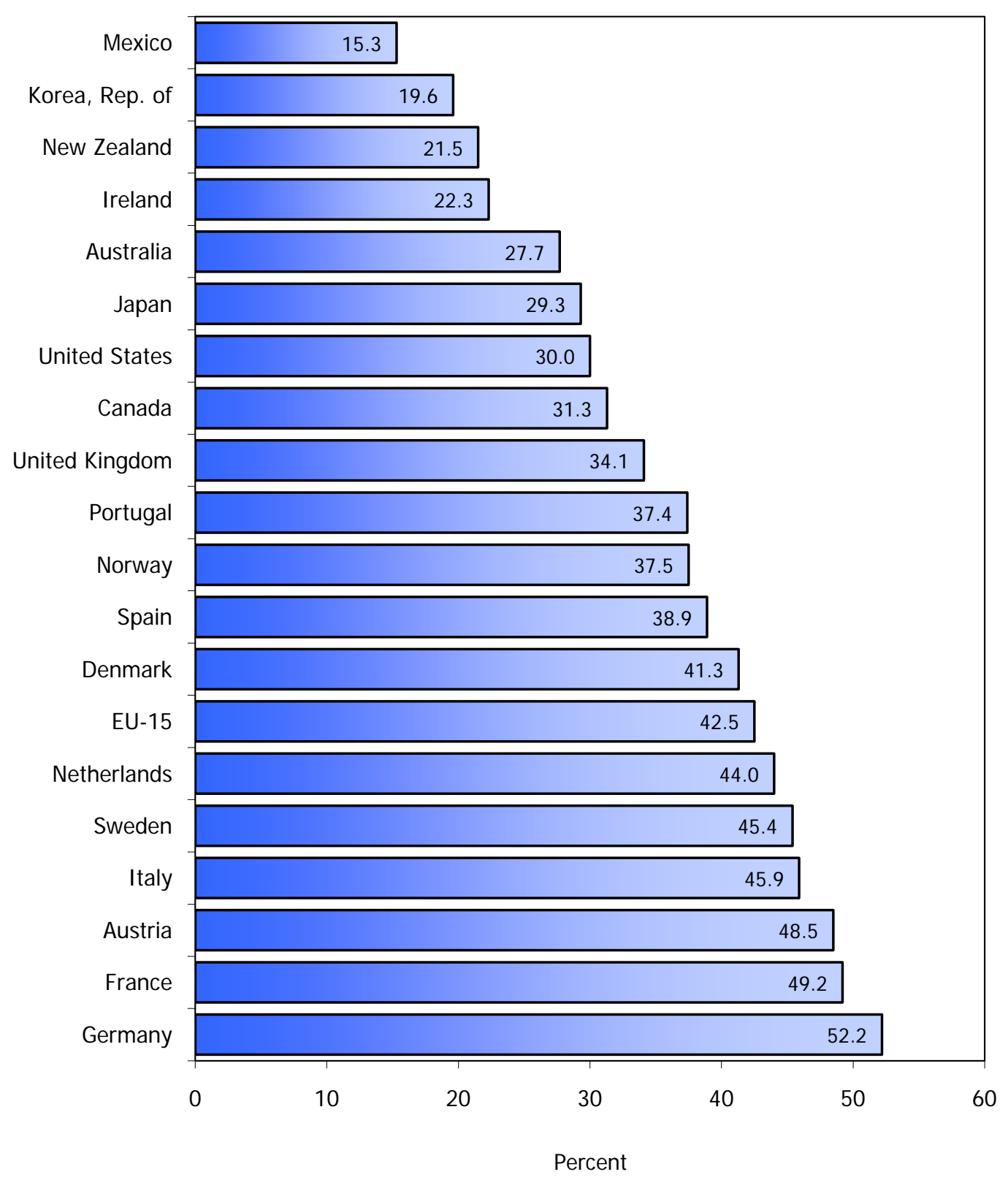

NOTE: Data refer to single persons without children at the income of the average worker.

SOURCE: Organization for Economic Cooperation and Development. 


\subsection{Dependency ratios, 2006 and projections to 2025}

- In 2006, Mexico had the highest dependency ratio and Hong Kong SAR had the lowest.

- Only Mexico's dependency ratio is expected to decrease by 2025; J apan is expected to have the highest dependency ratio.

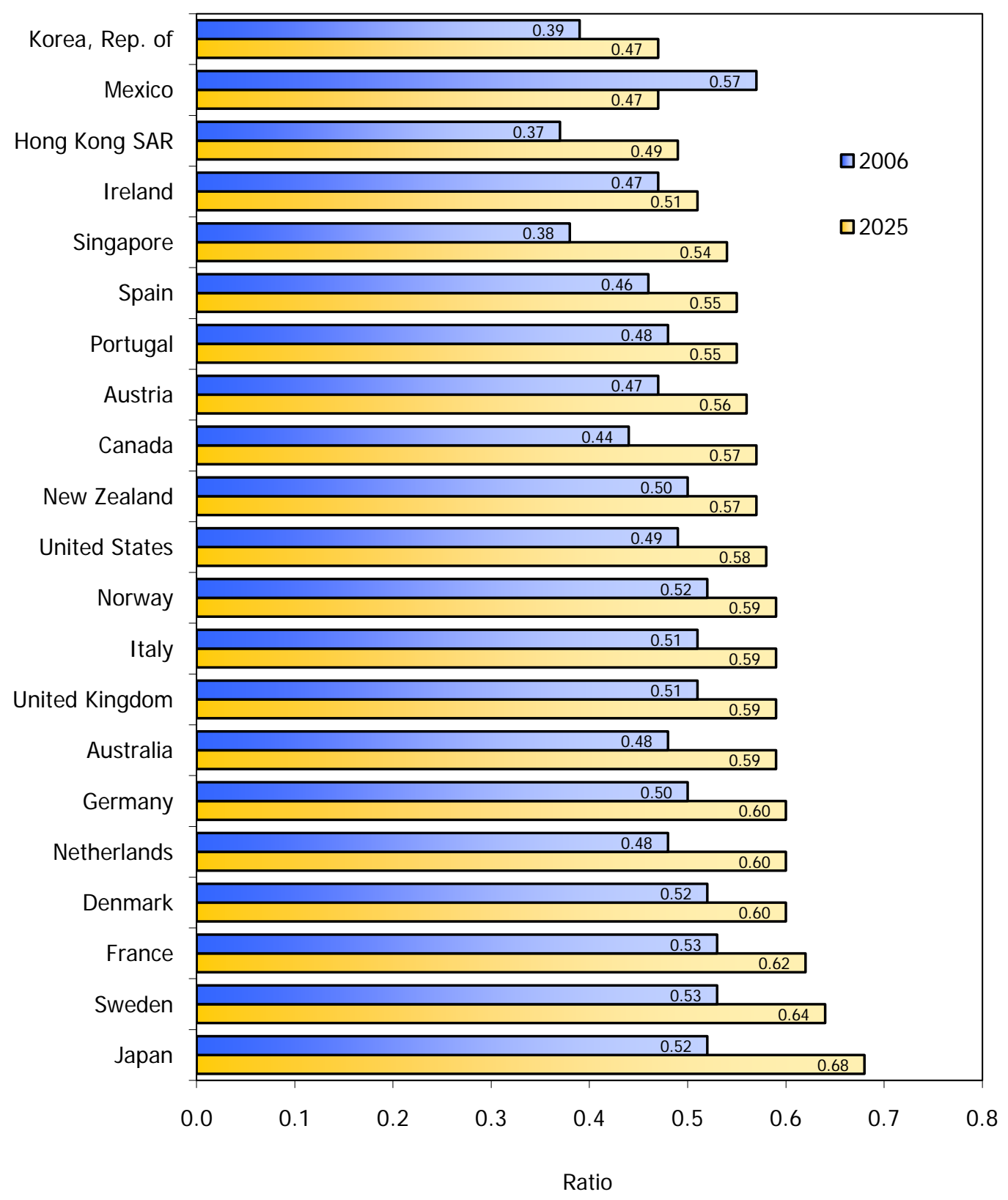

NOTE: Hong Kong SAR stands for Hong Kong Special Administrative Region of China. The dependency ratio is the ratio of dependents (persons ages 14 and under and persons ages 65 and over) to the working-age population (persons ages 15 to 64 ).

SOURCES: World Bank and United Nations. 


\subsection{Trade in goods as a percent of GDP, 2007}

- This indicator shows the relative importance of trade in goods to an economy.

- The United States and J apan had the lowest proportions of trade in goods to GDP. The relatively high figures for Singapore and the Netherlands reflect these countries' status as platforms for re-exports and trans-shipments.

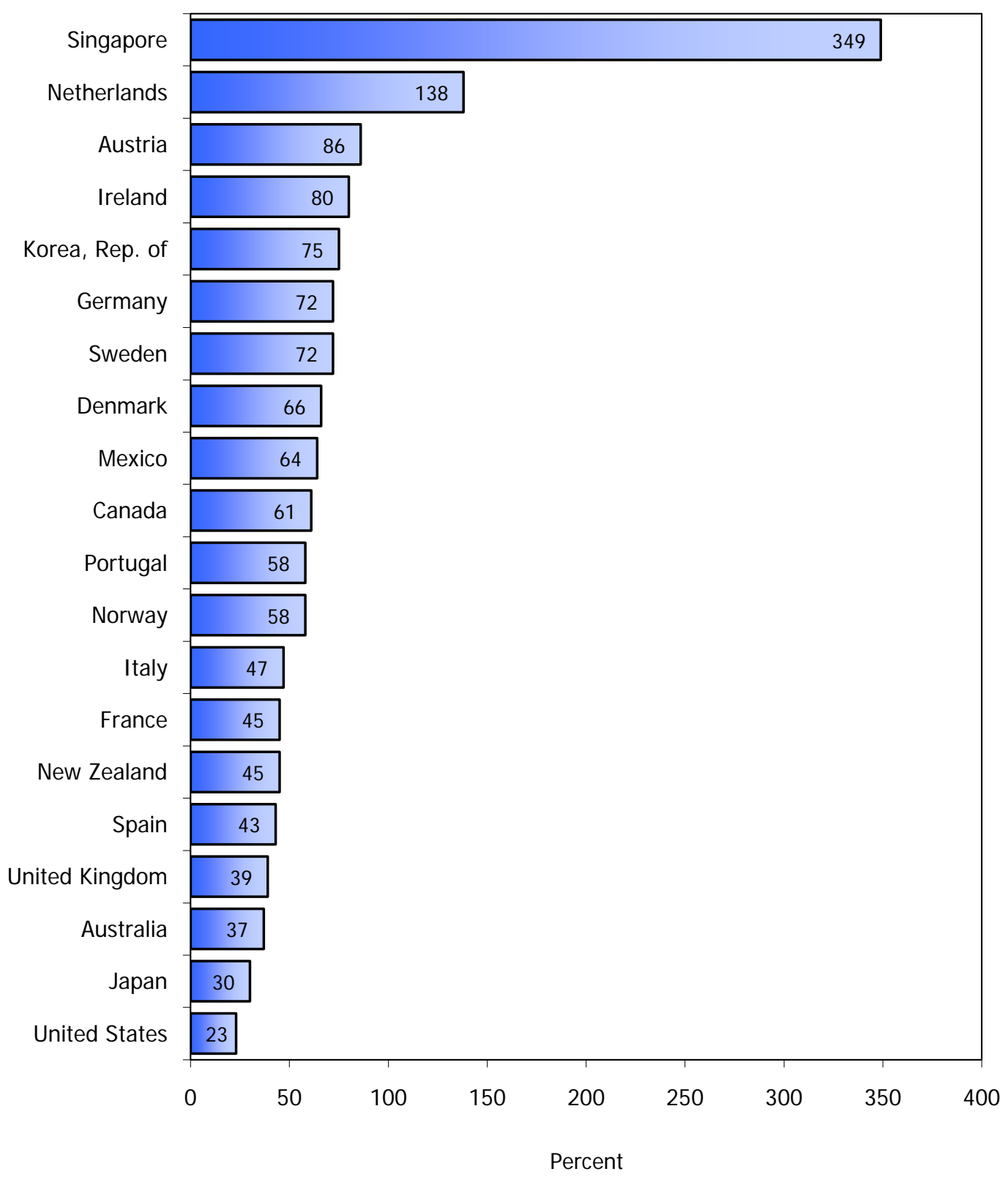

NOTE: Trade in goods is defined as the sum of merchandise exports and imports.

SOURCE: World Bank. 
Charts 5.1-5.9 provide a broad overview of basic economic indicators for the United States and six large emerging economies. These emerging economies are not included in the other charts in this chartbook due to data limitations.

\section{Indicators for} Large Emerging Economies
Charts 5.1-5.3 show population data in three varying ways: world population distribution, age composition of the population, and dependency ratios. Gross Domestic Product (GDP) comparisons are shown in chart 5.4 (GDP per capita) and chart 5.5 (GDP per employed person). Chart 5.6 presents labor force participation rates by age, and chart 5.7 highlights employment-topopulation ratios by sex. Chart 5.8 compares trade in goods as a percent of GDP. Chart 5.9 shows manufacturing output as a percent of world manufacturing output.

All of these charts include the United States, which is used as a reference point, and six large emerging economies: Brazil, China, India, Indonesia, the Russian Federation, and South Africa. In addition, a weighted aggregate for the rest of the world is shown on two charts. 


\subsection{World population distribution, 2007}

- The large emerging economies-Brazil, China, India, Indonesia, the Russian Federation, and South Africa-made up 46 percent of the world's population.

- China and India together made up well over one-third of the world's population.

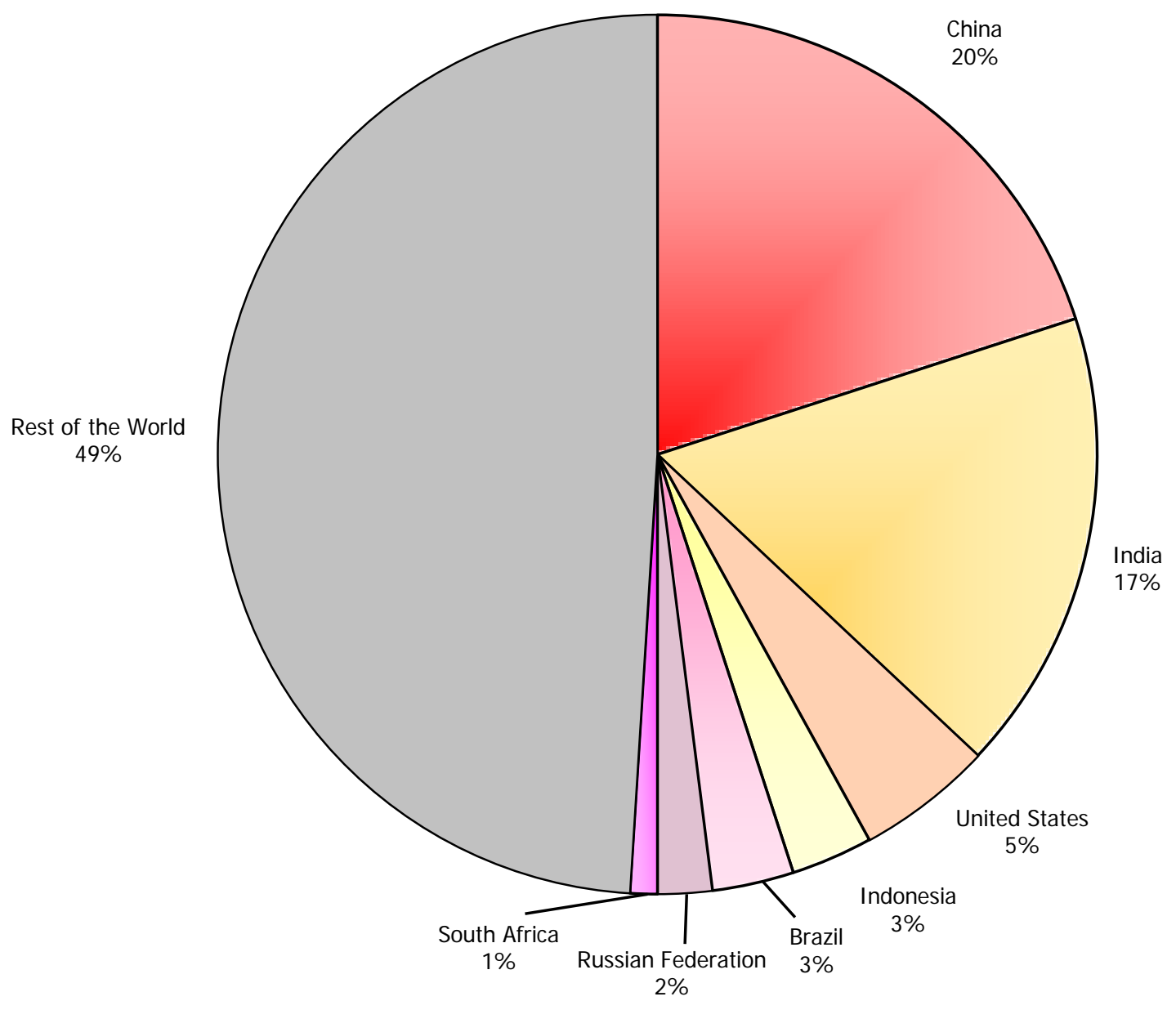

SOURCE: World Bank. 


\subsection{Age composition of the population, 2006}

- The Russian Federation had the lowest proportion of persons ages 14 and under and the highest proportion ages 65 and over.

- India had the largest proportion of persons ages 14 and under, accounting for almost onethird of the country's total population.

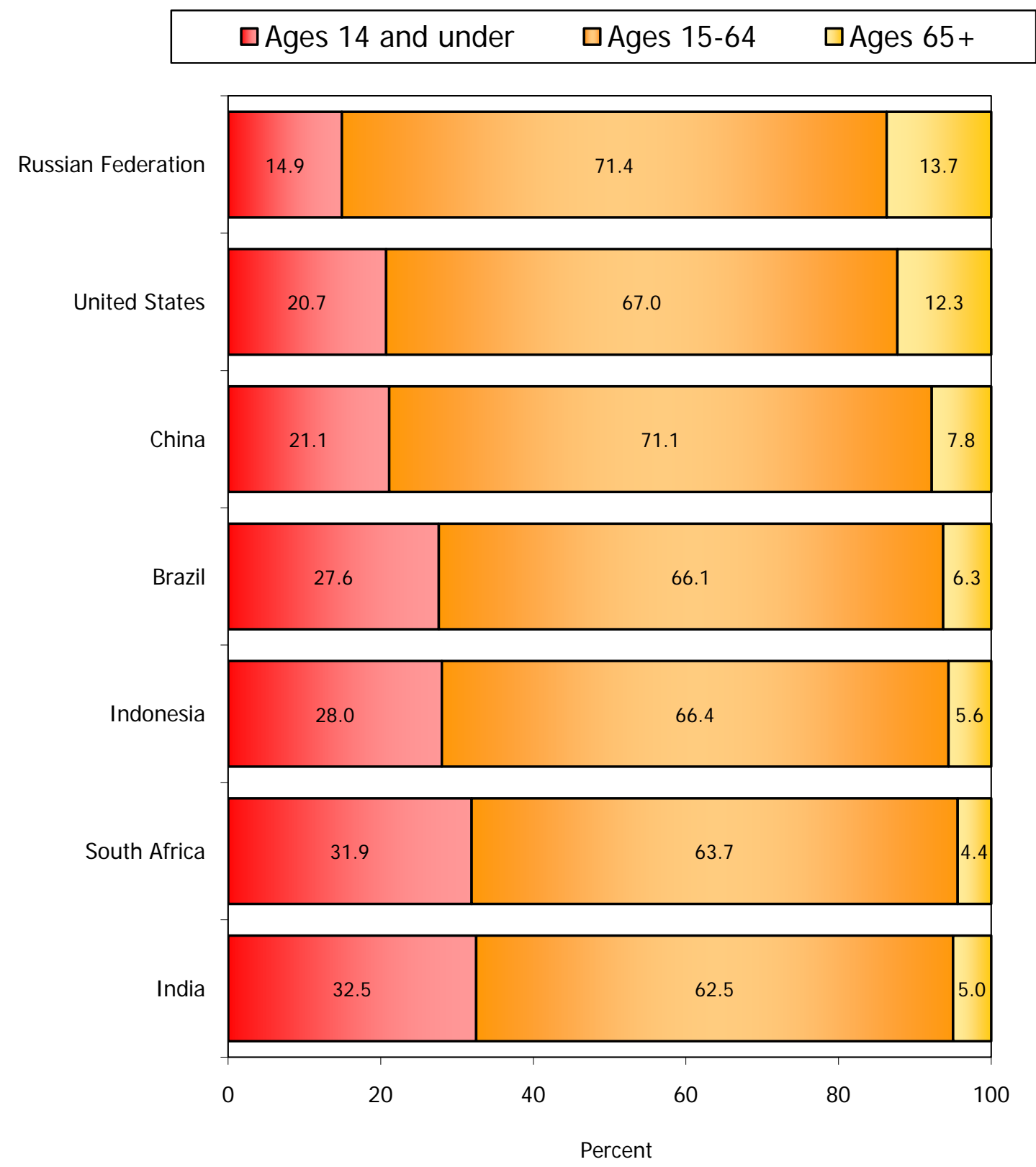




\subsection{Dependency ratios, 2006 and projections to 2025}

- India had the highest dependency ratio in 2006; however, between 2006 and 2025, India's ratio is expected to experience the largest decline.

- It is expected that by 2025 , the dependency ratio will be highest in the United States and lowest in Indonesia, although these two countries had similar dependency ratios in 2006.

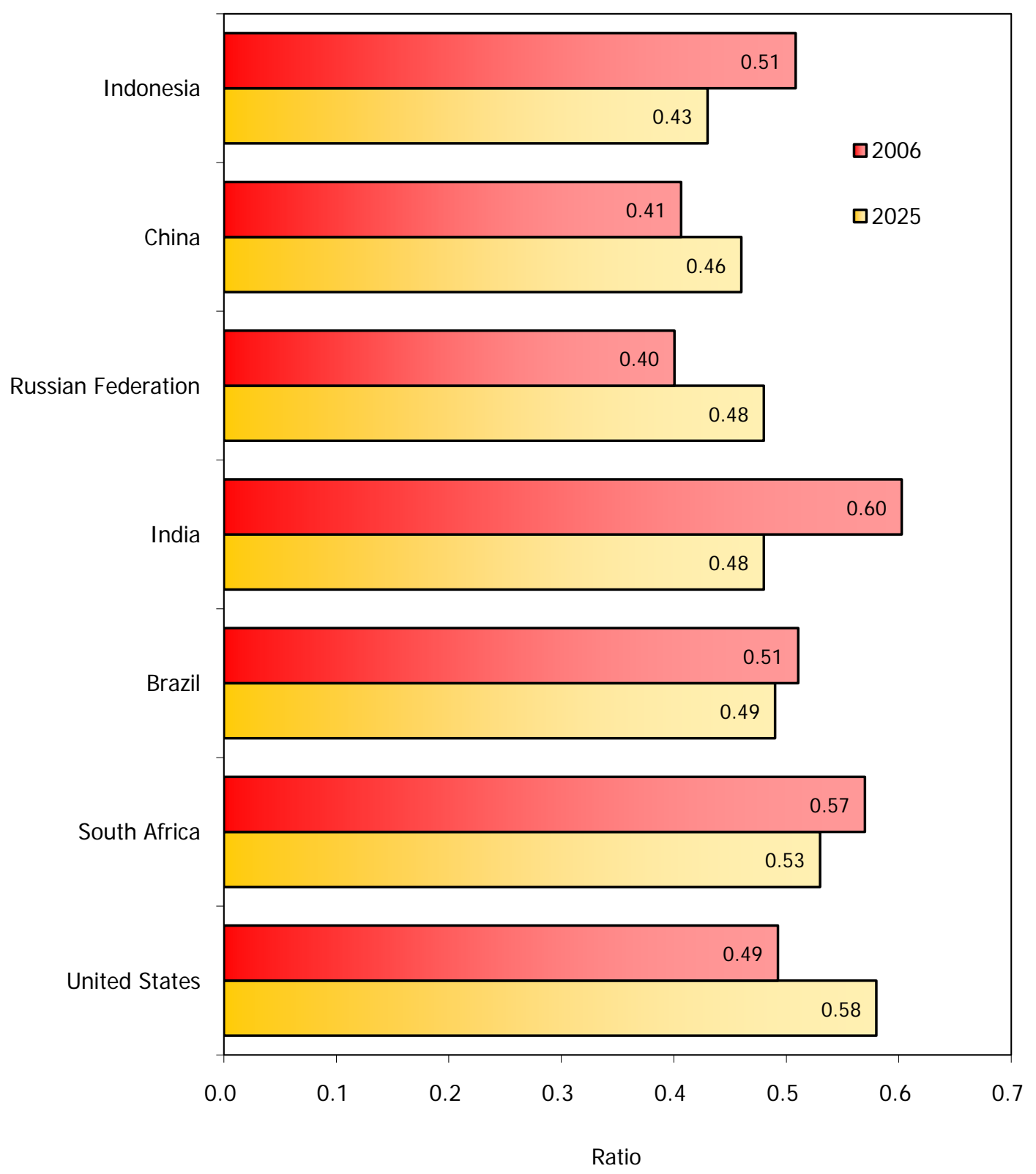

NOTE: The dependency ratio is the ratio of dependents (persons ages 14 and under and persons ages 65 and over) to the working-age population (persons ages 15 to 64).

SOURCES: World Bank and United Nations. 


\subsection{GDP per capita, 2007 converted at PPP rates}

- $\quad$ Among the large emerging economies, the Russian Federation, South Africa, and Brazil had the highest GDP per capita, about one-third to one-fifth of the U.S. level; India and Indonesia had the lowest, at less than one-tenth of the U.S. level.

- China was in the middle of the group, with a GDP per capita at nearly 12 percent of the U.S. level.

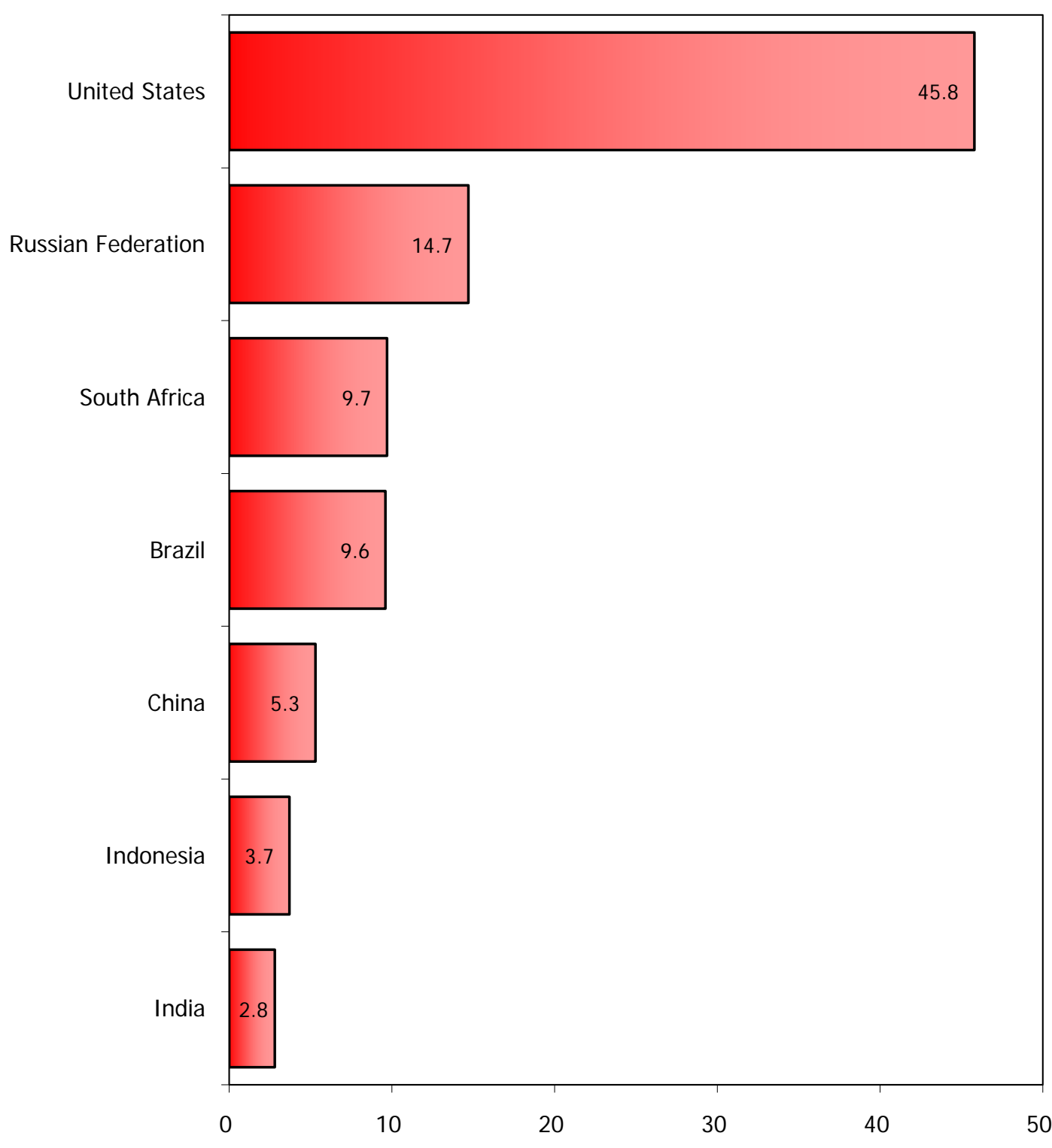

Thousands of U.S. dollars

NOTE: Purchasing Power Parity (PPP) is the number of foreign currency units required to buy goods and services in a foreign country equivalent to what can be bought with one dollar in the United States.

SOURCES: Bureau of Labor Statistics and World Bank. 


\subsection{GDP per employed person, 1995 and 2005}

in 1990 U.S. dollars converted at PPP rates

- $\quad$ Among the large emerging economies, GDP per employed person was highest in the Russian Federation and Brazil.

- $\quad$ China had the largest percentage increase in GDP per employed person from 1995 to 2005 , with an average annual growth rate of 6.9 percent.

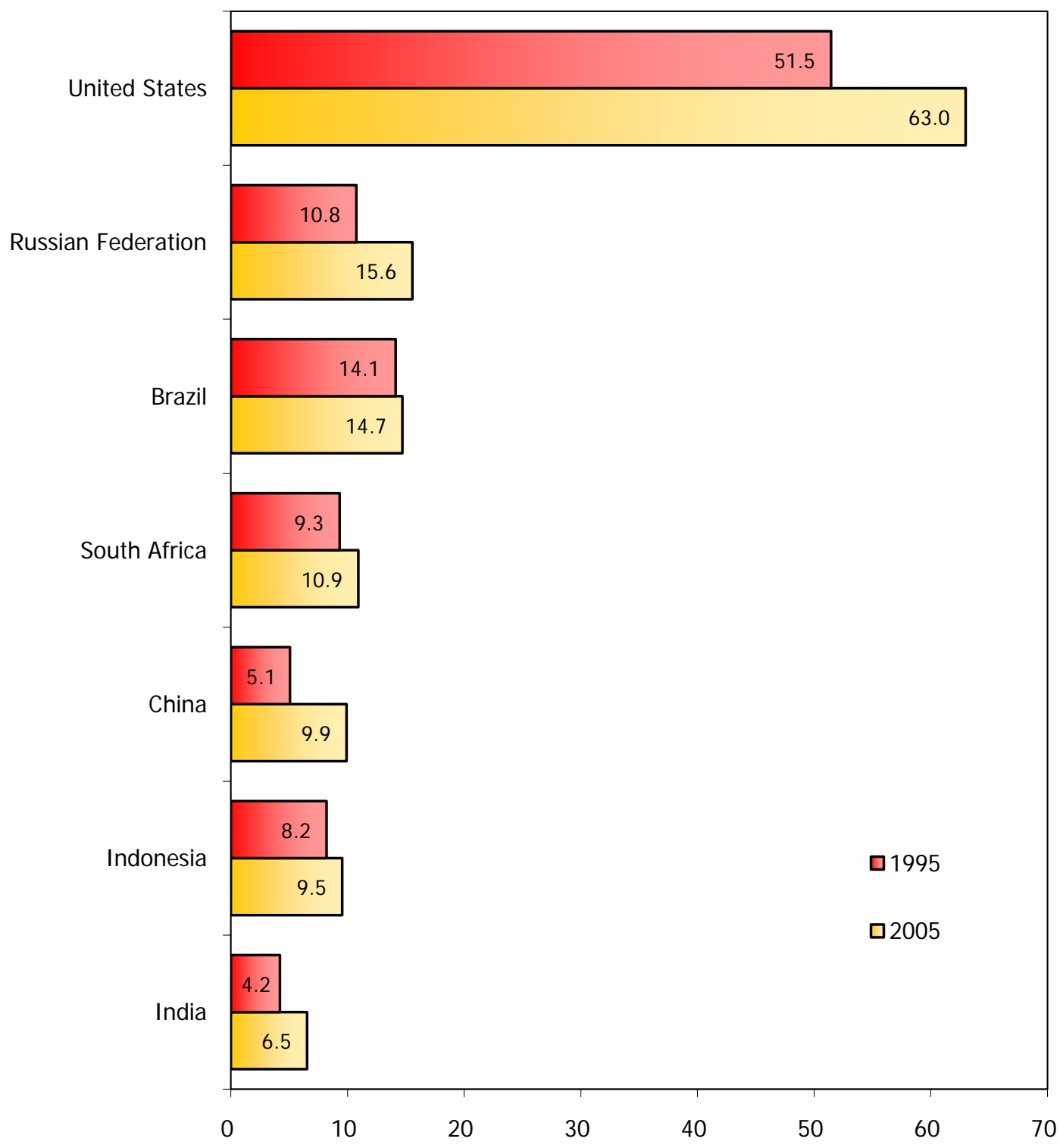

Thousands of 1990 U.S. dollars

NOTE: Purchasing Power Parity (PPP) is the number of foreign currency units required to buy goods and services in a foreign country equivalent to what can be bought with one dollar in the United States.

SOURCE: International Labor Office. 


\subsection{Labor force participation rates by age, 2007}

- Youths and persons ages 55 to 64 participated in the labor force to a much lesser extent in South Africa than in the other countries.

- $\quad$ China had the highest rate of labor force participation for prime-age persons (ages 25 to 54), at about 93 percent. Persons ages 65 and over had a particularly high rate of labor force participation in Indonesia.

Ages 15-24

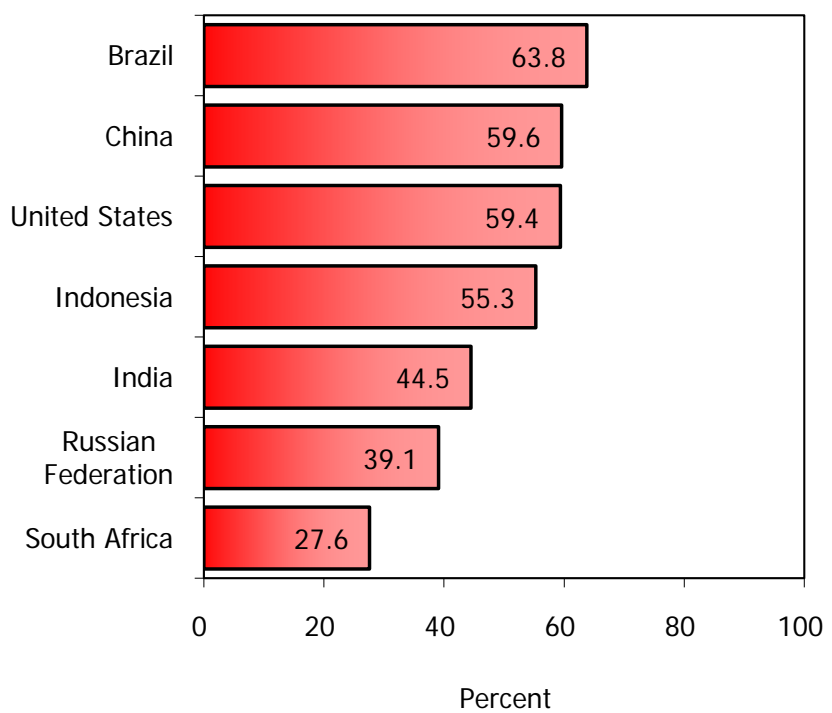

Ages 55-64

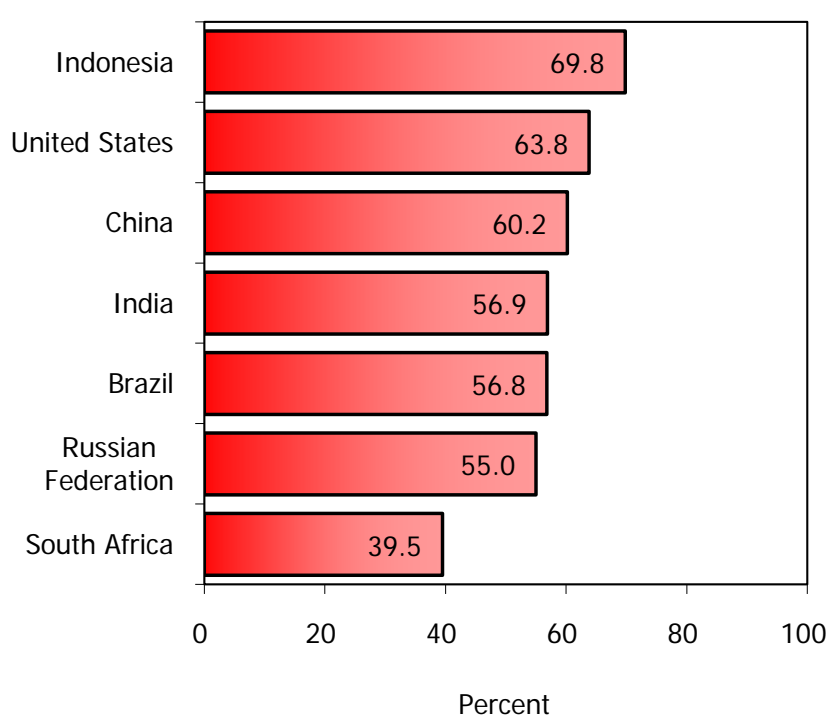

Ages 25-54

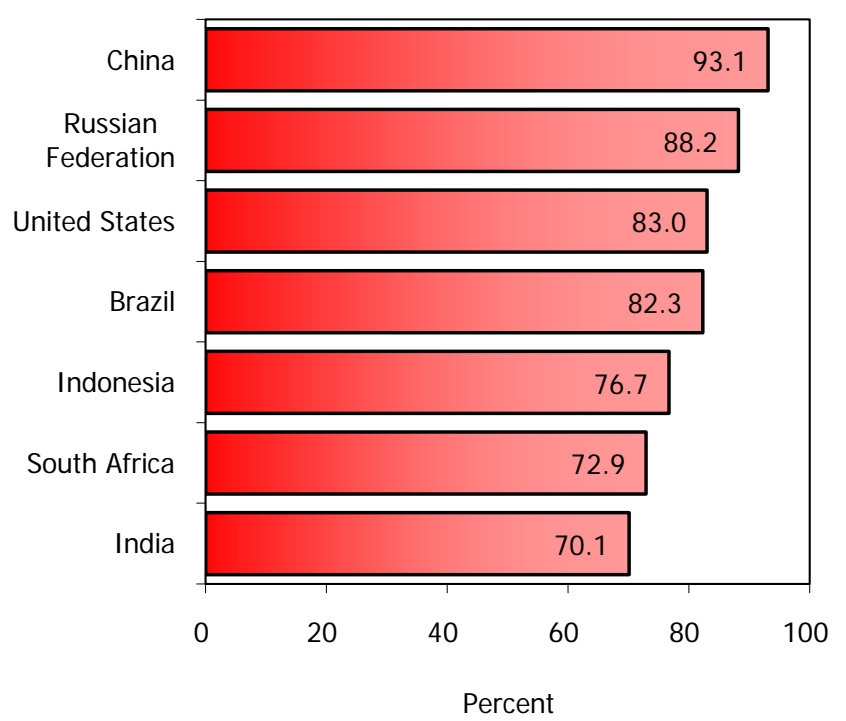

Ages 65+

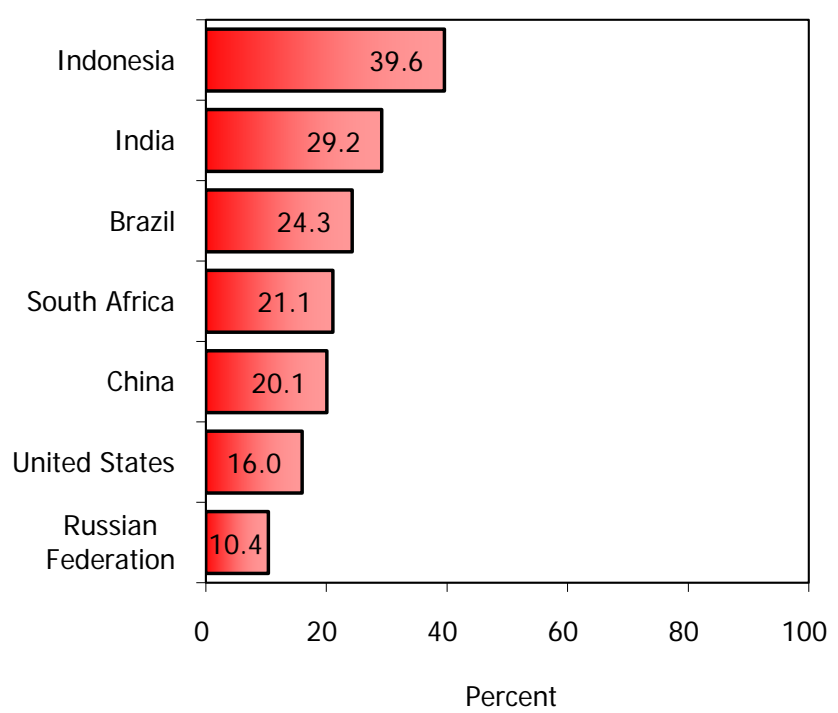

NOTE: Persons ages 16 to 24 instead of ages 15 to 24 for the United States.

SOURCES: Bureau of Labor Statistics and International Labor Office. 


\subsection{Employment as a percent of the working-age population by sex, 2006}

- China had the highest percentages of employed working-age men and working-age women.

- Less than one-third of the female working-age population was employed in South Africa and India.

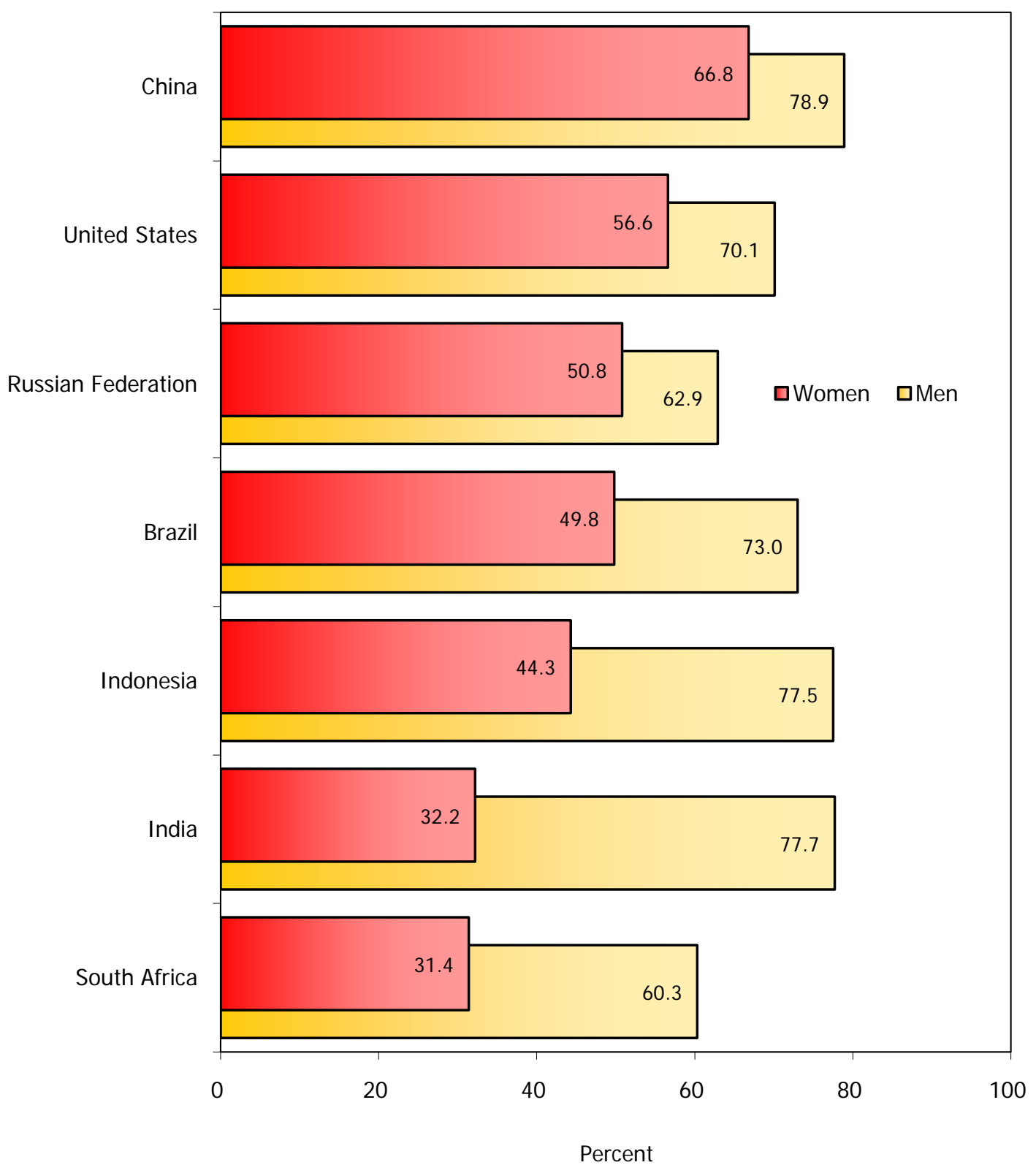

NOTE: The working-age population is defined as persons ages 15 and over for all countries except the United States, where it is defined as persons ages 16 and over.

SOURCES: Bureau of Labor Statistics and International Labor Office. 


\subsection{Trade in goods as a percent of GDP, 2007}

- This indicator shows the relative importance of trade in goods to an economy.

- China had the highest proportion of trade in goods to GDP, followed by South Africa and Indonesia; Brazil and the United States had the lowest proportions.

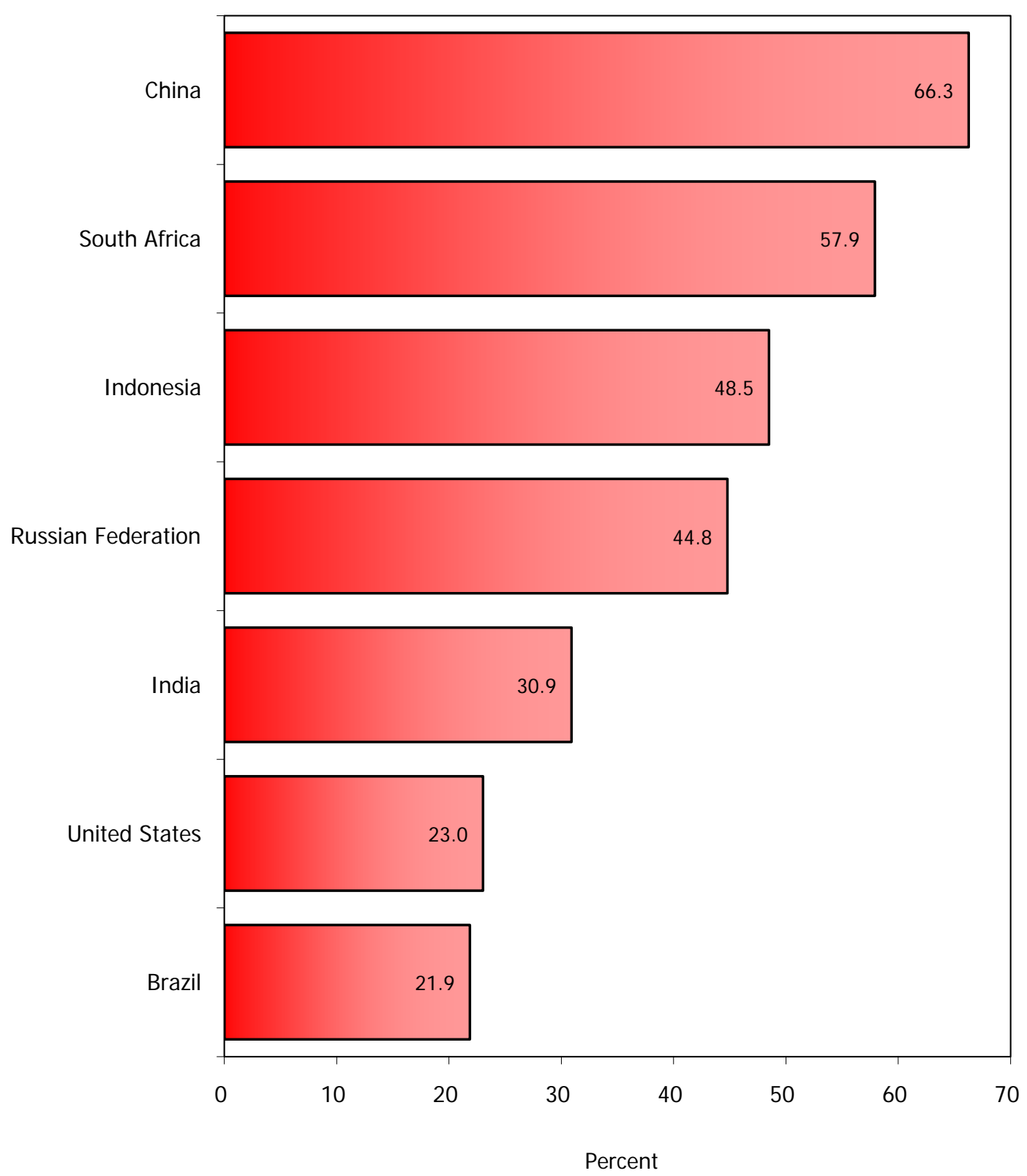

NOTE: Trade in goods is defined as the sum of merchandise exports and imports.

SOURCE: World Bank. 


\subsection{Manufacturing output as a percent of world manufacturing output, 2007}

- The U.S. share of world manufacturing output was nearly equal to the combined share of the large emerging economies.

- Among the large emerging economies, China had the largest share of world manufacturing output.

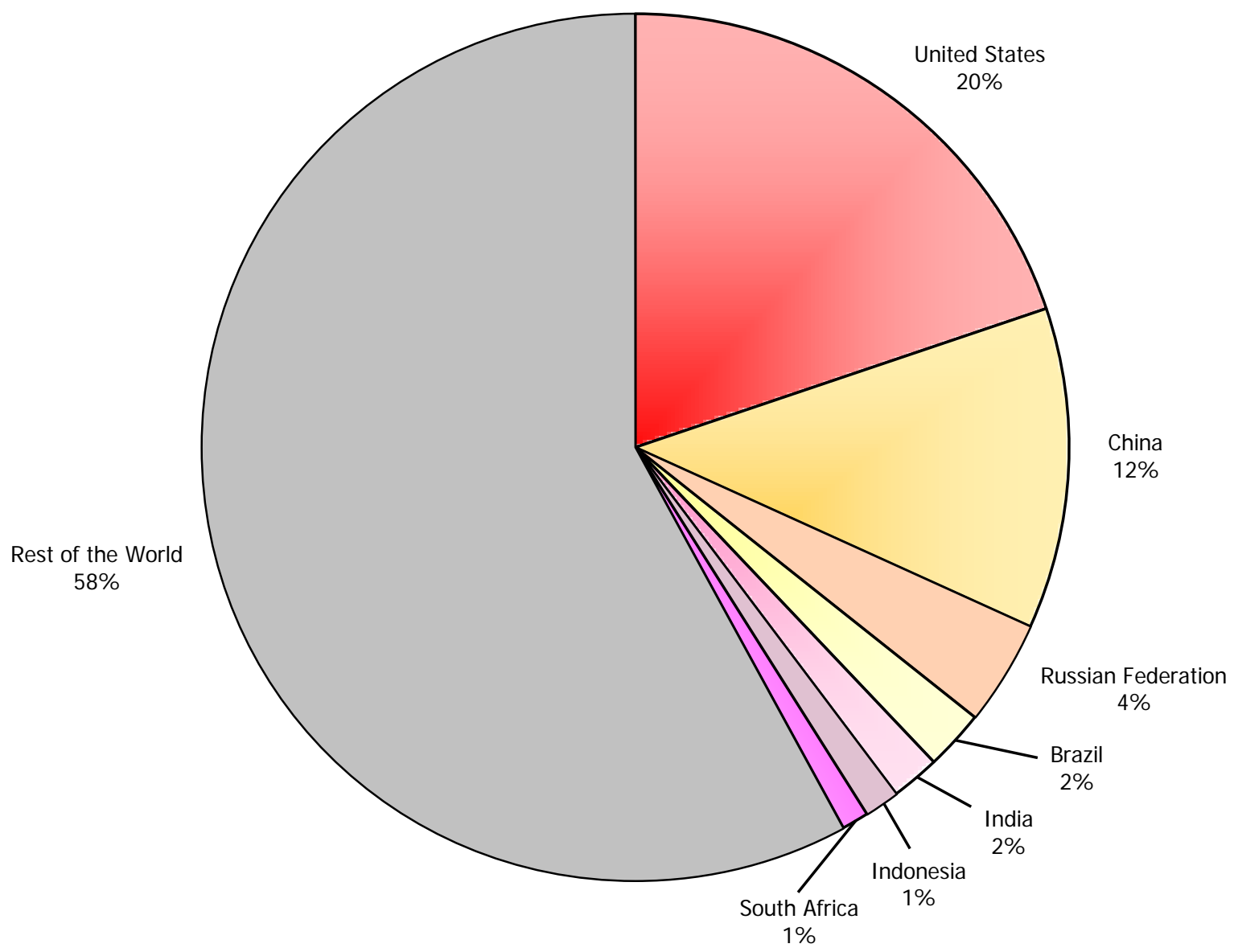

NOTE: Including mining, quarrying, and public utilities for the Russian Federation.

SOURCE: United Nations. 
Employment Outlook Indicators
This section presents a visual abstract of the 2008 Employment Outlook published by the Organization for Economic Cooperation and Development (OECD). The Employment Outlook is an annual publication that explores recent labor market developments of interest to the 30 OECD member countries.

Through their participation in the OECD Working Party on Employment, the U.S. Department of Labor and labor ministries from the other member countries advise OECD staff during the preparation of the Employment Outlook.

Each chart in this section illustrates a different chapter of the Employment Outlook and provides a brief summary of that chapter in the second bullet. Chart 6.1 highlights the incidence of part-time employment for youths. Chart 6.2 shows the gender employment gap. Chart 6.3 compares the rate of psychological distress of low-skilled workers to that of all employed persons. Lastly, chart 6.4 presents foreign direct investment (FDI) trends. The Employment Outlook also includes a chapter on informal employment; however, this chapter is not charted because of difficulties associated with measuring informal employment.

The number of countries covered in this section varies from 8 to 19 . In addition, weighted aggregates for the 30 OECD member countries and the rest of the world are shown on one chart. Countries and years charted in this section conform to coverage in Sections 1-4 of this chartbook; for some indicators, additional coverage is available in the Employment Outlook chapters. Readers interested in exploring the Employment Outlook further may visit http://www.oecd.org/els/employment/outlook. 


\subsection{Part-time employment for youths as a percent of total employment for youths, 1996 and 2006}

- The incidence of part-time employment among young workers increased in most countries.

- The OECD chapter examines recent labor market performance of young workers, the sensitivity of youth employment to business cycles, the prevalence of part-time and temporary work arrangements among young workers, the relationship between youth employment and schooling decisions, and employment challenges facing some school leavers.

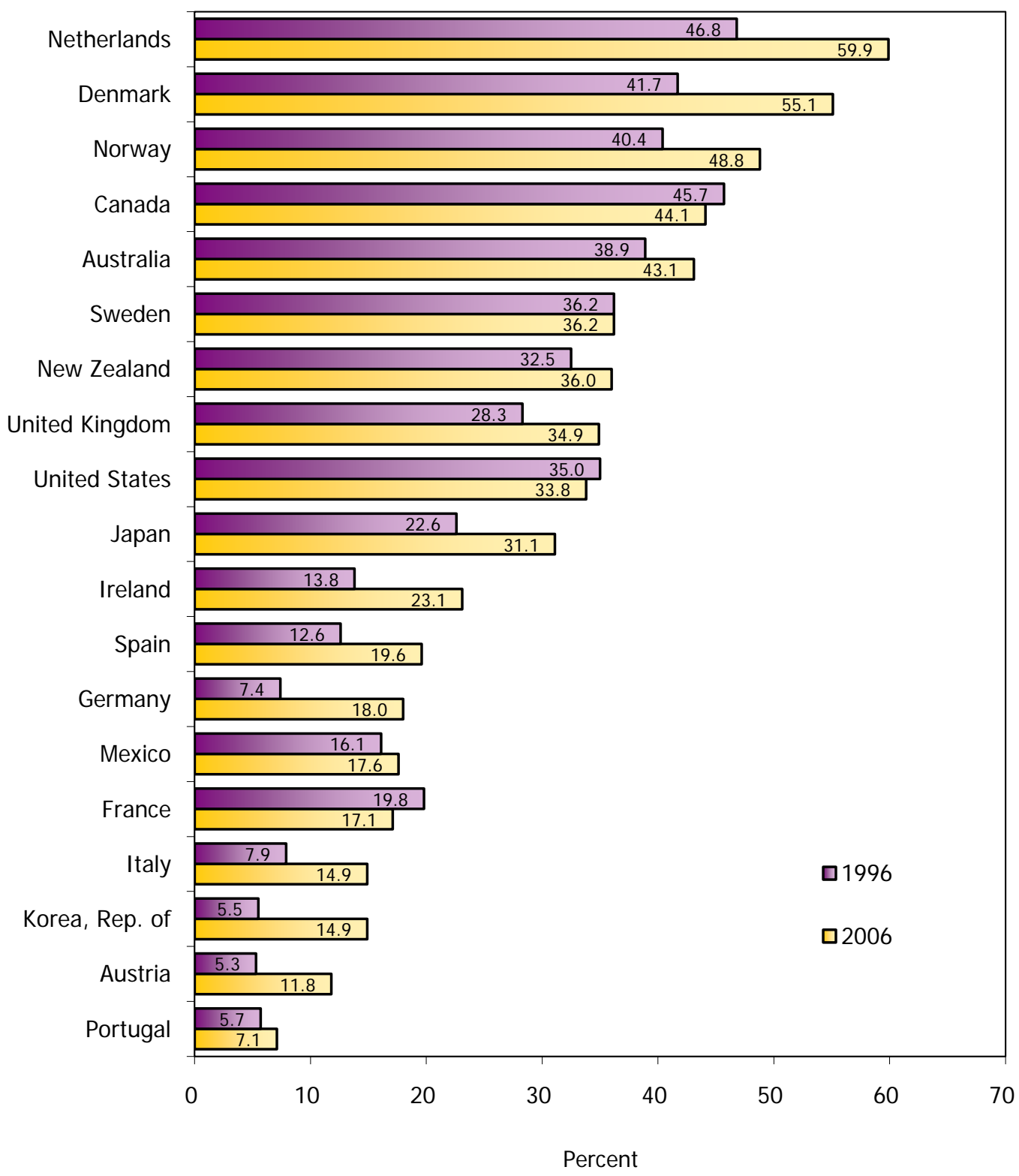

NOTE: Youths are defined as persons ages 15 to 24 .

SOURCE: Organization for Economic Cooperation and Development. 


\subsection{Employment as a percent of the prime-age population by sex, 2007}

- In all countries, prime-age women had lower employment rates than men.

- The OECD chapter discusses how the gender employment gap may be traced to educational attainment, the timing of marriage and children, the gender wage gap, and discriminatory labor practices.

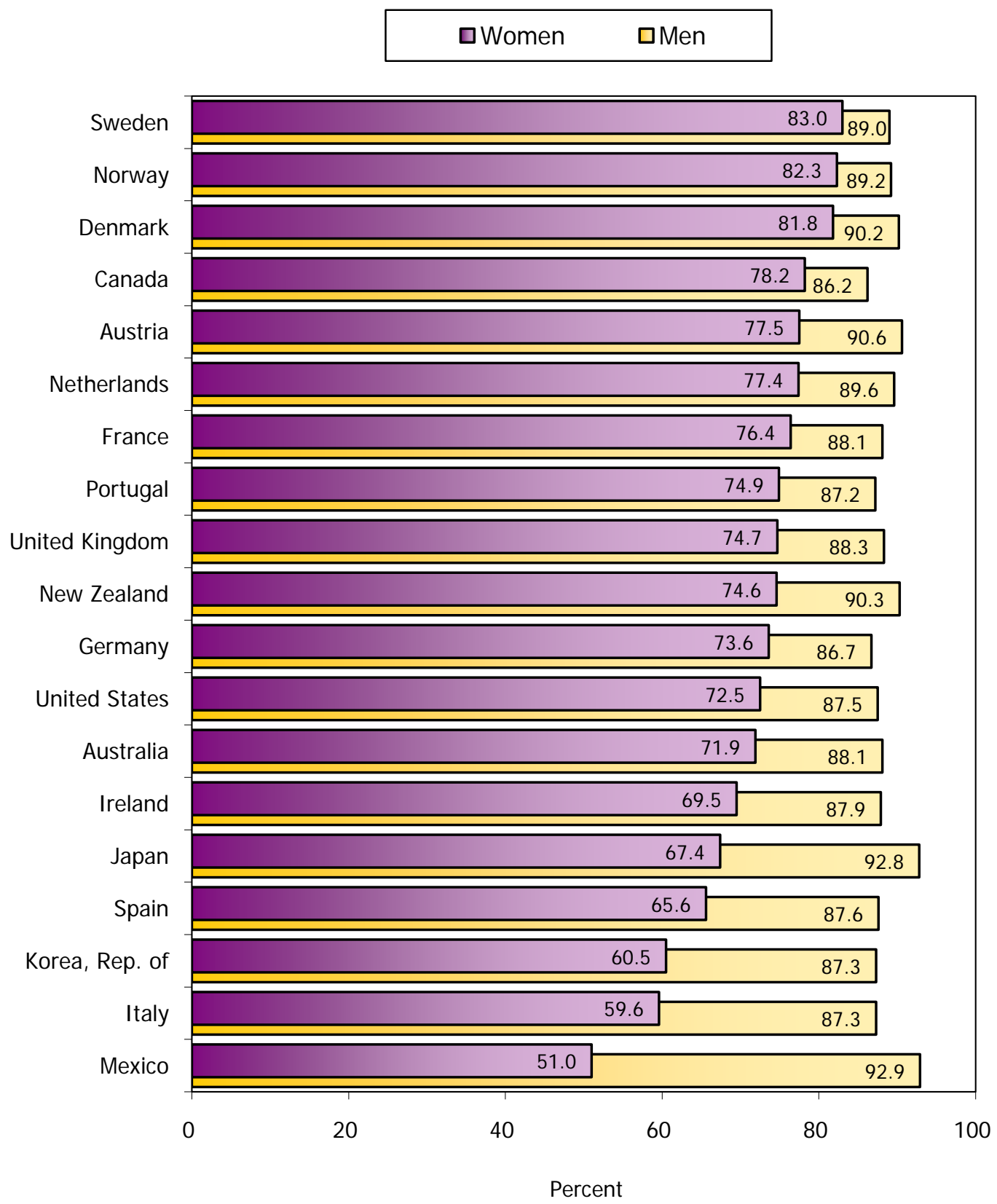

NOTE: The prime-age population is defined as persons ages 25 to 54 .

SOURCE: Organization for Economic Cooperation and Development. 


\subsection{Ratios of psychological distress rates of workers in low- skilled occupations to those of all employed persons}

- In all countries, except Italy, workers in occupations that require low skill and consist of simple and routine tasks experienced higher rates of psychological distress than did the total employed population. In the United States, the psychological distress rate of workers in low-skilled occupations was 80 percent higher than that of the total employed population.

- The OECD chapter explores patterns of work-related mental health problems and their relationship with new work patterns.

United States (2003)

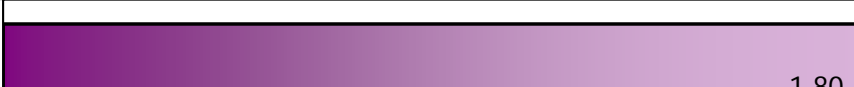

Korea, Rep. of (2005)

New Zealand (2003)

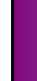

1.44

United Kingdom (2004)

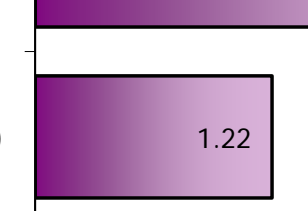

Australia (2004-05)

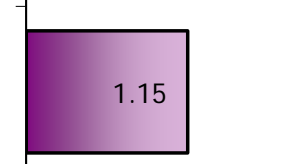

Sweden (2001)

1.10

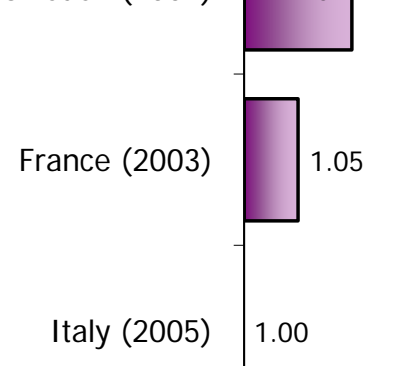

Italy (2005)

1.0

1.2

1.4

Ratio

SOURCE: Organization for Economic Cooperation and Development. 


\subsection{Shares of global foreign direct investment expenditures and receipts, 1995, 2000, and 2005}

- Global foreign direct investment (FDI) increased dramatically over the period. While the vast majority of FDI activities occurred among OECD countries, the non-OECD countries experienced increasing shares of both FDI expenditures and receipts.

- The OECD chapter considers how wages and working conditions within countries are affected by FDI receipts.

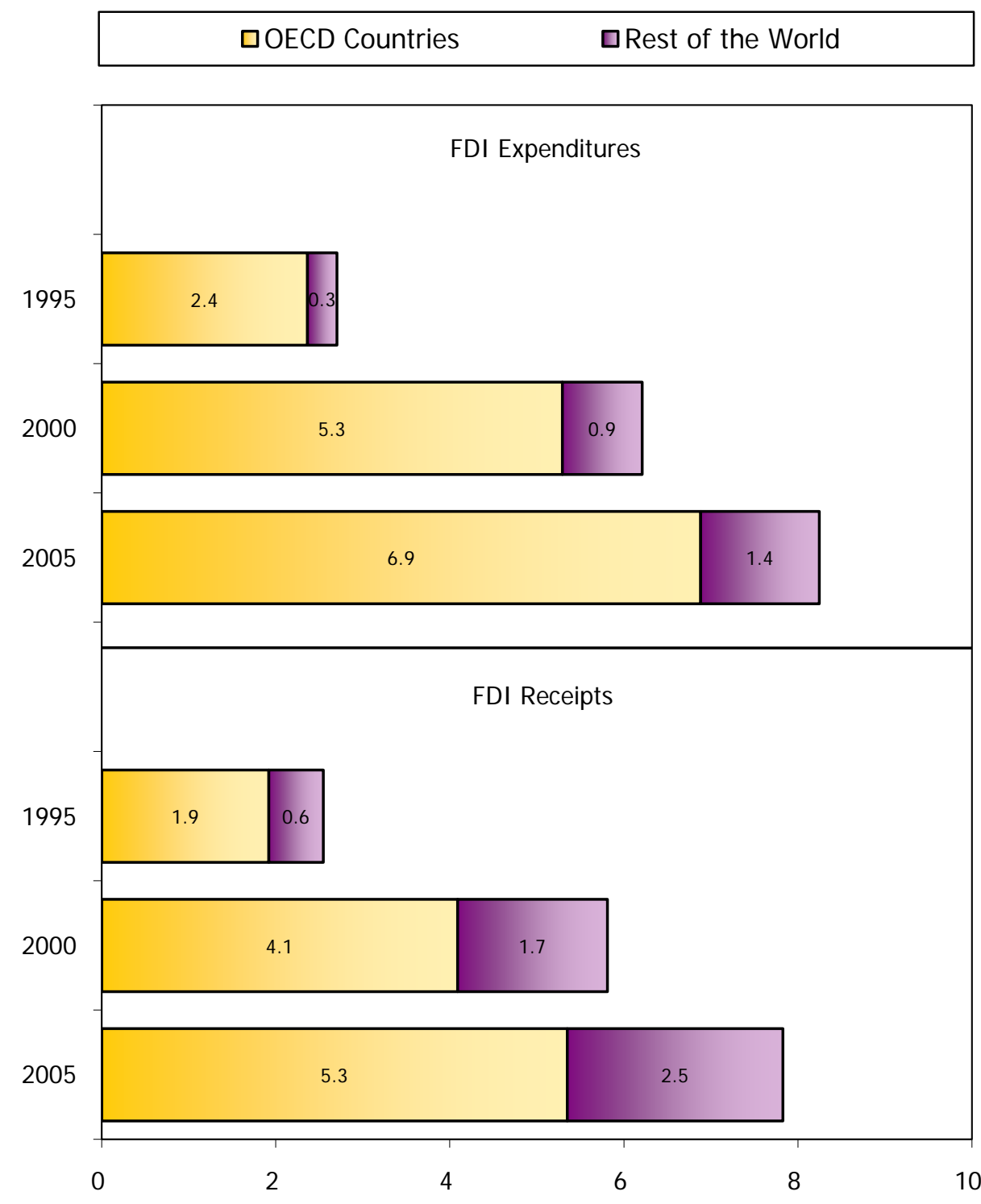

Trillions of U.S. dollars

NOTE: In principle, global FDI expenditures should equal receipts; however, due to gaps in coverage and the use of different reporting systems across countries, measured levels of expenditures and receipts often differ.

SOURCE: Organization for Economic Cooperation and Development. 



\section{APPENDI X}

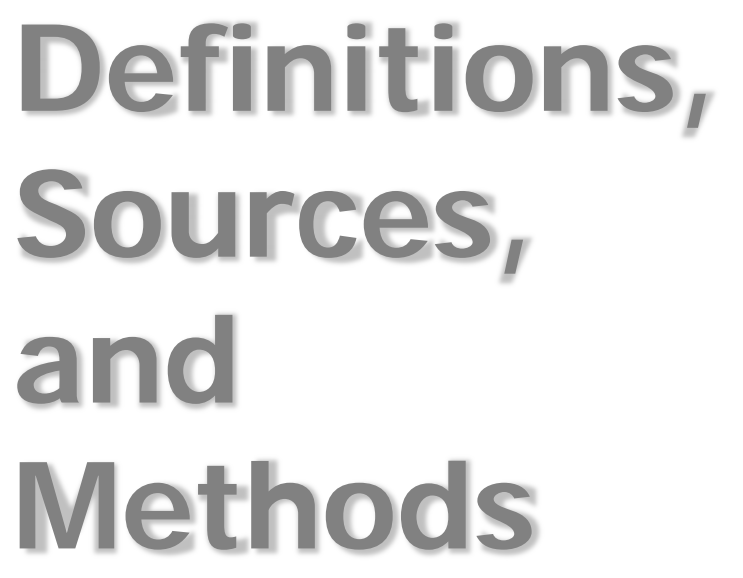

This chartbook is based partially upon the output of the Bureau of Labor Statistics (BLS) program of international comparisons of labor force, compensation, and productivity. In order to increase country and indicator coverage, BLS data are supplemented by data from the Organization for Economic Cooperation and Development (OECD) and other organizations.

BLS adjusts foreign statistics to a common conceptual framework, thereby aiding users in making meaningful international comparisons. Comparability issues arise due to, for example, differences in definitions, time periods, and population coverage. Summary descriptions of the BLS comparative series are provided below. More detailed information can be found in the source documents listed, which are available on the BLS international labor comparisons Web site at http://www.bls.gov/ilc/.

To increase country coverage for some of the GDP per capita and labor market indicators charts (sections 1 and 2), BLS data are supplemented by data mainly from OECD, but also from the International Labor Organization's International Labor Office (ILO), World Bank, and national sources. The data from these alternative sources are judged reasonably comparable with the BLS series unless otherwise noted. The charts on hourly compensation and productivity in manufacturing (charts 3.1-3.6) have not been supplemented by other sources; data are from the BLS series. To provide other indicators of interest, 26 of the charts (charts 2.4, 2.5, 2.8, 2.9, 2.13-2.15, 3.7, and all charts in sections 4,5 , and 6) are based on statistics compiled by other organizations, mainly OECD, but also the United Nations, World Bank, and ILO. Discussion of the data from the non-BLS sources is included below. Although some adjustments may have been made by the source organizations to enhance comparability, these data generally are not considered fully comparable across countries. Where applicable, some caveats concerning comparability are noted.

Country coverage varies by indicator. Coverage in sections 1, 2, and 4 varies from 18 to 21 countries. In addition, weighted aggregates for 15 European Union countries (EU-15) are shown on most charts. These 
represent European Union member countries prior to the expansion of the European Union to 25 countries on May 1, 2004, and to 27 countries on January 1, 2007. The 15 countries are Austria, Belgium, Denmark, Finland, France, Germany, Greece, Ireland, Italy, Luxembourg, the Netherlands, Portugal, Spain, Sweden, and the United Kingdom. It should be noted that some countries for which data are available are not included on the charts for analytical or presentation purposes. Fourteen countries appear on all charts in the first four sections: Australia, Canada, Denmark, France, Germany, Italy, Japan, the Republic of Korea, the Netherlands, Norway, Spain, Sweden, the United Kingdom, and the United States. In addition, data for Austria, Ireland, Mexico, New Zealand, and Portugal appear on almost all charts in sections 1-4; data for Hong Kong SAR, Singapore, and Taiwan appear only on some charts. For section 3, coverage ranges from 16 economies on the productivity charts to 22 economies on the hourly compensation charts. Section 5 covers the United States, which is used as a reference point, and six large emerging economies: Brazil, China, India, Indonesia, the Russian Federation, and South Africa. Coverage in section 6 varies from 8 to 19 countries.

The latest data available are shown for each chart. All data are either annual averages or mid-year estimates. Average annual growth rates are calculated using the compound rate method. For trends, there are some breaks in the historical continuity of the labor force and employment series; however, the breaks generally do not substantially affect the trends depicted. The nature of the breaks is documented in the source publications.

In the descriptions that follow, some charts are discussed as a group, while others warrant individual treatment.

\section{GROSS DOMESTIC PRODUCT (charts 1.1, 1.2, 5.4, and 5.5)}

A country's Gross Domestic Product (GDP) represents the sum of value added by all producers in that country. Value added is the value of the gross output of producers less the value of intermediate goods and services used in production. It is generally used to measure the size of an economy. However, it should not be interpreted as necessarily measuring the wealth and well-being of the residents of that country. A better measure of the latter is Gross National Income.

Gross National Income (GNI), which was previously called Gross National Product (GNP), measures the total domestic and foreign value added claimed by residents. It includes GDP plus net receipts of primary income from non-resident sources, where "primary income" is defined as compensation of employees and property income. For many countries, the inflows and outflows of primary income tend to balance out, leaving little difference between GDP and GNI. However, for some countries, the difference can be substantial. For example, GDP was 21 percent higher than GNI in Ireland in 2007. Purchasing Power Parities (PPPs) are currency conversion rates that allow output in different currency units to be expressed in a common unit of value. A PPP is the ratio between the number of units of a country's currency and the number of U.S. dollars required to purchase an equivalent basket of goods and services within each respective country.

\section{GDP per capita (charts 1.1, 1.2, and 5.4)}

GDP per capita converted at PPP rates (charts 1.1 and 5.4). The comparisons shown in charts 1.1 and 5.4 are based on measures of GDP converted at PPP rates and on population size. Measures for chart 1.1 are taken from the data underlying a periodic report published by BLS for Australia, Austria, Belgium, Canada, Denmark, France, Germany, Italy, Japan, the Republic of Korea, the Netherlands, Norway, Spain, Sweden, the United Kingdom, and the United States. For the remaining countries, the measures are based on data published by the World Bank. For chart 5.4, BLS data are used for the United States while the comparisons shown for the emerging economies are based on World Bank data.

Sources: BLS, "Comparative Real Gross Domestic Product Per Capita and Per Employed Person, 16 Countries, 1960-2007," July 7, 2008, http://www.bls.gov/ilc/; and World Bank, World Development Indicators Database, http://www.worldbank.org/.

Average annual growth rates for real GDP per capita (chart 1.2). Real GDP is GDP that has been adjusted for overall price changes over time in order to remove the effects of inflation. Change in real GDP per capita over time is the result of changes in both a country's real GDP and in its population. 
For chart 1.2, the estimates of real GDP are based on data from BLS, OECD, and national sources. Measures are taken from the data underlying a periodic report published by BLS for Australia, Austria, Belgium, Canada, Denmark, France, Germany, Italy, Japan, the Republic of Korea, the Netherlands, Norway, Spain, Sweden, the United Kingdom, and the United States. Data for Hong Kong are from the Hong Kong Census and Statistics Department, and data for the remaining countries are from OECD.

Sources: BLS, "Comparative Real Gross Domestic Product Per Capita and Per Employed Person, 16 Countries, 1960-2007," July 7, 2008, http://www.bls.gov/ilc/; OECD, OECD.Stat: OECD's Statistical Data Warehouse, http://stats.oecd.org/; and Hong Kong Census and Statistics Department, http://www.info.gov.hk/censtatd/.

\section{GDP per employed person (chart 5.5)}

This indicator gives GDP measured in 1990 U.S. dollars converted at PPP rates divided by the number of employed persons. For an extensive discussion of the indicator, including details of its construction and some limits to comparability, see the source document cited below.

The use of employed persons in the denominator of the indicator does not standardize sufficiently the measure of labor input. The number of hours worked, on average, by each employed person can vary markedly across countries and over time.

This indicator may be viewed as giving the amount of GDP attributable on average to each employed person, working in tandem with all other inputs or factors of production.

Source: ILO, Key Indicators of the Labor Market software, $5^{\text {th }}$ Ed., Geneva, 2007, table 18a, http:/ / www.ilo.org/kilm.

\section{LABOR MARKET I NDI CATORS (charts 2.1-2.15 and 5.6-5.7)}

Charts in section 2 depict aspects of the labor force. Charts 2.1-2.3, 2.6, 2.7, and 2.10-2.12 contain BLS comparative data on labor force, employment, and unemployment and are supplemented by data from OECD. These comprise the first set of charts discussed in this section. Charts 2.4, 2.5, 2.8, 2.13, 2.14 also show data on labor force, employment, and unemployment, but data are from OECD, so these are discussed as a second set. Chart 2.9, annual hours worked per employed person, and chart 2.15, educational attainment of the adult population, are discussed individually. Finally, charts 5.6 and 5.7, which present labor market indicators for large emerging economies, are discussed as a set at the end of the section.

\section{Labor force, employment, and unemployment (charts 2.1-2.3, 2.6, 2.7, 2.10- 2.12)}

BLS comparative measures of the civilian labor force, employment, unemployment, and related indicators are used for Australia, Canada, France, Germany, Italy, Japan, the Netherlands, Sweden, the United Kingdom, and the United States. OECD data are used for Austria, Denmark, the EU-15, Ireland, the Republic of Korea, Mexico, New Zealand, Norway, Portugal, and Spain.

In the BLS comparisons program, adjustments are made to each country's published data, if necessary and where possible, to provide measures approximately consistent with U.S. definitions. The data are adjusted to the U.S. concepts used in the Current Population Survey (CPS), the official source of U.S. labor force data. To adjust the data, BLS employs data from several sources, including data obtained by special request from the central statistical offices of the foreign countries. There is no upper age limit, and lower age limits vary slightly. Further information on the nature of the adjustments for each country can be found in the BLS source document cited at the end of this section.

The labor force is the sum of the employed plus the unemployed; the unemployment rate is the ratio of the unemployed to the labor force. In the United States, the unemployed are those not working but available for work in the reference week, and actively seeking work in the past 4 weeks. Those persons waiting to be recalled from layoff need not be seeking work to be classified as unemployed. The employed are those persons who during the reference week did work for at least 1 hour as paid employees, worked in their own business, profession, or on their own farm, or worked 15 hours or more as unpaid workers in an enterprise operated by a family member. Those temporarily absent from work but who had jobs or businesses to return to are also counted as employed. The labor force participation rate is the ratio of the labor force to the 
population of working age (ages 16 and over in the United States and ages 15 or 16 and over in the other countries); the employment-to-population ratio is the ratio of the employed to the population of working age.

The BLS data are supplemented in charts 2.1-2.3, 2.6, 2.7, and 2.10-2.12 with data from OECD. BLS adjusted some of the OECD data used for these charts to standardize lower age limits across countries. The OECD data are generally from labor force surveys that are based on the ILO guidelines for measurement of the labor force, employment, and unemployment. These guidelines are available on the Internet at

http://www.ilo.org/public/english/bureau/stat/dow nload/res/ecacpop.pdf.

The ILO guidelines have become standards for many countries; consequently, definitions used in labor force surveys are now broadly similar in outline and purpose if not in all of their details. The ILO guidelines facilitate cross-country comparisons because they draw countries toward a common conceptual framework. The charted OECD data are reasonably comparable to the corresponding BLS data, although some adjustments for comparability that are made by BLS are not made by OECD.

OECD produces a series of "standardized unemployment rates" (SURs) that are adjusted to ILO concepts. In recent years, the OECD series yielded unemployment rates closely comparable to the BLS comparative series of unemployment rates for the countries common to both programs, except for Canada, France, and Germany.

The OECD unemployment series are used to broaden the coverage of the unemployment data on chart 2.10. The unemployment rates for the following countries are obtained from the OECD SURs: Austria, Denmark, Ireland, the Republic of Korea, New Zealand, Norway, Portugal, and Spain. The unemployment rate for Mexico is from Mexico's labor force survey as published by the OECD. The rate for Mexico is not comparable to the other rates shown.

The OECD data used to broaden the country coverage of charts 2.1-2.3, 2.6, 2.7, 2.11, and 2.12 are not adjusted by OECD for comparability to the extent that the SURs are adjusted; OECD does not publish standardized labor force and employment figures or standardized unemployment figures for subgroups.

For a full discussion of comparability issues regarding the BLS and OECD series, see Constance Sorrentino, "International unemployment rates: how comparable are they?," Monthly Labor Review, June 2000, pp. 3-20. This article is available on the Internet at http://www.bls.gov/opub/mlr/2000/06/art1full.pdf.

Sources: BLS, "International Comparisons of Annual Labor Force Statistics, 10 Countries, 1960-2007," October 21, 2007, http://www.bls.gov/ilc/; and OECD, OECD.Stat: OECD's Statistical Data Warehouse, http://stats.oecd.org/.

\section{Labor force, employment, and unemployment (charts $2.4,2.5,2.8,2.13$, and 2.14)}

The charts discussed below are derived from OECD. Data from OECD are used because the BLS labor force comparisons program does not provide indicators for participation rates by age (charts 2.4 and 2.5), full-time and part-time employment (chart 2.8), duration of unemployment (chart 2.13), or unemployment by educational attainment (chart 2.14).

Labor force participation rates by age (charts 2.4 and 2.5). The participation rate for a given age group is defined as the percentage of the labor force for the age group as a share of the population for the age group. Two age groups are charted for youths in chart 2.4: persons ages 15 or 16 to 19 and persons ages 20 to 24 . Two age groups are charted for older workers in chart 2.5: persons ages 55 to 64 and persons ages 65 and over. Data for charts 2.4 and 2.5 are from OECD and are generally derived from labor force surveys. OECD has made no attempt to standardize these data to international definitions. According to OECD, international comparisons of these data must be made with caution. In countries where young people are conscripted into the armed forces, their measured participation rates will differ considerably according to whether the figures include or exclude the armed forces. Differences in the lower age limit also affect the comparability of the data.

Source: OECD, OECD.Stat: OECD's Statistical Data Warehouse, http://stats.oecd.org/. 
Average annual growth rates for full-time and part-time employment (chart 2.8). OECD has adjusted full-time and part-time employment to a common conceptual basis, insofar as possible. Full-time employment is defined as persons usually working over 30 hours per week in their main job. Part-time employment is defined as persons usually working 30 or fewer hours per week in their main job. Data are obtained from labor force surveys and are generally limited to persons declaring usual hours worked. Coverage includes persons ages 15 or 16 and over, except for Norway and Sweden, where the data refer to persons ages 16 to 74 and 16 to 64 , respectively.

Except for the United States, the data relate to total employment. For the United States, the data cover wage and salary employment only. This difference should not materially affect the comparisons because paid workers account for more than 90 percent of total U.S. employment.

Data for Japan are not comparable to those of the other countries for two reasons: (1) The Japanese data are based on "actual hours worked" rather than "usual hours worked," and (2) part-time employment in Japan is defined as working fewer than 35 hours per week. Thus, the Japanese data should not be used for comparisons of the level of full-time and part-time work. They are included in chart 2.8 to track the broad trends in full-time and part-time work. For Australia and the Republic of Korea, data also are based on "actual hours worked" rather than "usual hours worked."

Source: OECD, OECD.Stat: OECD's Statistical Data Warehouse, http://stats.oecd.org/.

Persons unemployed one year or longer as a percent of total unemployment (chart 2.13). The OECD data on duration of unemployment represent the length of time that persons unemployed have been looking for work. The OECD data have not been standardized, but they are all from labor force surveys. The data refer to persons ages 15 or 16 and over, except for Norway and Sweden, where the data refer to persons ages 16 to 74 and 16 to 64 , respectively.

Source: OECD, OECD.Stat: OECD's Statistical Data Warehouse, http://stats.oecd.org/.
Ratios of unemployment rates of persons without high school degrees to those of persons with college or university degrees (chart 2.14). Because educational systems vary widely across countries, OECD adopted a broad classification system based upon the International Standard Classification for Education (ISCED) developed by the United Nations Educational, Scientific, and Cultural Organization (UNESCO). OECD summarizes the UNESCO categories into seven educational attainment groupings-ISCED 0 to ISCED 6 -that refer to completed education. The OECD grouping "below upper secondary," which includes ISCED 0 through 2, corresponds to "without high school degrees." The grouping "tertiary-type A and advanced research programs," a subset of ISCED 5, corresponds to "with college or university degrees." The data on unemployment have not been standardized, but they are all from labor force surveys. The data refer to persons ages 25 to 64 .

Sources: OECD, Education at a Glance: OECD Indicators, 2008 Ed., Paris, November 2008, table A8.2a; and OECD, Employment Outlook, 2008 Ed., Paris, August 2008, table D.

\section{Annual hours worked per employed person (chart 2.9)}

The concept used is the total number of hours actually worked over the year divided by the average number of persons in employment. Data are generally intended for comparisons of trends over time. Annual hours worked per employed person are affected by legislation and agreements on normal and overtime hours. They also are influenced by factors such as the proportion of part-time workers and self-employed, who work fewer and longer hours, respectively. In addition, data sources and methods of estimation vary by country.

The ILO standard definition for hours actually worked includes hours actually worked during normal periods of work; time worked in addition to the normal periods and generally paid at higher rates; time spent at place of work in preparation, repair, and record keeping; time spent at place of work on stand-by basis or under a guaranteed work contract; and time corresponding to short rest periods, including tea or coffee breaks. Hours actually worked should exclude hours paid for but not worked, such as: annual leave, public holidays, paid sick leave, meal breaks, and time spent on travel between home and work. Comparative data on annual 
hours worked based precisely on this ILO definition are not available.

The comparisons shown in chart 2.9 are the published OECD data series on average annual hours actually worked per person in employment, which include some adjustments towards the above definition for each country. The data generally cover all persons in employment, including both full-time and part-time workers. Data sources include labor force surveys, establishment surveys, and administrative data. Annual estimates are based on actual or usual weekly hours worked from labor force and establishment surveys, or from normal hours worked from survey or administrative data. Hours data reported from establishment surveys or administrative sources exclude unpaid overtime. Hours data reported from labor force surveys are subject to respondent error. Methods of estimation include direct estimates using one survey source, component estimates using more than one survey source, or a combination of surveybased data and administrative or legislative information.

Data are consistent with national accounts concepts for 10 countries: Australia, Austria, Canada, Denmark, France, Germany, Italy, the Republic of Korea, Norway, and Sweden. Only two countries charted, New Zealand and the United Kingdom, directly measure hours actually worked with a continuous labor force survey, which accounts for every week of the year and avoids the need to adjust for holidays and other days lost. Hours data for Australia, Canada, Germany, Italy, Ireland, Mexico, the Netherlands, Portugal, and Spain are adjusted to varying degrees to account for effective weeks worked during the year, hours not worked due to annual leave and public holidays, and underreporting of hours lost due to illness and maternity leave. Data are on a per employed person basis except for Japan and Austria, where data are on a per job basis.

Data for the United States are OECD estimates. They are based on unpublished BLS statistics of annual hours worked per job estimated from the Current Employment Statistics Survey and the CPS. OECD adjusts these unpublished BLS statistics for multiple jobholding using data from the CPS to produce estimates of annual hours worked per employed person.
Source: OECD, OECD.Stat: OECD's Statistical Data Warehouse, http://stats.oecd.org/.

\section{Educational attainment of the adult population (chart 2.15)}

As discussed for chart 2.14, OECD uses UNESCO categories for seven educational attainment groupings. In chart 2.15, these are grouped into three broad categories. The grouping "less than high school" includes early childhood education (ISCED 0), primary level of education (ISCED 1), and lower secondary level of education (ISCED 2). The grouping "high school or trade school" includes upper secondary level of education (ISCED 3) and post-secondary non-tertiary level of education (ISCED 4). The grouping "college or university" includes the first stage of tertiary education (ISCED 5) and advanced research qualification (ISCED 6). The data refer to persons ages 25 to 64 .

Source: OECD, Education at a Glance: OECD Indicators, 2008 Ed., Paris, November 2008, table A1.1a.

\section{Labor market indicators for large emerging economies (charts 5.6 and 5.7)}

The charts discussed below are derived from BLS and ILO. Data for the United States are from BLS and data for the six large emerging economies are from ILO. Data from ILO are used because the BLS labor force comparisons program does not cover large emerging economies.

Chart 5.6 presents labor force participation rates by age. The participation rate for a given age group has been previously defined in this section. Chart 5.6 shows four age categories: youths (persons ages 15 or 16 to 24), prime working-age (persons ages 25 to 54), and two groups of older workers (persons ages 55 to 64 and persons ages 65 and over). The ILO series is harmonized using an econometric model to account for differences in national data and scope of coverage, collection and tabulation methodologies, and other country-specific factors such as military service requirements. For further information on the methodology used to harmonize estimates, see the source document. 
Chart 5.7 displays employment-to-population ratios by sex, which is defined as the ratio of the employed for a given sex to the working-age population for that sex. The working-age population in this chart is defined as persons ages 15 or 16 and over. The ILO employment series is derived from nationally reported data and the harmonized labor force data used to calculate labor force participation rates described previously. Nationally reported data are used only when they meet strict criteria in terms of international comparability and geographic coverage. Model estimates are used where national data are not available or satisfactory. Limitations to comparability are described more fully in the source document.

Sources: BLS, Labor Force Statistics from the Current Population Survey http://www.bls.gov/data/; and ILO, Key Indicators of the Labor Market software, 5th Ed., Geneva, 2007, tables 1 and 2, http://www.ilo.org/kilm.

\section{COMPETI TI VENESS I NDI CATORS FOR MANUFACTURING (charts 3.1-3.7 and 5.9)}

Section 3 focuses on several key labor-related indicators of competitiveness in world markets for goods: the level and trends in manufacturing hourly compensation costs, trends in productivity and unit labor costs, and manufacturing output as a percent of world manufacturing. The manufacturing sector provides the best data for such comparisons, and the BLS indicators presented in charts 3.1-3.6 have been adjusted to a common conceptual framework to facilitate comparisons. Nevertheless, it should be noted that these indicators allow only for a partial assessment of international competitiveness of economies. The aggregate (all manufacturing) nature of the indicators may mask important variations in competitiveness of manufacturing sub-sectors. In addition, competitiveness relationships in manufacturing may not be the same as the relationships in services, a growing sector for trade flows. Although competitiveness is heavily dependent on labor costs, there are many other factors that also influence competitiveness, including the quality of the product, the timeliness of its delivery, after-sales service, and the flexibility needed to respond to changes in customers' requirements. Note that the hourly compensation costs indicators in charts 3.1-3.3 show levels and trends, whereas the productivity and unit labor costs indicators in charts 3.4-3.6 are limited to trend comparisons.

\section{Hourly compensation costs for production workers in manufacturing (charts 3.1-3.3)}

These charts present data on comparative hourly compensation costs for manufacturing production workers in order to assess international differences in employer labor costs. Comparisons based on the more readily available average earnings statistics published by many countries can be very misleading-national definitions of average earnings differ considerably, average earnings do not include all items of labor compensation, and the omitted items of compensation frequently represent a large proportion of total compensation.

Hourly compensation costs include (1) hourly direct pay and (2) employer social insurance expenditures and other labor taxes. Hourly direct pay includes all payments made directly to the worker, before payroll deductions of any kind, consisting of (a) pay for time worked and (b) other direct pay. Pay for time worked includes basic time and piece rates plus overtime premiums, shift differentials, other premiums and bonuses paid regularly each pay period, and cost-ofliving adjustments. Other direct pay includes pay for time not worked (vacation, holidays, and other leave, except sick leave), seasonal or irregular bonuses and other special payments, selected social allowances, and the cost of payments in kind. Social insurance expenditures and other labor taxes include (c) employer expenditures for legally required insurance programs and contractual and private benefit plans and (d) other labor taxes. Social insurance expenditures include employer expenditures for retirement and disability pensions, health insurance, income guarantee insurance and sick leave, life and accident insurance, occupational injury and illness compensation, unemployment insurance, and family allowances. Other labor taxes includes taxes on payrolls or employment (or reductions to reflect subsidies), even if they do not finance programs that directly benefit workers, because such taxes are regarded as labor costs. Generally, other labor taxes account for less than 1 percent of total compensation. 
The BLS definition of hourly compensation costs is not the same as the ILO definition of total labor costs. Hourly compensation costs do not include all items of labor costs. The costs of recruitment, employee training, and plant facilities and services-such as cafeterias and medical clinics-are not included because data are not available for most countries. The labor costs not included account for no more than 2 percent of total labor costs in any country for which the data are available.

Production workers generally include those employees who are engaged in fabricating, assembly, and related activities; material handling, warehousing, and shipping; maintenance and repair; janitorial and guard services; auxiliary production (for example, power plants); and other services closely related to the above activities. Working supervisors are generally included; apprentices and other trainees are generally excluded.

Total compensation is computed by adjusting each country's average earnings series for items of direct pay not included in earnings and for employer expenditures for legally required insurance, contractual and private benefit plans, and other labor taxes. For the United States and other countries that measure earnings on an hours-paid basis, the figures are also adjusted in order to approximate compensation per hour worked. Earnings statistics are obtained from surveys of employment, hours, and earnings or from surveys or censuses of manufactures.

Adjustment factors are obtained from periodic labor cost surveys and interpolated or projected to nonsurvey years on the basis of other information for most countries. The information used includes tabulations of employer social security contribution rates provided by the International Social Security Association, information on contractual and legislated fringe benefit changes from ILO and national labor bulletins, and statistical series on indirect labor costs. For other countries, adjustment factors are obtained from surveys or censuses of manufactures or from reports on fringebenefit systems and social security. For the United States, the adjustment factors are special calculations for international comparisons based on data from several surveys.

The statistics are also adjusted, where necessary, to account for major differences in worker coverage; differences in industrial classification systems; and changes over time in survey coverage, sample benchmarks, and frequency of surveys. Nevertheless, some differences in industrial coverage remain, and in many countries other than the United States, the data exclude very small establishments (less than 5 employees in Japan and less than 10 employees in most other countries). For the United States, the methods used, as well as the results, differ somewhat from those of other BLS series on U.S. compensation costs.

The compensation measures are computed in national currency units and are converted to U.S. dollars using the average daily exchange rate for the reference period. The exchange rates used are prevailing commercial market exchange rates as published by either the U.S. Federal Reserve Board or the International Monetary Fund. Changes over time in compensation costs denominated in U.S. dollars reflect the underlying national wage and benefit trends measured in national currencies, as well as frequent and sometimes sharp changes in currency exchange rates.

The hourly compensation figures in U.S. dollars shown in the tables provide comparative measures of employer labor costs; they do not provide inter-country comparisons of the relative living standards of workers or the purchasing power of worker incomes. Prices of goods and services vary greatly among countries, and the commercial market exchange rates used to compare employer labor costs do not reliably indicate relative differences in prices. Purchasing Power Parities (defined previously in the Gross Domestic Product section) must be used for meaningful international comparisons of the relative purchasing power of worker incomes.

Total compensation converted to U.S. dollars at Purchasing Power Parities would provide one measure for comparing relative real levels of labor income. It should be noted, however, that total compensation includes employer payments to funds for the benefit of workers in addition to payments made directly to workers. Payments into these funds provide either deferred income (for example, payments to retirement funds), a type of insurance (for example, payments to unemployment or health benefit funds), or current social benefits (for example, family allowances), and the relationship between employer payments and current 
or future worker benefits is indirect. On the other hand, excluding these payments would understate the total value of income derived from work because they substitute for worker savings or self-insurance to cover retirement, medical costs, etc.

Total compensation, because it takes account of employer payments into funds for the benefit of workers, is a broader income concept than either total direct earnings or direct spendable earnings. An even broader concept would take account of all social benefits available to workers, including those financed out of general revenues as well as those financed through employment or payroll taxes.

Source: BLS, "International Comparisons of Hourly Compensation Costs in Manufacturing, 2006," January 25, 2008, Department of Labor News Release USDL 08-0093, http://www.bls.gov/ilc/.

\section{Manufacturing productivity and unit labor costs (charts 3.4-3.6)}

The productivity estimates refer to labor productivity, defined as real output per hour worked. It is based on the manufacturing output produced in each country and the total labor input in the form of hours worked. Output is defined as the real (deflated) GDP produced in the manufacturing sector of the economy. GDP has been defined previously (see Gross Domestic Product section). The output data are published as part of each country's national accounts.

Hours worked in manufacturing include the hours of all persons engaged in the manufacturing process, including the self-employed. For some countries, the data on the number of hours worked in manufacturing are also published with the national accounts. For other countries, BLS constructs its own estimates of aggregate hours worked, multiplying employment figures published with the national accounts by estimates of average annual hours worked.

Manufacturing unit labor costs are defined as the cost of labor compensation per unit of output. Changes in unit labor costs reflect the net effect of changes in hourly worker compensation and in labor productivity. Unit labor costs rise when compensation per hour rises faster than labor productivity. Conversely, if labor productivity rises faster than hourly compensation, unit labor costs decline. Because labor costs are frequently a major factor in total production costs, changes in unit labor costs affect the prices of manufactured products.

Labor compensation includes employer expenditures for legally required insurance programs and contractual and private benefit plans, in addition to all payments made in cash or in kind directly to employees. Data on labor compensation are usually taken from the countries' national accounts. When data for the selfemployed are not available, total compensation is estimated by assuming the same hourly compensation for self-employed and employees.

Changes in a country's unit labor costs, expressed in U.S. dollars, are estimated by combining changes in the unit labor cost expressed in each nation's currency with changes in the exchange rate of the country's currency against the U.S. dollar.

Source: BLS, "International Comparisons of Manufacturing Productivity and Unit Labor Cost Trends 2007, Revised," March 3, 2009, Department of Labor News Release USDL 090222, http://www.bls.gov/ilc/.

\section{Manufacturing output as a percent of world manufacturing output (charts 3.7 and 5.9)}

Manufacturing output is defined as the value added in the manufacturing sector of each country.

Each country's manufacturing value added, expressed in U.S. dollars, is divided by world manufacturing value added. The value added series are converted to U.S. dollars by applying the corresponding exchange rate for the year shown in the chart, as reported by the International Monetary Fund (IMF). Reported rates are annual averages of the exchange rates communicated to the IMF by the monetary authority of each member country.

While exchange rates are the most appropriate conversion method, one must keep in mind that they are volatile by nature and can change suddenly and significantly, leading to sharp realignments of the comparative levels shown in the charts. For example, if a country's currency is relatively "undervalued," the share of world manufacturing output shown on the chart for that country will be relatively low. If the currency were to strengthen, the country's share (in U.S. 
dollars) would rise, even if its manufacturing output (in local currency units) remained unchanged.

Source: United Nations, National Accounts Main Aggregates Database, http://unstats.un.org/.

\section{PUBLIC EXPENDI TURES ON LABOR MARKET PROGRAMS AS A PERCENT OF GDP}

(chart 4.1)

Public expenditures on labor market programs include the following programs, although not all countries have all programs: public employment services and administration; training; employment recruitment and maintenance incentives; integration of the disabled; direct job creation; business start-up incentives; out-of work and income maintenance and support, including unemployment compensation; and early retirement incentives. The data presented refer to 2004 for Denmark, to fiscal year 2006-2007 for Australia, Canada, Japan, New Zealand, the United Kingdom, and the United States, and to 2006 for the remaining countries. The fiscal year begins on April $1^{\text {st }}$ for Canada, Japan, and the United Kingdom, on July $1^{\text {st }}$ for Australia and New Zealand, and on October $1^{\text {st }}$ for the United States. GDP has been defined previously (see Gross Domestic Product section).

Source: OECD, OECD.Stat: OECD's Statistical Data Warehouse, http://stats.oecd.org/.

\section{MEASURES OF REGULATI ON ON LABOR AND PRODUCT MARKETS} (chart 4.2)

The measure of labor market regulation gauges the extent of regulations governing the hiring and firing of workers-often termed employment protection legislation. It is a summary measure that ranges from 0 (no restrictions) to 6 (very restrictive). The following factors are considered: the extent of procedural requirements that employers must follow in individual or collective dismissals, notice and severance pay requirements, and the degree of regulation on temporary forms of employment.

The measure of product market regulation is based on a simple average of indicators for seven industries, where each industry is rated from 0 (no restrictions) to 6 (very restrictive). The industries are gas, electricity, postal and courier activities, telecommunications, air transport, railways, and road freight. Depending on the industry, the following factors are considered: barriers to entry, public ownership, market structure, vertical integration, and price controls.

Both indicators are constructed by OECD from a variety of national sources as well as from multi-country surveys. The construction of these summary measures involves difficult choices of quantification and weighting. For further information on these choices, see the source documents.

Sources: OECD, OECD.Stat: OECD's Statistical Data Warehouse, http://stats.oecd.org/; and Conway, P., V. Janod and G. Nicoletti, "Product Market Regulation in OECD Countries, 1998 to 2003," OECD Economics Department Working Paper No 419, 2005, http:/ / www.oecd.org/.

\section{SHARE OF LABOR COSTS TAKEN BY TAX AND SOCI AL SECURITY CONTRIBUTI ONS (chart 4.3)}

This series measures the difference between the salary cost of an average worker to his or her employer and the amount of disposable income (net wage) that he or she receives. Labor costs are gross wages plus employer social security contributions and payroll taxes. The taxes included are income taxes paid by the employee, employee social security contributions, employer social security contributions, and, where in effect, payroll taxes. The types of taxes included in the measure are fully comparable across countries, as they are based on common definitions agreed upon by all OECD countries.

Because income taxes and access to work-related cash benefits vary by family status and in complex ways in nearly all countries, simple cross-country comparisons require a restriction to workers with a common family status. The figures presented in chart 4.3 pertain to single persons without children at the income of the average worker.

The information on the average worker income level is supplied by the ministries of finance in all OECD countries and is based on national statistical surveys. 
The amount of taxes paid by the worker is calculated by applying the tax laws of the country concerned. Thus, the tax rates are the result of a modeling exercise rather than direct observation of taxes actually paid.

Source: OECD, OECD.Stat: OECD's Statistical Data Warehouse, http://stats.oecd.org/.

\section{POPULATI ON (charts 4.4 and 5.1-5.3)}

Figures represent the de facto population, which includes all residents of a country regardless of legal status or citizenship-except for refugees not permanently settled in the country of asylum, who are generally considered part of the population of their country of origin. The values shown are mid-year estimates for the current year (2006 or 2007) and projections for 2025 .

Standard demographic techniques are used to estimate population for the current year. For most countries, national population censuses are the main source of data; however, frequency and quality vary by country. Most countries conduct a complete enumeration no more than once a decade. Pre- and post-census estimates are interpolations or extrapolations based on demographic models. Surveys conducted by international organizations, such as the Demographic and Health Surveys Program, are often the source of the most recent demographic information for developing countries.

Data for 2025, shown on charts 4.4 and 5.3, are projected by applying assumptions regarding future trends in fertility, mortality, and migration. Because future trends cannot be known with certainty, a number of projection variants are produced by the United Nations. The data charted are based on the medium variant. For further information on the assumptions for the medium variant, see the source document.

International comparability of population indicators is limited by differences in the concepts, definitions, data collection procedures, and estimation methods used by national statistical agencies and other organizations that collect population data. Furthermore, ages are not always reported accurately, particularly in developing countries.
For charts 4.4 and 5.3, 2006 data are from the World Bank and projections to 2025 are from the United Nations. Data for charts 5.1 and 5.2 are from the World Bank.

The dependency ratio (charts 4.4 and 5.3) is the ratio of dependents (persons ages 14 and under and persons ages 65 and over) to the working-age population (persons ages 15 to 64). The dependency ratio is an overall measure of the dependence that children and the elderly have on people of working age. Whereas dependency ratios show the age composition of a population, they do not necessarily show economic dependency. Some children and elderly persons are part of the labor force and some working-age persons are not.

The world population distribution (chart 5.1) shows each country's share of the total world population. The total population presents one overall measure of the potential impact of the country on the world and within its region.

The age composition of the population (chart 5.2) refers to the percentage of the total population that constitutes each specific age group. Three age groups are presented in chart 5.2: persons ages 14 and under, persons ages 15 to 64 , and persons ages 65 and over.

Sources: World Bank, World Development Indicators Database, http://www.worldbank.org/; World Bank, World Development Indicators, Washington, D.C., 2008, table 2.1; and United Nations, World Population Prospects: The 2006 Revision Population Database, http://esa.un.org.

\section{TRADE I N GOODS AS A PERCENT OF GDP (charts 4.5 and 5.8)}

Trade in goods as a percent of GDP is the sum of merchandise exports and imports divided by GDP, all of which are valued in current U.S. dollars. The value taken by the indicator does not give the share of GDP generated by imports and exports; rather, it indicates that the value of imports and exports is equivalent to the resulting percentage of GDP. GDP has been defined previously (see Gross Domestic Product section).

Source: World Bank, World Development Indicators Database, http://www.worldbank.org. 


\section{EMPLOYMENT OUTLOOK I NDI CATORS \\ (charts 6.1-6.4)}

This section highlights data from the 2008 Employment Outlook published by the OECD. The Employment Outlook is an annual publication that explores recent labor market developments of interest to the 30 OECD member countries. The member countries are Australia, Austria, Belgium, Canada, the Czech Republic, Denmark, Finland, France, Germany, Greece, Hungary, Iceland, Ireland, Italy, Japan, the Republic of Korea, Luxembourg, Mexico, the Netherlands, New Zealand, Norway, Poland, Portugal, Slovakia, Spain, Sweden, Switzerland, Turkey, the United Kingdom, and the United States.

Each chart in this section provides a visual abstract of an Employment Outlook chapter. Chart 6.1 highlights the incidence of part-time employment for youths. Chart 6.2 shows the gender employment gap. Chart 6.3 compares the rate of psychological distress for lowskilled workers relative to that of all employed persons. Lastly, chart 6.4 presents foreign direct investment (FDI) trends. The Employment Outlook also includes a chapter on informal employment; however, this chapter is not charted because of difficulties associated with measuring informal employment.

Countries and years charted in this section conform to coverage in Sections 1-4 of this chartbook; for some indicators, additional coverage is available in the Employment Outlook chapters.

Readers interested in exploring the Employment Outlook further may visit

http://www.oecd.org/els/employment/outlook.

\section{Employment (charts 6.1-6.2)}

For definitions, refer to the Labor Market Indicators section.

Sources: OECD, Employment Outlook, 2008 Ed., Paris, 2008, Chapter 1, "Off to a Good Start? Youth Labor Market Transitions in OECD Countries," figure 1.1; Chapter 3, "The Price of Prejudice: Labor Market Discrimination on the Grounds of Gender and Ethnicity," figure 3.2; and "Statistical Annex," Table C.

\section{Psychological distress (chart 6.3)}

Psychological distress refers to the presence of emotional and mood-related symptoms that may indicate a potential mental health problem, but do not reach the threshold for psychiatric diagnosis. Data were gathered through a variety of mental health modules included in national health and wellbeing surveys. Differences in survey question formulation, length of the reference period, and method of collecting information limit the cross-country comparability of psychological distress indicators. In addition, all countries except Canada used household-based surveys, which generally omit the institutionalized population. Consequently, persons who require hospitalization or other institutionalized care are not included in the sample for these countries. The exact definitions and methods of collecting information presented in chart 6.3 vary by country; for further information, see the source document cited.

Figures for this chart represent the psychological distress rate for low-skilled workers divided by the psychological distress rate for all employed persons. A figure of 1 indicates that the psychological distress rates for these two groups are equal; a figure greater than 1 indicates that the rate of psychological distress of lowskilled workers is higher than that of the total employed population.

Data for this chart are based on the International Standard Classification of Occupations (ISCO) developed by the ILO, which organizes jobs into clearly defined groups according to the tasks and duties undertaken in the job. "Low-skilled workers" corresponds to ISCO-88 major group 9 and includes sales and services occupations such as street vendors, shoe cleaners, domestic helpers, building caretakers, messengers, and garbage collectors; agricultural, fishery and related laborers; and laborers in mining, construction, manufacturing and transport.

Source: OECD, Employment Outlook, 2008 Ed., Paris, 2008, Chapter 4, "Are All Jobs Good for Your Health? The Impact of Work Status and Working Conditions on Mental Health," figure 4.4 . 


\section{Foreign Direct I nvestment (chart 6.4)}

Foreign Direct Investment (FDI) reflects the objective of an entity in one economy ("direct investor") to obtain a lasting interest in an entity in another economy ("direct investment enterprise"). Lasting interest implies the existence of a long-term relationship between the direct investor and the direct investment enterprise and a significant degree of influence on the management of the enterprise. Direct investment involves both the initial transaction between the two entities and all subsequent capital transactions between them and among affiliated enterprises.

FDI expenditures are the sum of FDI contributed by a direct investor to the enterprise. FDI receipts are the sum of FDI received by the enterprise from the direct investor. Chart 6.4 highlights the share of global FDI expended and received by two groups of countries OECD member countries and the rest of the world. In principle, global FDI expenditures should equal receipts; however, due to gaps in coverage and the use of different reporting systems across countries, measured levels of expenditures and receipts often differ.

Source: OECD, Employment Outlook, 2008 Ed., Paris, 2008, Chapter 5, "Do Multinationals Promote Better Pay and Working Conditions," figure 5.1. 